\title{
EXPERIMENTAL INVESTIGATION OF SUCTION SLOT GEOMETRY ON A GOLDSCHMIED PROPULSOR
}

\author{
A Thesis \\ presented to the \\ Aerospace Engineering Department \\ California Polytechnic State University, San Luis Obispo \\ In Partial Fulfillment of Requirements for the \\ Degree of Master of Science in Aerospace Engineering
}

\author{
By \\ Nicole Thomason \\ February 23, 2012
}


(C) 2012

Nicole Thomason

ALL RIGHTS RESERVED

Page ii 
TITLE: $\quad$ Experimental Investigation of Suction Slot Geometry on a Goldschmied Propulsor

AUTHOR: Nicole Thomason

DATE SUBMITTED: $\quad$ February 2012

COMMITTEE CHAIR: Dr. Tina Jameson, Instructor Faculty, Aerospace Engineering

COMMITTEE MEMBER: Dr. Rob McDonald, Instructor Faculty, Aerospace Engineering

COMMITTEE MEMBER: Dr. Russell Westphal, Instructor Faculty, Mechanical Engineering

COMMITTEE MEMBER: Mark D. Buchholz, Aerodynamics Engineer, Lockheed Martin Aeronautics 


\begin{abstract}
Experimental Investigation of Suction Slot Geometry on a Goldschmied Propulsor Nicole Thomason
\end{abstract}

The Goldschmied Propulsor concept combines boundary layer suction and boundary layer ingestion to improve propulsive efficiency and reduce drag on an axisymmetric body. This investigation of a Goldschmied Propulsor aimed to determine influential characteristics of the suction slot geometry to aid in better slot geometry design and to decrease the suction flow requirements for maintaining attached flow over the entire model surface. The Propulsor model was 38.5 inches in length with a max diameter of 13.5 inches. Three suction slot geometries were investigated with the addition of aluminum cusps to the slot entrance. The cusps varied in the distance they protruded into the incoming suction flow and in the angle they took from the lip into the suction slot. Wind tunnel testing was completed in the Cal Poly $3 \mathrm{ft} x 4 \mathrm{ft}$ test section of the draw-down tunnel at a Reynolds Number of $2.3 \times 10^{6}$. Results show that of the three cusp geometries, the smallest Cusp A protruding only 0.05 inches into the suction flow, produced the greatest reductions in pressure drag and total axial force for the fan speeds tested. When compared to the no cusp condition, none of the three cusp geometries produced any significant improvement in total drag or in required suction flow rate. 


\section{Acknowledgements}

A big thanks to Joshua Roepke, my unofficial thesis partner. We worked side by side on this project and I couldn't have done it without him. I would like to thank Dr. Tina Jameson for her support and trust throughout this project and Dr. Russell Westphal for his advice and guidance in navigating this experimental challenge. Thank you Dr. McDonald for your constant encouragement and help in finding access to the resources needed to overcome all the obstacles this project presented. Thank you Mark Moore at NASA Langley for sponsoring this work and allowing the students involved in this task the opportunity to acquire quality data to support future testing and development of this concept. Thank you Brian Ujiie for taking awesome flow visualization photographs and Brad Schab for sharing your knowledge of RC aircraft components. Thank you Mark Buchholz for being an excellent resource for all questions about wind tunnel testing. Thank you John Gorski for machining quality parts on request. Lastly, I would like to thank my wonderful family for their constant encouragement. 


\section{Table of Contents}

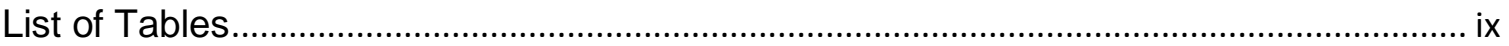

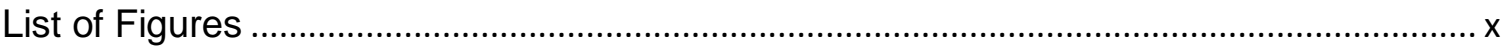

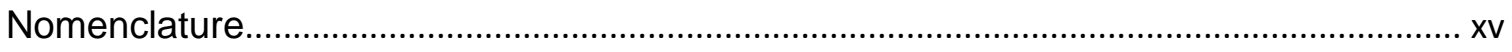

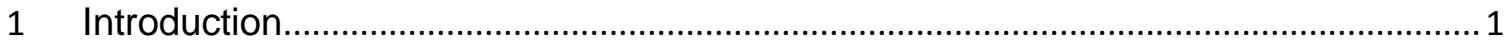

$1.1 \quad$ The Goldschmied Propulsor Concept ............................................................... 1

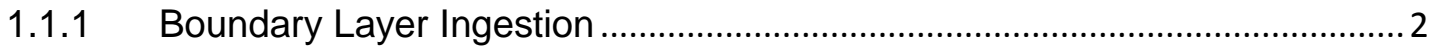

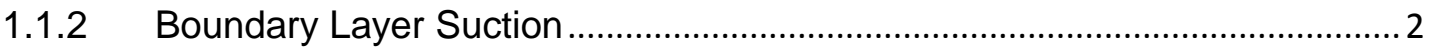

1.2 Background on the Goldschmied Propulsor Concept ........................................ 2

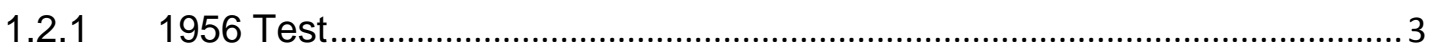

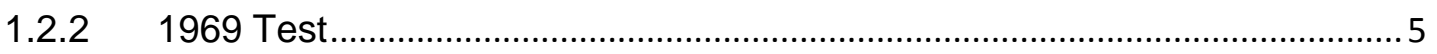

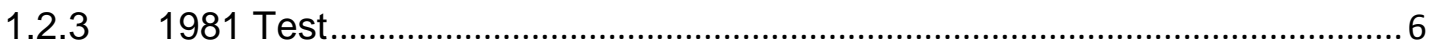

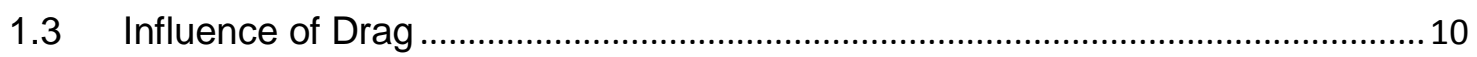

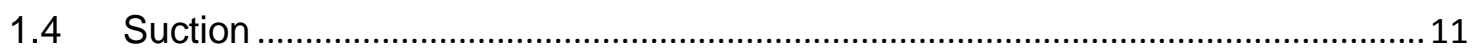

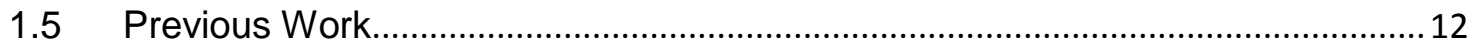

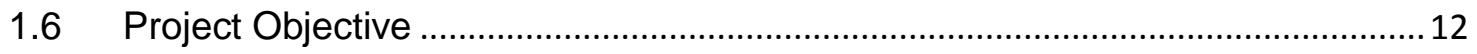

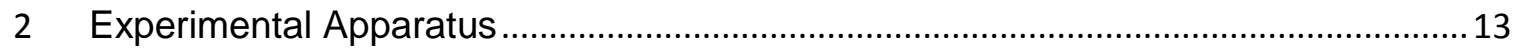

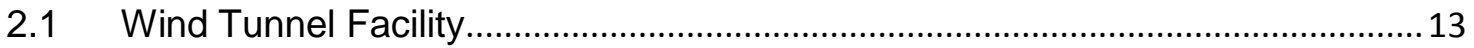

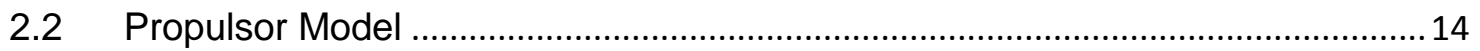

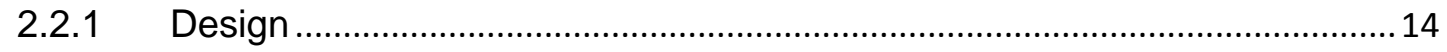

2.2.2 Model Manufacturing Process .................................................................. 17

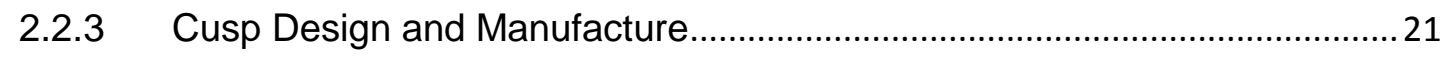

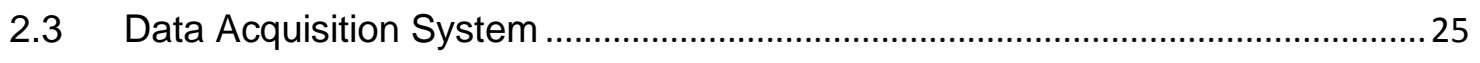

2.3.1 Measurement Computing USB Data Acquisition Device ............................. 25

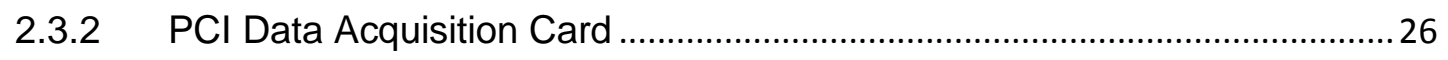




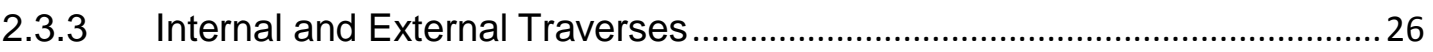

2.3.4 Pressure Transducers and Static Pressure Ports ........................................ 27

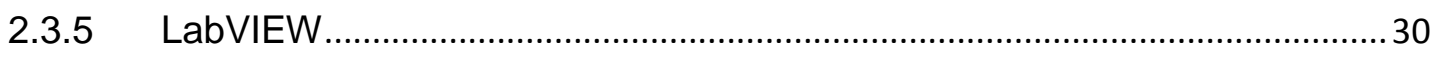

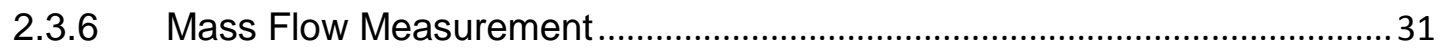

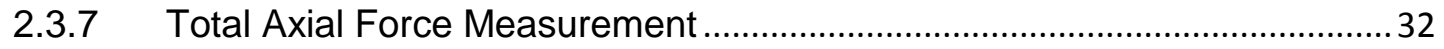

2.3.8 Fan Thrust and Fan Torque Measurement …............................................... 32

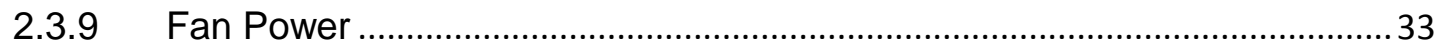

2.3.10 Fan Temperature and Pressure Change .................................................... 35

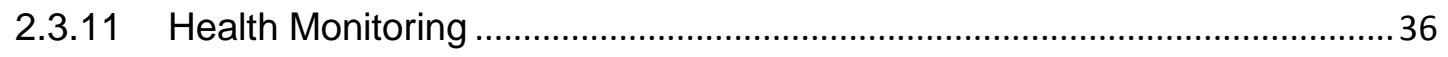

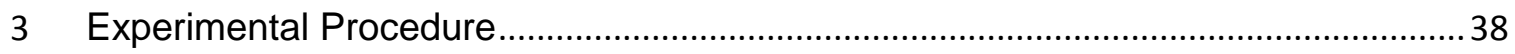

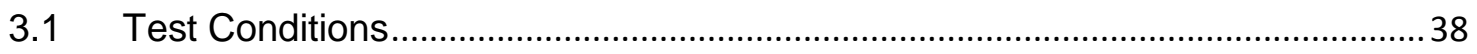

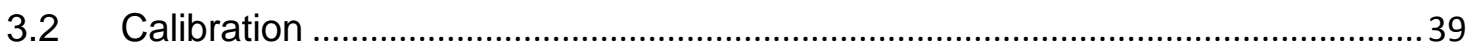

$4 \quad$ Data Acquisition and Post Processing ........................................................................ 43

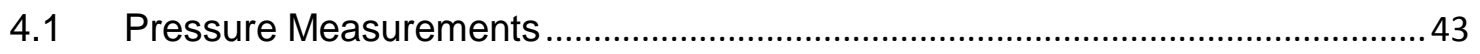

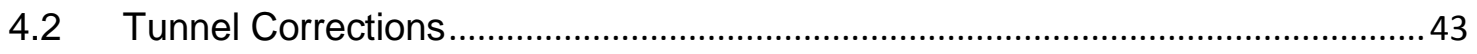

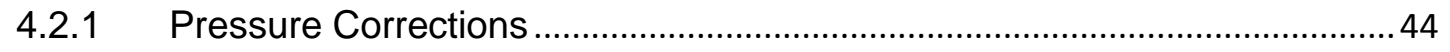

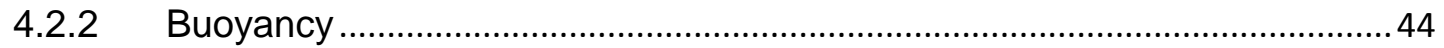

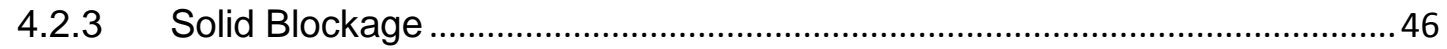

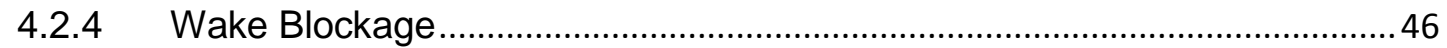

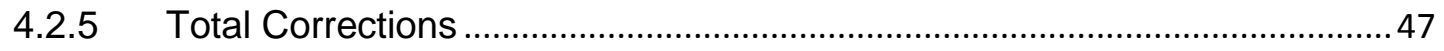

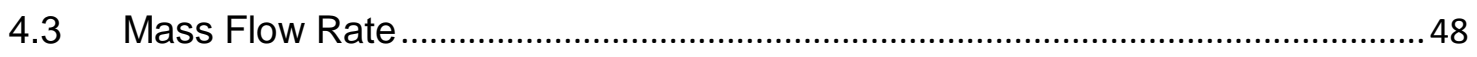

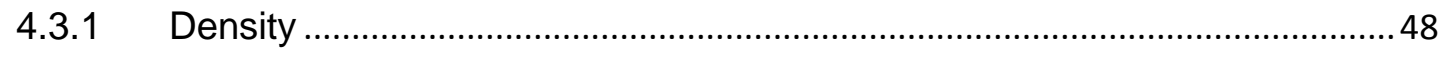

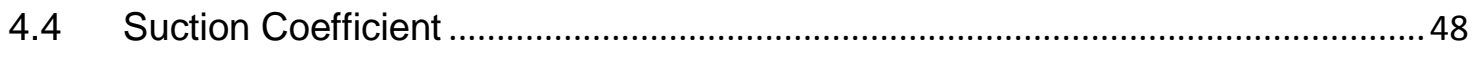

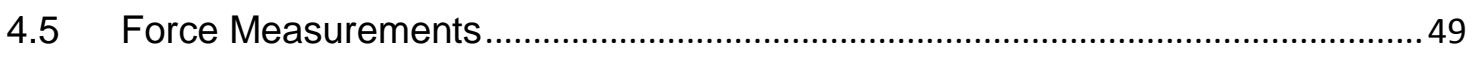

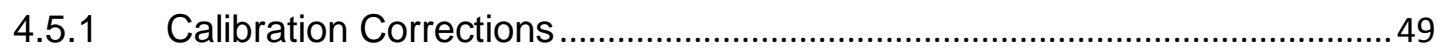

Page vii 


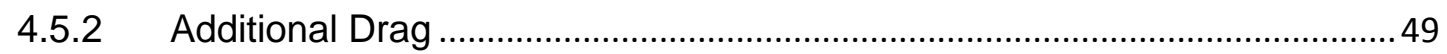

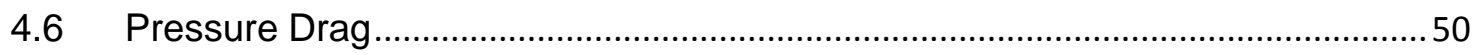

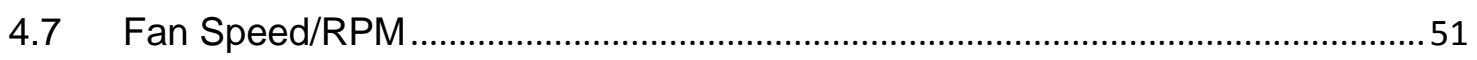

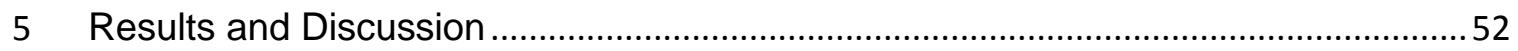

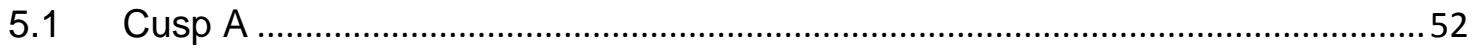

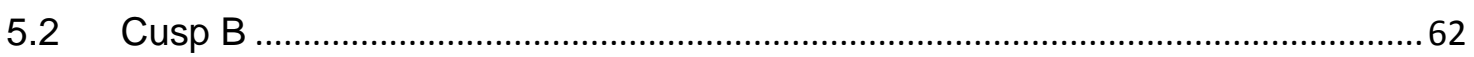

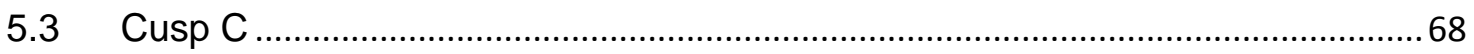

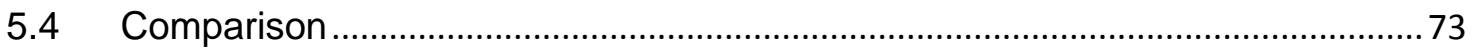

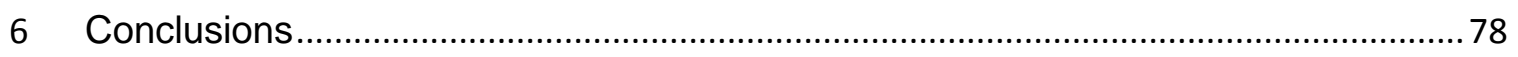

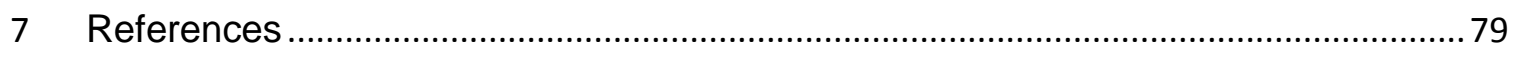

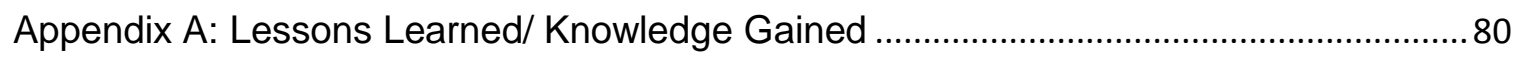

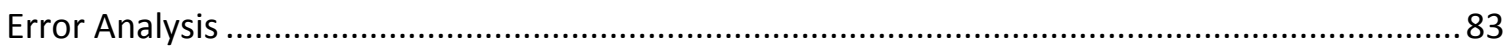

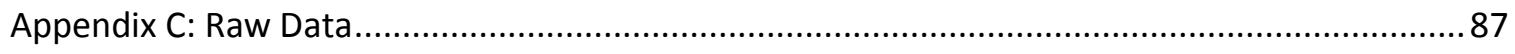

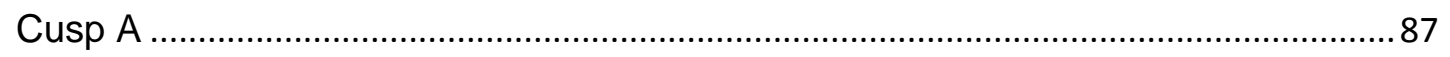

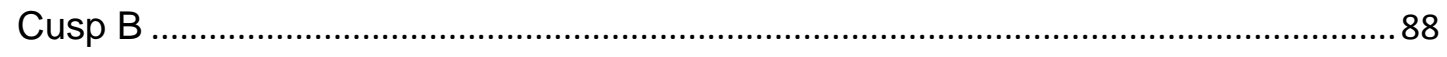

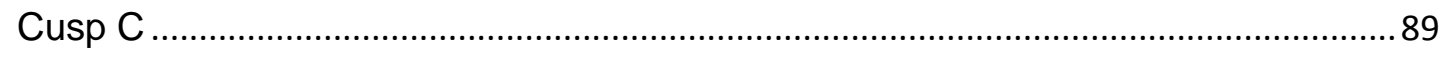

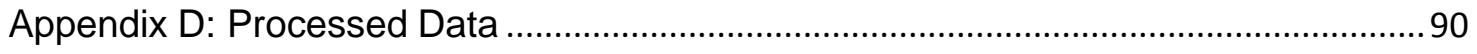

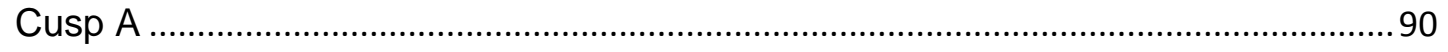

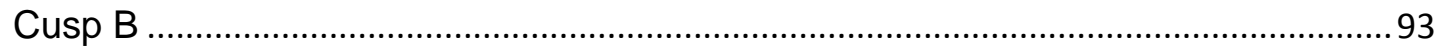

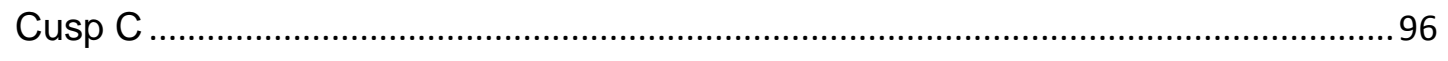




\section{List of Tables}

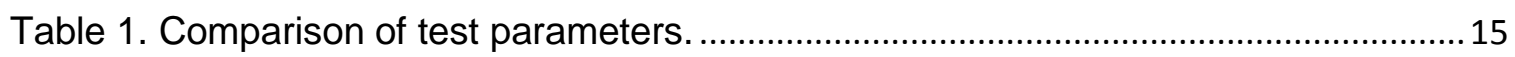

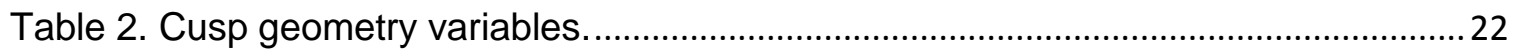

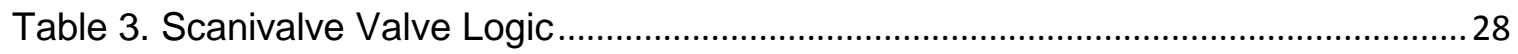

Table 4. Throttle settings for fan power at specified performance conditions. ..................34

Table 5. Measured parameters for the Goldschmied propulsor model. .............................37 


\section{List of Figures}

Figure 1. Diagram of boundary layer control airship model from 1956 Goldschmied test. $^{4}$......

Figure 2. Tail cone configurations for Goldschmied model used in the 1956 wind tunnel test where a) illustrates the plain gap suction slot and b) shows the tail cone with a shroud. ${ }^{5}$

Figure 3. Fabio Goldschmied with the 1981 model featuring the long aftbody and the empennage. ${ }^{6}$

Figure 4. Schematic of the 1981 model featuring the short aftbody and illustrating the many direction changes in the flow path for the suction flow. ${ }^{6}$.

Figure 5. a) Diagram and b) photograph of the Cal Poly $3 \mathrm{ft}$ by $4 \mathrm{ft}$ low-speed, drawdown wind tunnel, and c) the test section with our Goldschmied Propulsor model mounted inside.

Figure 6. Basic schematic of current wind tunnel model used in Round 1 and Round 2 of the Cal Poly Goldschmied investigation.

Figure 7. Model skin manufacturing process starting with a) the forebody female mold CNC machined from high density foam, b) spraying on the Duratec primer after application of a sealer, c) final sanding of the mold with Duratec primer leaving a smooth surface free of imperfections that would translate to the final part, d) the vacuum bag set-up to cure the resin infused carbon, e) one half of the forebody skin after curing in the mold, and f) one half of the forebody skin completed and ready to be trimmed. $\mathrm{g}$ ) is a photograph of the aftbody female mold after final sanding and polishing.

Figure 8. Photographs of the fairing a) internal ribs and spars, b) final assembly, and c) mounted in the wind tunnel test section housing the strut, electrical wiring, and pressure tubing.

Figure 9. Aluminum forebody closure shield, formed in a bowl shape to maintain constant volume in the suction slot.

Figure 10. Diagram of the clay cusp used in the 1981 wind tunnel test. ${ }^{8}$.

Figure 11. Original cusp geometry imitated for current tests, and other cusp geometries with different $X$ and $\theta$ values.

Figure 12. Solid model images of Cusp A a) with cusp shape visible and connection tabs, b) the full ring with connection tabs, and c) connection ring where the cusp geometries snap in to attach to the back of the forebody. 
Figure 13. Photographs showing a) installed aluminum connection ring for cusp attachment with transition smoothed with red wax and b) installed Cusp $C$ with all transitions smoothed with red wax.

Figure 14. Data Acquisition System including the power supply for the model sensors, the terminal blocks for sensor connections to be sent to the $\mathrm{PCl}$ card in the computer, the Measurement Computing DAQ, the controller for the internal traverse, and the controller for the model fan motor that is programmed through the computer. (Pressure measurement subsystem not pictured).

Figure 15. Pressure measurement subsystem is the Scanivalve system made up of a power supply, a USB extender, the RAD3200 analog to digital converter, and the ZOC33 pressure scanner

Figure 16. Typical Scanivalve System Configuration.

Figure 17. Photograph showing a view of the forebody surface static pressure ports.....29

Figure 18. Distribution of 58 surface static pressure ports along the propulsor. .29

Figure 19. Front panel of LabVIEW vi for collecting and monitoring Goldschmied propulsor model sensor data.

Figure 20. Back panel of LabVIEW vi used to collect and display Goldschmied propulsor model sensor data.

Figure 21. Photograph of the load cells measuring fan thrust and fan torque in the model aftbody. Two $1 \mathrm{lb}$ load cells measure thrust at the top and bottom of the fan and two $1 \mathrm{lb}$ load cells measure torque at the right and left side of the fan.

Figure 22. Schubeler $30 \mathrm{~cm}^{2}$ ducted fan performance chart. ${ }^{12}$ .35

Figure 23. a) Schubeler $30 \mathrm{~cm}^{2}$ ducted fan with static pressure taps to measure pressure before the fan blades. b) Diagram of fan placement in aftbody and flow directionality through the suction slot and the aftbody. 36

Figure 24. Round 2 test plan for investigating influential parameters of slot geometry. .38

Figure 25. Photographs of a) the total axial force calibration set-up and b) the total axial force calibration clamping assembly.

Figure 26. Total axial force load cell calibration curve.

Figure 27. Photographs of a) the thrust calibration set-up and b) the torque calibration set-up highlighting the calibrated weight and the pulley system.

Figure 28. Thrust load cell calibration curve. 
Figure 29. Torque load cell calibration curve.

Figure 30. Aftbody stations diagram.

Figure 31. Total axial force coefficient vs fan speed in RPM with Cusp A attached at the suction slot. 53

Figure 32. Mass flow rate in $\mathrm{kg} / \mathrm{s}$ vs fan speed in RPM comparison at different slot gaps with Cusp A geometry attached to suction slot.

Figure 33. Smoke flow visualization with the model fan off and Cusp C slot geometry...54

Figure 34. Pressure distribution over Goldschmied body with Cusp A slot geometry and slot gap of 0.5 inches. Port 1 is the most upstream location at the model nose and port 58 is the most downstream location at the aftbody exit.

Figure 35. Pressure distributions over Goldschmied body with Cusp A slot geometry and constant throttle setting (fan speed 20700 RPM). .56

Figure 36. Pressure distributions over Goldschmied body with Cusp A slot geometry and constant throttle setting (fan speed $\sim 32500$ RPM)...... 56

Figure 37. Smoke flow visualization with Cusp C and model fan speed of 26000 RPM. 57

Figure 38. Flow visualization with Cusp C and fan speed of 33000 RPM. .57

Figure 39. Pressure recovery step vs suction coefficient for Cusp A. .58

Figure 40. Pressure drag vs fan speed for Cusp A .59

Figure 41. Total axial force and pressure drag plotted against slot gap size at a fan speed of 20750 RPM. 59

Figure 42. Pressure loss across the fan with increasing fan speed for Cusp A. 60

Figure 43. Fan power vs fan speed with Cusp A slot geometry. 60

Figure 44. Fan thrust at varying fan speeds and different slot gaps with Cusp A. 61

Figure 45. Fan torque at varying fan speeds and different slot gaps with Cusp A. ........ .61

Figure 46. Total axial force vs fan speed for Cusp B slot geometry. .63

Figure 47. Fan thrust vs fan speed for Cusp B slot geometry. .63

Figure 48. Fan torque vs fan speed for Cusp B slot geometry. 64

Figure 49. Fan power vs fan speed for Cusp B slot geometry. 64 
Figure 50. Mass flow rate through aftbody with Cusp B slot geometry. .65

Figure 51. Pressure drag vs fan speed for Cusp B slot geometry...... .65

Figure 52. Pressure change across suction slot vs suction coefficient with Cusp B slot geometry.

Figure 53. Total axial force vs suction coefficient for all slot gap sizes with Cusp B slot geometry.

Figure 54. Pressure distribution over Goldschmied body with Cusp B slot geometry and constant throttle setting (fan speed $\sim 15000$ RPM).

Figure 55. Pressure distribution over Goldschmied body with Cusp B slot geometry and constant throttle setting (fan speed $\sim 32500$ RPM)..

Figure 56. Pressure rise across the model fan with Cusp B slot geometry. .68

Figure 57. Total axial force vs fan speed with Cusp C slot geometry.

Figure 58. Pressure drag vs fan speed with Cusp C slot geometry.

Figure 59. Pressure recovery across suction slot vs suction coefficient with Cusp C slot geometry.

Figure 60. Mass flow rate through the aftbody of the Goldschmied propulsor with Cusp C slot geometry.

Figure 61. Pressure distribution over a Goldschmied body with Cusp C slot geometry and constant throttle setting (fan speed $\sim 17000$ ).

Figure 62. Pressure distribution over a Goldschmied body with Cusp C slot geometry and constant throttle setting (fan speed $~ 32800$ ).

Figure 63. Fan thrust vs fan speed with Cusp C slot geometry.

Figure 64. Fan torque vs fan speed with Cusp C slot geometry.

Figure 65. Pressure rise across the model fan vs fan speed for Cusp C slot geometry.. 73

Figure 66. Fan power vs fan speed for Cusp C slot geometry.

Figure 67. Total axial force of Goldschmied Propulsor with different cusp geometries at the suction slot.

Figure 68. Pressure drag on a Goldschmied body with different suction slot geometries. 
Figure 69. Pressure change across the suction slot vs suction coefficient for three slot

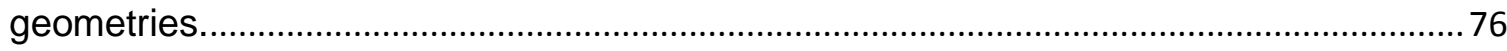

Figure 70. Fan power vs fan speed for three different slot geometries. .............................77

Figure 71. Pressure rise across the fan during testing of three different suction slot

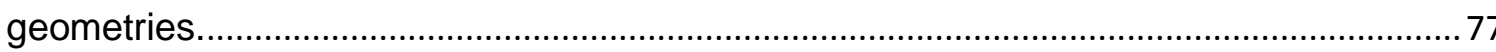




\section{Nomenclature}

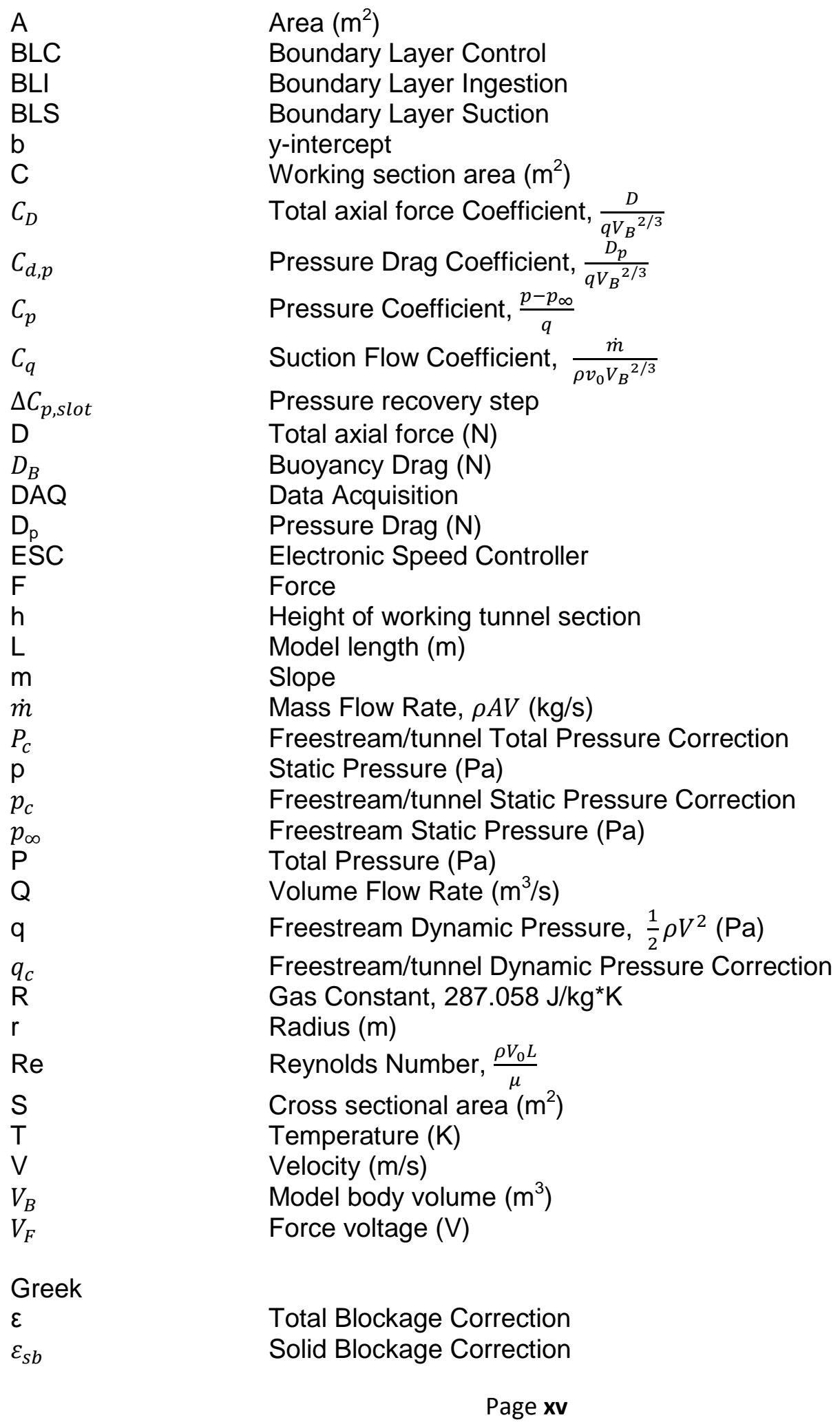


$\varepsilon_{w b}$

$\rho$

$\mu$

\section{Subscripts}

C

u

$\infty$

0

2

3

4

Wake Blockage Correction

Density

Dynamic Viscosity

Correction value

Uncorrected value

Freestream

Freestream

Before Model Fan

After Model Fan

Aftbody Exit

Wake Region 


\section{Introduction}

\subsection{The Goldschmied Propulsor Concept}

In 1954 Fabio Goldschmied proposed a concept that combined boundary layer ingestion (BLI) and boundary layer suction (BLS). ${ }^{1,2}$ Both BLI and BLS have been investigated individually and have shown benefits in drag reduction, however, before the Goldschmied Propulsor they had not been tested together in a system that aims to reap the benefits of both. The Goldschmied Propulsor concept uses suction through a single slot for boundary layer control and then utilizes the ingested boundary layer fluid for use as propulsive fluid. Goldschmied tested his concept with three wind tunnel tests of an axisymmetric body that featured a rear suction slot. ${ }^{2}$ Removal of the boundary layer through the rear suction slot created a more positive pressure gradient before the slot. This positive pressure gradient allowed for the freestream flow to smoothly cross the discontinuity of the suction slot, and the boundary layer was able to regrow on the aftbody after the slot. This prevented separation, maintaining flow attachment over the entire body. By eliminating separation there was a considerable decrease in profile drag. The slow moving boundary layer that was ingested could then be used as propulsive fluid, increasing propulsive efficiency. Being ingested radially, swirl, which would create an extra component of drag, was reduced. Theoretically the propulsive fluid exits at the back of the model, filling in the wake created by the body which additionally reduces the total axial force. BLI and BLS combined create a unique surface pressure gradient with high pressure downstream at the back of the model. This pressure gradient is ideal for a body being propelled forward and results in even greater decreases in drag. 


\subsubsection{Boundary Layer Ingestion}

Boundary layer ingestion removes the slow moving boundary layer created at the surface of the model and uses that ingested flow for greater propulsive efficiency. Greater propulsive efficiency is realized because the propulsion system requires less energy to get the same percent increase in momentum from the low speed flow as it would for a higher speed flow. For example, less energy is required to speed up a flow from $10 \mathrm{~m} / \mathrm{s}$ to $30 \mathrm{~m} / \mathrm{s}$ than to speed up a flow from $30 \mathrm{~m} / \mathrm{s}$ to $50 \mathrm{~m} / \mathrm{s}$.

\subsubsection{Boundary Layer Suction}

Boundary layer control, or shear layer control, is an attractive endeavor for manmade flow systems to delay separation through either suction or blowing. By postponing separation, form drag is reduced, stall is delayed, lift is enhanced, and pressure recovery can be improved. Separation is determined by external conditions, and is accompanied by a thickening of the rotational flow region and ejection of vorticity. The velocity gradient is positive upstream of the separation, zero at the point of separation, and negative after separation in the reverse flow region. In a three dimensional flow around an axisymmetric body, like the one being investigated in the Goldschmied concept, the 3-D boundary layers produce less skin friction and are generally more capable of overcoming an adverse pressure gradient without extreme separation. For this reason only a small amount of suction is needed to keep the flow attached and provide the fore mentioned benefits to the system. Suction removes the decelerated near-wall particles from the boundary layer, making it more energized and able to stay attached longer.

\subsection{Background on the Goldschmied Propulsor Concept}

Fabio Goldschmied tested his concept through three separate wind tunnel tests. ${ }^{2}$ A lack of transparency in data and procedures causes many to question his results. Not 
enough information is available to exactly replicate Goldschmied's tests and therefore it is unknown if the benefits he claimed with his concept can actually be realized. The current tests have aimed to match trends in the original test results to prove the validity of the concept. The tests described in this paper will expand upon that goal to provide greater detail and insight into specifics of the Propulsor design.

\subsubsection{Test}

The first test of a Goldschmied Propulsor was run in 1956 by Goodyear Aircraft Company at the David Taylor Model Basin in the $7 \mathrm{ft}$ by $10 \mathrm{ft}$ transonic wind tunnel as a proof of the 1954 concept. The results were published in 1957 by Peter Cerreta. ${ }^{3}$ The basic model type used included an axisymmetric body with a single fixed suction slot near the trailing edge separating the forebody from the aftbody. The model used in this first test had a closed cone for the aftbody and the ingested boundary layer was exhausted through a tube that ran out the tunnel. The goal of this test was to observe the effects of the suction slot. No propulsion was tested or installed in this model. In developing the model body, for the lowest skin friction drag and pressure drag, Goldschmied found that the fineness ratio of the body experimentally should be between $5: 1$ and $6: 1$. Fineness ratio is the ratio of length to maximum width and describes the overall shape of a streamlined body, so a 6:1 ratio would describe a body that is six times longer than its maximum thickness. A smaller fineness ratio, one that approaches unity, is desirable to minimize the surface area over volume ratio and thereby minimize skin friction. With pressure drag being controlled or eliminated by boundary layer control, the fineness ratio decreases towards unity and minimizes skin friction and hull weight. The body also utilizes the Griffith airfoil concept that yields favorable pressure gradients throughout, except for a small velocity discontinuity caused by a short adverse pressure region that is small enough to be encompassed by a suction slot so that the boundary 
layer is able to cross the discontinuity. The Griffith concept is valid over a range of angles of attack and reduces the pressure drag to negligible values. A $34 \%$ symmetrical airfoil with the velocity discontinuity located at $83 \%$ length was used to yield a $3: 1$ body with an adequate angle-of-attack range. Then this 2-D profile was converted into a 3-D axisymmetric shape. Figure 1 is a diagram of the airship model shape used in the 1956 wind tunnel test.

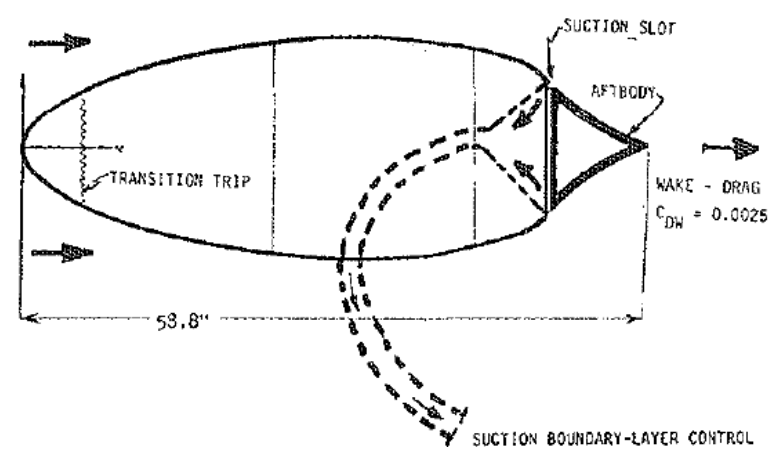

Figure 1. Diagram of boundary layer control airship model from 1956 Goldschmied test. ${ }^{4}$

The results from Cerreta showed that there was a significant reduction in drag with the addition of suction near the trailing edge, and that although there was a minimum suction rate required for initial flow attachment, the suction rate could then be reduced to maintain attachment. The suction slot width was found experimentally to be $g / L=0.008$, where $g$ is the suction slot width and $L$ is the body length. This width gives the lowest equivalent drag coefficient and the lowest suction power. At the slot the flow may be considered as 2-D and airfoil theory can be applied for analysis because the body-radius/momentum-thickness ratio is very large. It was also reported that adding extra suction above the minimum value for flow attachment provided no extra benefit. As Reynolds number increased, so did the required suction. An interesting observation was the addition of a shroud on the tail cone reduced the required minimum suction rate and 
extended the Reynolds number range for which the suction could work. ${ }^{3}$ Figure 2 shows two of the tail cone configurations tested.

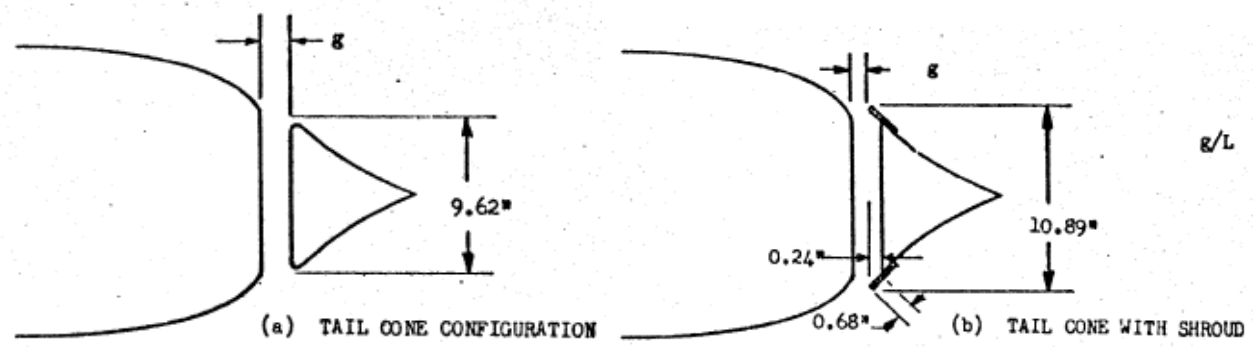

Figure 2. Tail cone configurations for Goldschmied model used in the 1956 wind tunnel test where a) illustrates the plain gap suction slot and b) shows the tail cone with a shroud. ${ }^{5}$

\subsubsection{Test}

After the initial test in 1956, F. R. Goldschmied continued his research privately at the University of Utah. He believed that his concept had applications not only to airships, but to any submerged self-propelled body. In his testing Goldschmied considered Reynolds numbers to $10^{9}$ and over, so it was assumed turbulent boundary layers throughout. One potential problem with the fixed location of the suction slot was that due to the large adverse pressure area, the slot would experience a wide variety of boundary layer thicknesses and profiles.

In 1969, the second test was performed. This time slot geometry was varied with the addition of what was called a 'Ringleob cusp.' The addition of a Ringleob cusp was reported to reduce suction flow requirements and provide stability to the flow in the suction slot. The reports from the 1969 test are unavailable and therefore none of the data or explanation about the cusp geometries used in the test are known. Many of the papers published by F.R. Goldschmied do reference a paper by Friedrich Ringleb discussing trapped vortices and potential flows. However, there is no mention of suction or a cusp being utilized with suction in Ringleb's report. A Ringleob cusp placed at the 
entrance of the suction slot could be expected to create a trapped vortex that sits at the lip of the slot. This trapped vortex would help the surface flow traveling over the model more easily make the sharp turn into the suction slot. Goldschmied reported this also created stability in the flow and reduced the suction requirements to acquire attached flow over the aftbody.

\subsubsection{Test}

In 1981 Goldschmied's engineering office was tasked to overhaul the 1956 wind tunnel model with upgrades to the suction slot configuration, the aftbody, and the empennage and add a self-propulsion fan. The system tested comprised five basic elements: an envelope with a pressure step at $85 \%$ length and a fineness ratio of $2.72: 1$, boundary layer control to realize the pressure step which requires a suction slot, a Ringleob cusp, a slender rear tailboom for stable operation, a suction/propulsion axial fan, a stern propulsion jet, and an empennage mounted on the tailboom. Test runs were taken for three different configurations, with free transition, transition tripped at $10 \%$ and transition tripped at 58\%, with different aftbody designs, and with and without an empennage. Figure 3 is a photograph of Fabio Goldschmied with the rebuilt 1981 model.

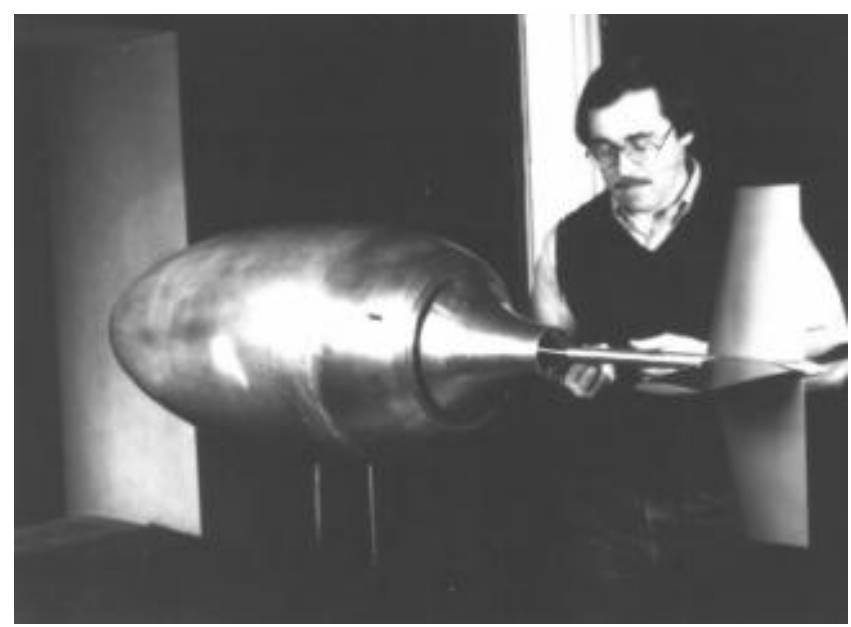

Figure 3. Fabio Goldschmied with the 1981 model featuring the long aftbody and the empennage. ${ }^{6}$

Page 6 
The pressure distribution on the model body was dependent on the geometry, the boundary layer suction, and the stern jet. The envelope was designed to have a favorable pressure gradient over the forebody up to $85 \%$ and over the entire aftbody. At the aftbody, the flow was turbulent and in a favorable pressure gradient. The entrainment of the aftbody boundary layer into the propulsion jet reduced the momentum thickness in the back and thereby reduced the wake drag. In fact, theoretically, the wake drag could be decreased by a factor of 10 for a suction increase of only an order of 2 .

A stepwise pressure distribution was selected over the conventional adverse pressure gradient after $20 \%$ length for an airship because it prevents the large increase in momentum thickness due to the adverse pressure gradient and allows for better static pressure recovery at the tail. To avoid the momentum thickness growth due to an adverse pressure gradient, suction had to be applied. Suction controls the wake drag and the momentum drag, and because the momentum drag is so much larger than the wake drag as suction is increased, the suction mass flow rate required for full aftbody attachment had to be minimized. A range of flow rates had to be determined where suction was low enough to avoid triggering jet static-pressure steps, and high enough to ensure full body attachment to prevent high wake drag and flow instabilities. The suction through a single slot was found to be unstable, so again a Ringleob cusp was added to the leading-edge of the slot and provided significant passive boundary layer control, thereby lowering the minimum required suction coefficient. In the preliminary test phase, the two-stage, axial-flow fan appeared to have poor performance and could not maintain attached flow. This poor performance was thought to be due to losses in total pressure from the dramatic direction changes the flow had to make while moving through the system. Figure 4 is a schematic of the 1981 test model, illustrating the turns the flow had 
to make to get from the slot to the fan inlet. To improve the fan performance, flow straightening vanes were added before and after the fan.

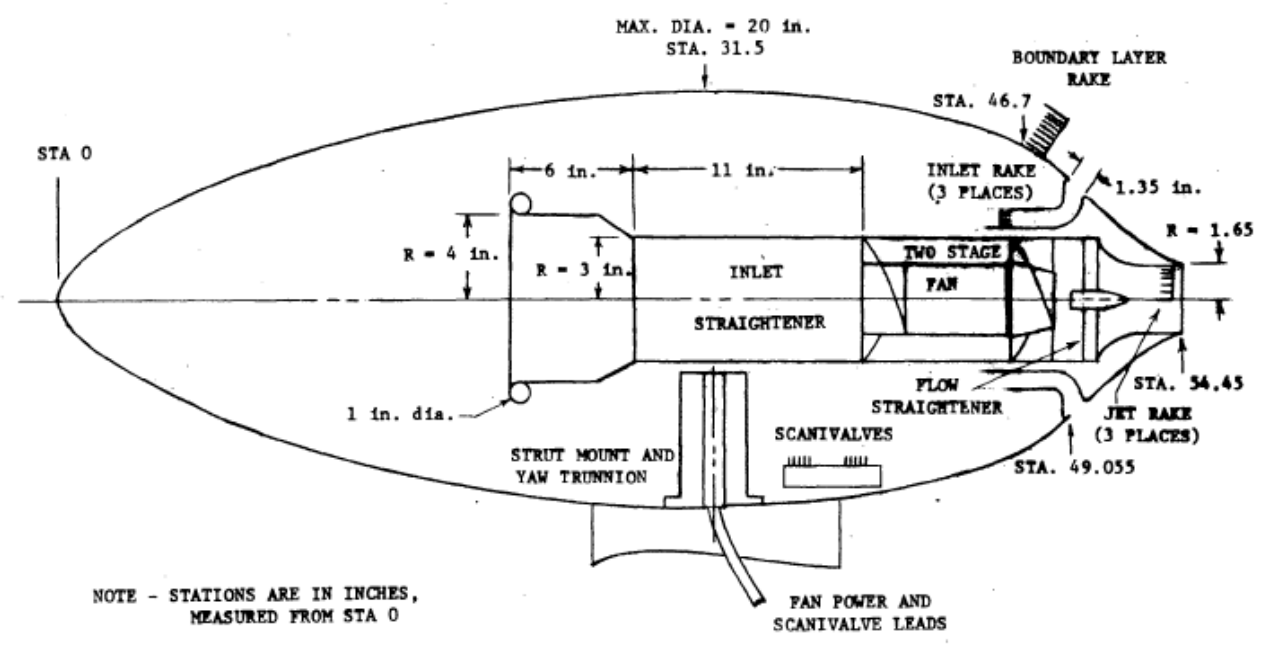

Figure 4. Schematic of the 1981 model featuring the short aftbody and illustrating the many direction changes in the flow path for the suction flow. ${ }^{6}$

A slender tailboom was mounted to the aftbody to stabilize the flow field closure behind the body. The purpose of the stern jet was to achieve sufficient thrust to offset the wake drag and the suction momentum drag, as well as affect the aftbody static pressure distribution. The jet on the 1981 model made this the first wind-tunnel test of the Goldschmied concept with a self-propelled model. At the jet discharge there was found to be a very high static pressure recovery. In both free transition and at the $10 \%$ tripped transition cases, full stagnation values were achieved. This must have been due to full flow field closure at the tailboom. The tailboom was added to achieve neutral static stability and the overall empennage span needed to be limited to the maximum envelope diameter. The minimum tailboom length to satisfy the flow requirements was believed to be $D / 3$. It is interesting to note that the empennage lift was dependent on full aftbody flow attachment. ${ }^{7}$ 
One of the most important results Goldschmied claims from the 1981 tests is the determination of the air power coefficient of the fan where there is zero axial force. The axial force coefficient was determined by measuring wake integrated momentum with a fixed rake, and by the calibrated strut force as measured by the wind-tunnel balance. Goldschmied also concludes that his test model yields a $50 \%$ less drag than a conventional streamlined body with an empennage, in both the free transition and tripped transition cases.

In 1983 Goldschmied emphasized his results from the 1981 tests at the Applied Aerodynamics Conference. One of his key points is that if adequate boundary layer control is applied, the momentum thickness across the pressure step remains constant. ${ }^{5}$ The avoidance of the momentum-thickness growth that is caused by an adverse pressure gradient is a very important benefit. The other key point is that with this concept, it is no longer necessary to exceed freestream total head to generate thrust. The suction momentum drag is generated by the radially inward ingestion of mass flow into the body, which destroys its axial momentum. Then, the thrust generation must start from this radially-inward flow with associated zero axial momentum. So, the jet totalhead is dictated by the required thrust, and that may be no more than freestream. ${ }^{8}$

Benjamin Neumann and Harvey Howe filed their own report on the data collected from Goldschmeid's 1981 model. They called the test system the Suction Afterbody Propulsion (SAP) concept. $^{6}$ Their report explains the test set-up, the model materials, as well as gives surface coordinates for the shape of the forebody. The surface coordinates given are static pressure port locations and are the points used in the development of the model shape for the current tests. In the 1981 test, the varied parameters were the fan speed, tunnel air speed, aftbody and tail configuration, body yaw angle, and lastly the trip strip location. The authors observed that it was harder to maintain attached flow 
to a short aftbody as compared to a longer aftbody, however, once attached the short aftbody produced a smaller total power coefficient. ${ }^{6}$

\subsection{Influence of Drag}

Any body moving through a fluid experiences drag. Drag opposes the body motion and is produced in multiple ways. Total axial force is most simply made up of induced drag and parasitic drag. Induced drag is drag due to lift. Where high pressure flow from the bottom of a lifting body and the low pressure from the top are allowed to mix, vortices are created that cause an induced component of drag. Induced drag typically increases at lower speeds because greater angles of attack are needed to create lift. Induced drag is minimal on the current model because of its axisymmetric shape and the model was only tested at zero angle of attack.

Parasitic drag is due to the movement of an object through a fluid. It is composed of form drag, interference drag, and skin friction drag. Form drag, also known as pressure drag or profile drag, and is the largest contributor of the three. The size and shape of a body directly influences form drag, so our current model with its low fineness ratio can expect some significant form drag. Boundary layer separation also increases form drag, and low speed (low Reynolds Number) reduces form drag. The interaction of flow over different body surfaces causes interference drag. We can hope for low interference drag on the current model because of the lack of fins or other appendages that may protrude into the flow. The fairing will be the main source of interference drag. At the low speed (low Reynolds Number) run in these tests, skin friction drag is reduced. While the turbulent boundary layer increases skin friction drag, minimizing surface roughness and wetted area of the model decreases skin friction drag. 
Previously it was mentioned that suction controls both wake drag and momentum drag. Wake drag is formed from the void that is created behind a body that is typically a highly turbulent area is called a wake and is an area of low pressure that creates another component of drag. On our current model, the fluid that is ingested through the suction slot gains velocity through the fan and then exits out the back of the model as a jet that fills in the wake behind the body, essentially eliminating the momentum deficit of the wake. Momentum drag is drag due to changes in momentum. When flow is pulled through a suction slot, there are changes in flow speed and pressure, causing a change in momentum. If the suction flow is being forced to slow down, decrease momentum, there needs to be some reaction force which is the momentum drag. Because the rear suction slot is ingesting boundary layer fluid, that is relatively slow moving compared to freestream, the momentum drag is decreased. So, by minimizing suction flow rate, the incoming flow has less drastic momentum changes and therefore less momentum drag.

\subsection{Suction}

Like the original wind tunnel test in 1957, the baseline tests of Round 1 explained in this paper feature a simple gap slot. For the slot geometry sensitivity testing, several different cusp designs were added to the forebody at the slot entrance to evaluate more complex slot geometries. A cusp should gently turn the flow leaving the forebody to match the slope of the aftbody surface. Then as the flow hits the point of the cusp, it circulates, creating a trapped vortex that aids the rest of the flow in either making the sharp turn into the suction slot or making a nice transition over the suction slot to attach to the aftbody. The original tests showed an increase in flow stability through the slot and reduced suction flow requirement for attached flow over the aftbody. 


\subsection{Previous Work}

In Round 1 of the current wind tunnel tests reported by Josua Roepke, the author aimed to match trends from Goldschmied's original tests. By doing this a baseline was created and further investigation of the concept was justified in that significant benefits in drag reduction and propulsive efficiency could be attained.

\subsection{Project Objective}

This paper details Round 2 of experimental tests on a Goldschmied Propulsor.

Round 2 is the follow-on to Round 1 and investigates the addition of a cusp to the suction slot entrance, with the objective being to determine influential slot parameters to create a base for cusp design and thereby slot geometry design. By determining the influential slot parameters, the best performing slot characteristics can be incorporated into the design of new cusps for future testing. 


\section{$2 \quad$ Experimental Apparatus}

\subsection{Wind Tunnel Facility}

The current investigation was conducted in the Cal Poly 3' x 4' low-speed opencircuit wind tunnel. A $150 \mathrm{hp}, 440$ Volt three-phase motor powers a nine-blade axial fan by a belt drive system. The tunnel inlet has an 11:1 contraction with a honeycomb flow straightening section followed by three mesh screens at the entrance. The variation in mean velocity is less than $1 \%$ and the freestream turbulence intensity is less than $0.5 \%$ over the center three fourths of the tunnel cross section. ${ }^{13}$ The tunnel facility and the test section can be seen in Figure 5.
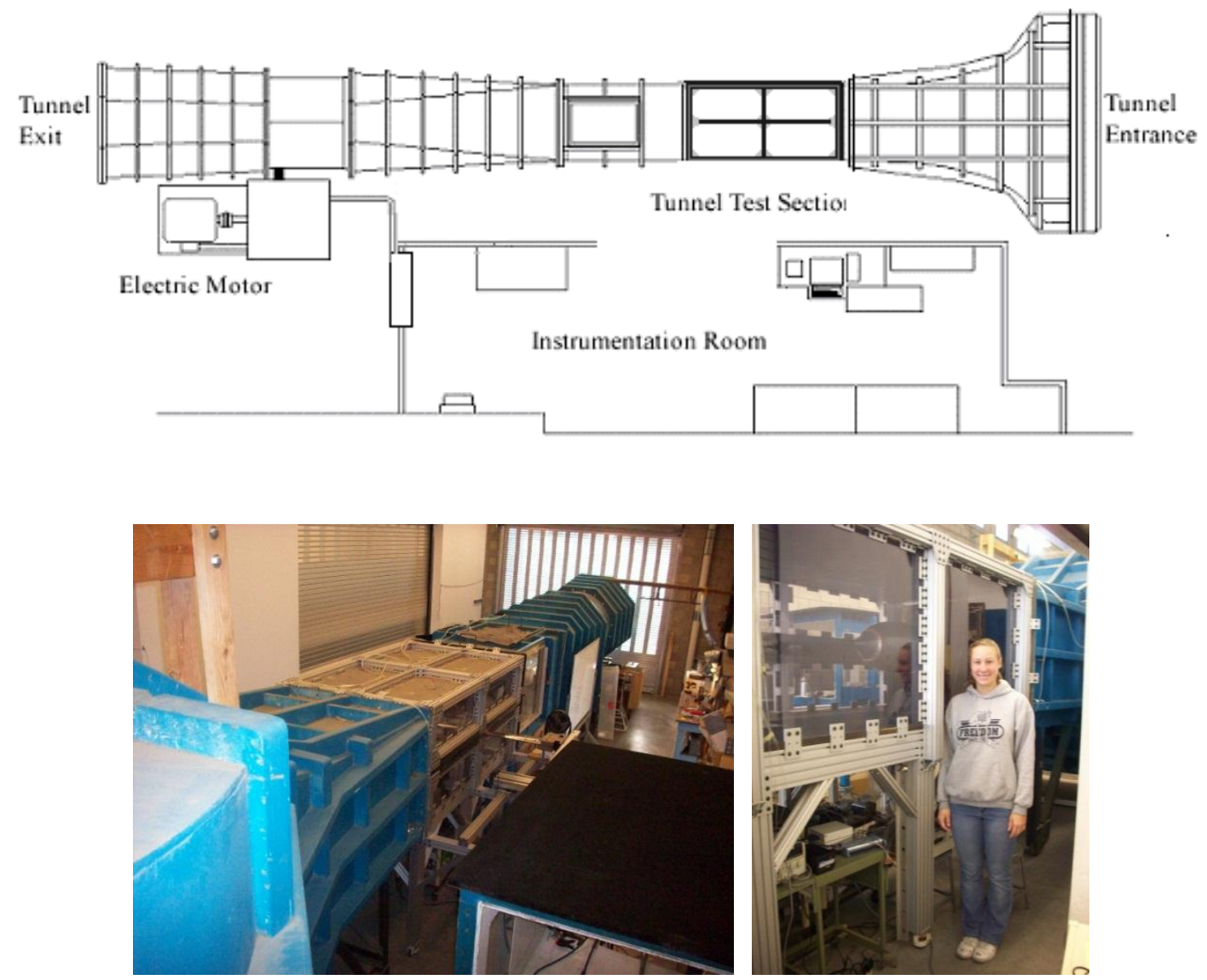

Figure 5. a) Diagram and b) photograph of the Cal Poly $3 \mathrm{ft}$ by $4 \mathrm{ft}$ low-speed, draw-down wind tunnel, and c) the test section with our Goldschmied Propulsor model mounted inside.

Page 13 
A section between the test section and the contraction area was removed because it was determined to be the cause of large boundary layer growth. This was probably due to poor seals around the section and poor wall surface quality in the section. By removing the tunnel section before the test section, the floor boundary layer at the model mounting point was reduced from a thickness of about 5 inches to a thickness of about 1 inch. A pressure ring system installed across the inlet was used to measure total and static pressure to determine tunnel speed.

\subsection{Propulsor Model}

The Propulsor model manufactured for the current tests was designed to resemble, as closely as possible, the previous Goldschmied models. The reason for this was to allow for comparison between the data sets. However, the original model was difficult to duplicate due to a lack of sufficient records describing the original model design or shape. Major components of the current model include the forebody, which provides the bulk of the model volume, and an aftbody. The forebody features a pressure step at $85 \%$ of the length, same as 1981 test, and houses the internal traverse that allows for slot gap adjustment and provides an attachment point for the aftbody which houses the suction/propulsion axial fan. A rear suction slot is located between the forebody and aftbody for boundary layer control to realize the pressure step.

\subsubsection{Design}

In the design of the current model some obvious changes needed to be made just to accommodate the tests in the Cal Poly wind tunnel which is considerably smaller and lower speed than the wind tunnel at the David W. Taylor testing facility. The model dimensions are therefore smaller than the original, and the Reynolds numbers are considerably smaller. Table 1 compares the key differences between the current test 
conditions with the original tests. Surface pressure port location points are given in several papers, but the points vary between papers, and they do not produce a smooth model shape. The points from one paper were chosen and in areas where there were a high concentration of pressure ports, near the nose and the suction slot, the points were thinned by removing some to create a smoother surface to be used for the current model shape. The most important piece of missing information about the model is the shape of the suction slot cusps. No data exists that sufficiently describes the shape of the cusps used in any of the Goldschmied tests. The 1969 test evaluated many cusp designs and resolved to one that was used for all the 1981 tests. As was mentioned previously, none of the reports from 1969 are currently available, and the 1981 test reports provide no data on the cusp geometries. In place of the missing data, photographs and diagrams were used to estimate dimensions and general shapes.

Table 1. Comparison of test parameters for Cal Poly wind tunnel tests and original Goldschmied tests.

\begin{tabular}{|c|ccc|}
\hline & $\begin{array}{c}\text { Original WT } \\
\text { Tests }\end{array}$ & $\begin{array}{c}\text { Round 1 WT } \\
\text { Test }\end{array}$ & Round 2 WT Test \\
\hline $\operatorname{Re}_{\mathrm{L}} \times 10^{6}$ & $3.2-12$ & 2.23 & 2.23 \\
\hline Mach & $0.13-0.32$ & 0.087 & 0.087 \\
\hline Length & $54.5^{\prime \prime}$ & $38.5^{\prime \prime}$ & $38.5 ”$ \\
\hline Max Diameter & $20.0 "$ & $13.5 ”$ & 2.8 \\
\hline Fineness ratio (L/D) & 2.7 & 2.8 & $0.25-1.56$ \\
\hline Slot width (\%of L) & $0.4-1.6$ & $0.4-1.6$ & \\
\hline
\end{tabular}


The internal workings of the model were also redesigned in order to represent a more realistic configuration with more usable volume for use in real aircraft, and to avoid the fan performance issues that the original model suffered. The original model housed the fan inside the forebody and featured an inlet. This configuration forced the suction flow to turn 90 degrees to travel up the forebody and then turn another 180 degrees to enter the fan inlet, where it also underwent a rapid expansion. Due to the rapid turns and expansion, large pressure losses were seen that dramatically reduced the performance of the fan. ${ }^{3}$ In the original model they fixed this problem by adding flow straighteners before and after the fan. Although they claim to have restored the fan to its rated performance in the original tests, fan performance issues due to abrupt changes in flow path direction wanted to be avoided in the current tests. The entire fan assembly is housed in the aftbody, so suction flow turns once to enter the slot and then once more to enter the fan. A schematic of the model is shown in Figure 6.

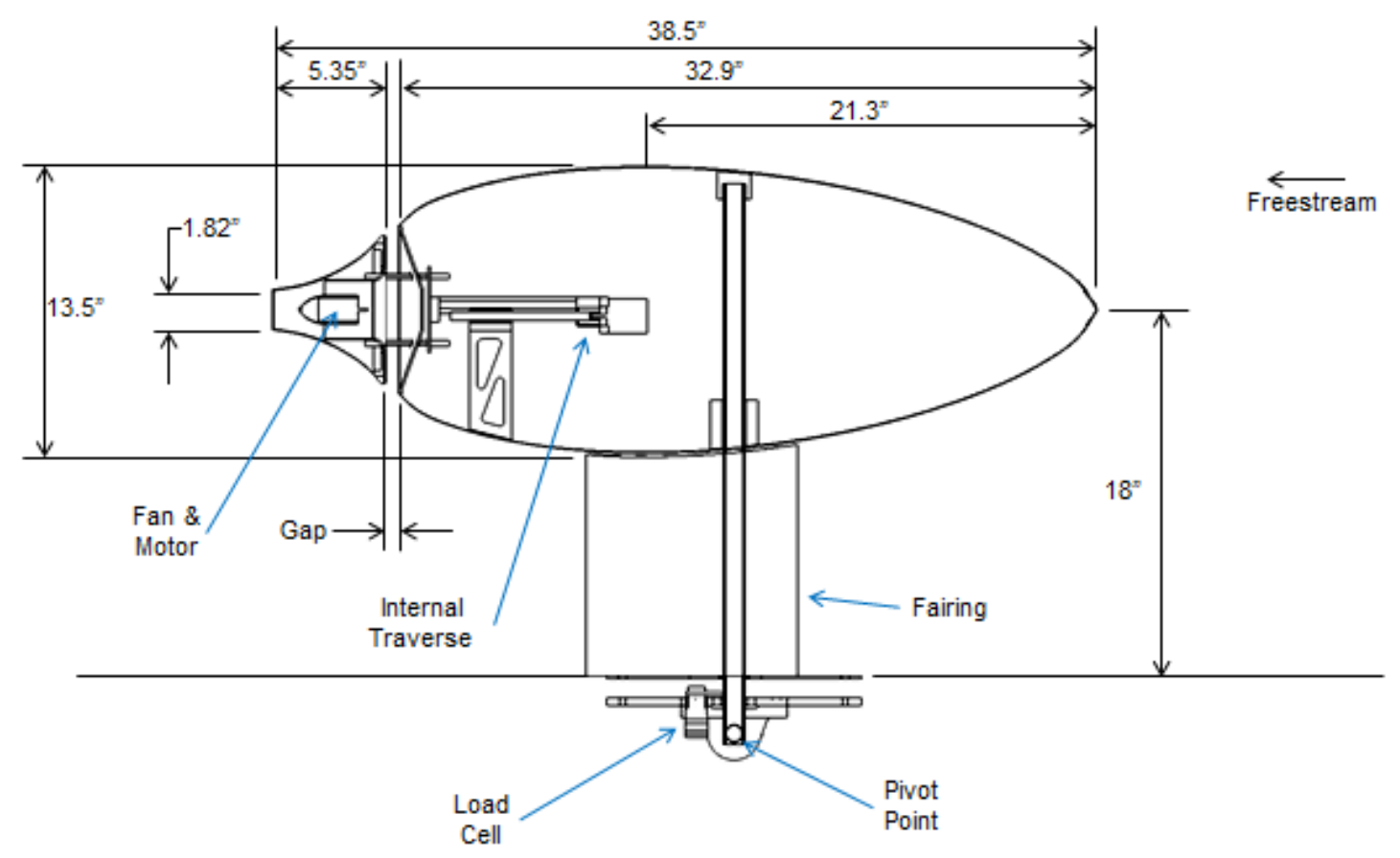

Figure 6. Basic schematic of current wind tunnel model used in Round 1 and Round 2 of the Cal Poly Goldschmied investigation. 
The material choices for the current model also vary from those of the original. The original model shape was formed with aluminum, and it was noted in the later tests that the model surface had aged showing signs of rust and waviness. ${ }^{6}$ The cusps on the original model were formed with clay, so we can imagine that the geometries were not very exact, and could easily be damaged and altered. It was decided that the current model skins would be made of carbon fiber because of the availability of the material, its strength, its light weight, and it could be laid up in a fashion that produced a good surface finish that did not require painting or polishing. The cusps for the suction slot were manufactured from aluminum to allow for more precise, even shapes, as well as to make them more durable for multiple rounds of testing.

For more detailed explanations of the model design and manufacture refer to the paper describing Round 1 of testing by Joshua Roepke.

\subsubsection{Model Manufacturing Process}

The propulsor model skins are made of carbon fiber twill. To get the desired forebody and aftbody shapes, the Solid Works models where cut into high density foam female molds with a CNC machine. The molds were prepared first with a Duratec Technologies clear sealer and then grey surface primer and sanded up to 600 grit for a smooth surface. The primer was thinned out to avoid bubbles in the finish with a Duratec thinner. Alternating layers of colored green primer were applied for visual checks of uniformity when sanding. The primer was then polished to be ready for a carbon fiber layup. For each layup the molds where waxed with a spray on Fre-kote and then a Duratec Technologies high gloss top coat was applied that would stick to the final part and create a smooth surface finish. Once the glossy top coat became tacky the carbon fiber twill was laid up in a wet layup, wetting out the carbon first with resin and then placing it in the mold. The part was then hooked up to a vacuum to pull the material 
down against the mold for curing. The forebody skin is made of four sheets of carbon fiber with two layers in the line of the static pressure ports to give greater thickness for press fitting in the $1 / 16$ " OD steel static pressure tubes. There are also three honeycomb ribs approximately 1.5 inches wide. One rib is placed on either side of the strut mounts and the last is at the back of the model near where the aftbody attaches. The aftbody skin is made of two layers of carbon fiber. Figure 7 contains photographs of the manufacturing process for the forebody and aftbody skins.

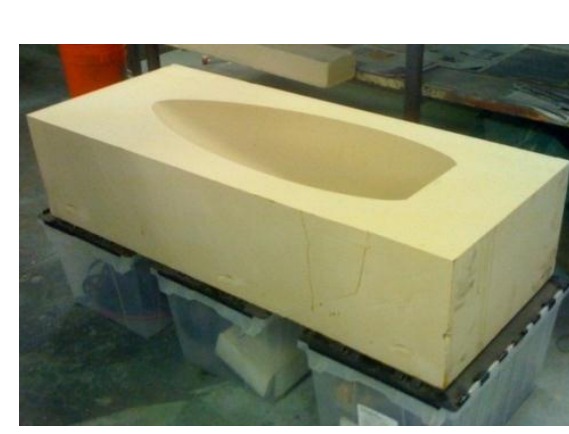

a) High density foam mold
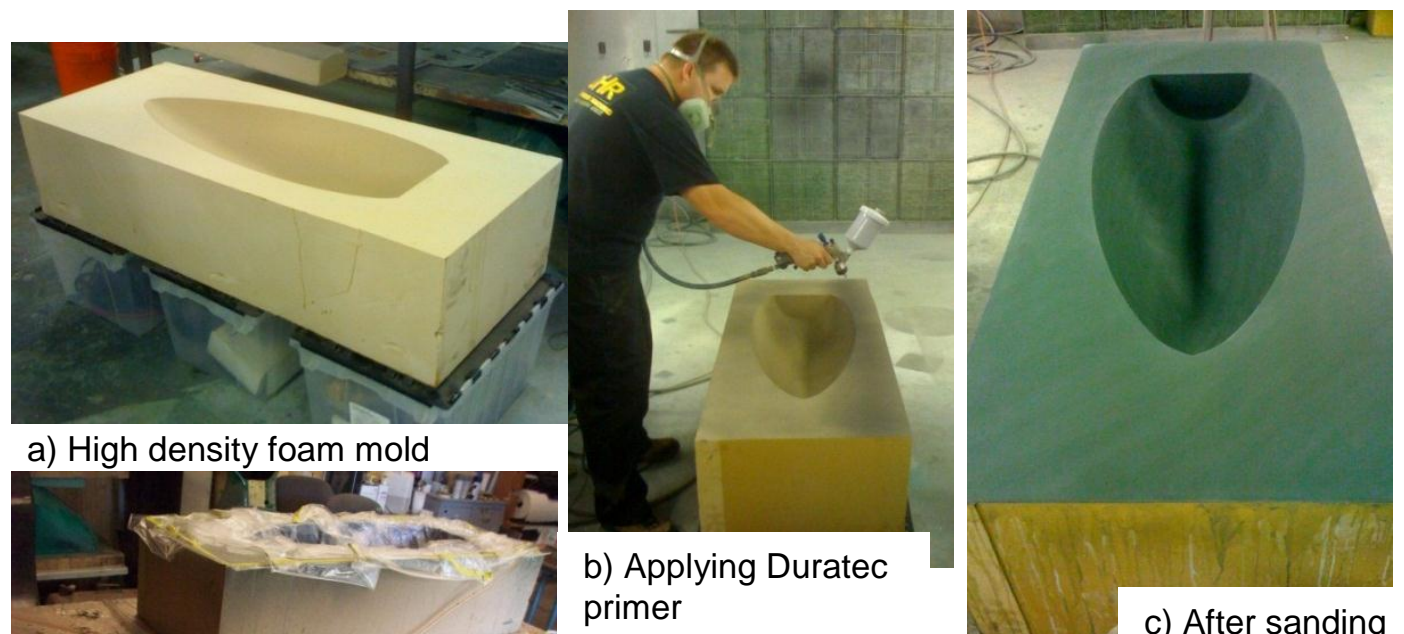

primer

c) After sanding

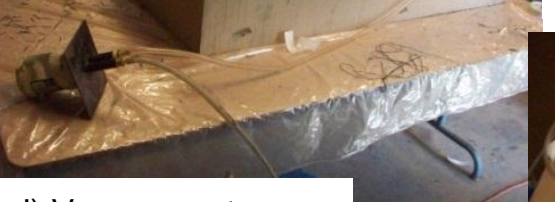

d) Vacuum set-up

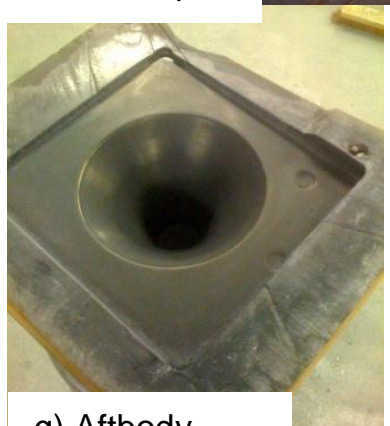

g) Aftbody

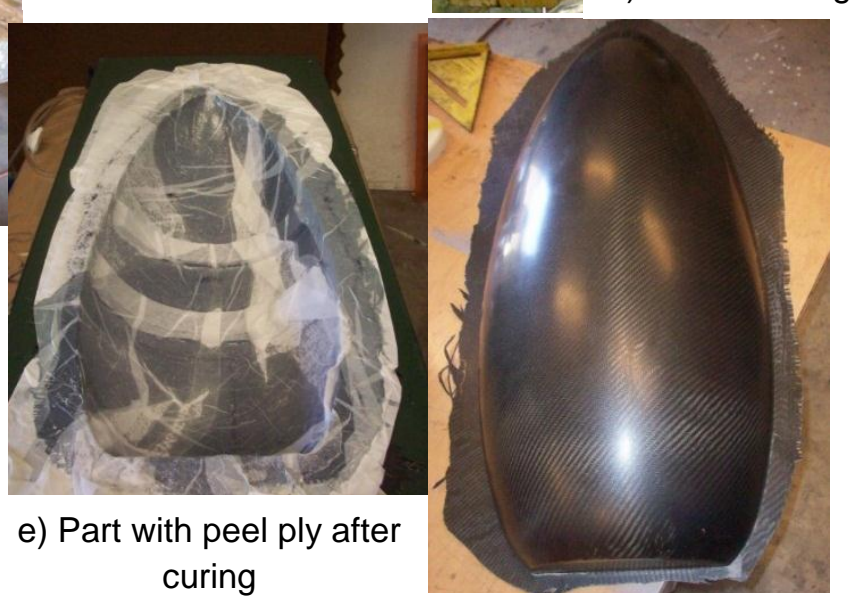

f) Final skin

Figure 7. Model skin manutacturing process starting with a) the forebody female mold CNC machined from high density foam, b) spraying on the Duratec primer after application of a sealer, c) final sanding of the mold with Duratec primer leaving a smooth surface free of imperfections that would translate to the final part, d) the vacuum bag set-up to cure the resin infused carbon, e) one half of the forebody skin after curing in the mold, and f) one half of the forebody skin completed and ready to be trimmed. $g$ ) is a photograph of the aftbody female mold after final sanding and polishing. 
Two aluminum mounts at the top and bottom of the forebody hold the steel strut that runs up through the bottom of the model. The strut mounts in the model are designed to allow for fine adjustment of the model orientation on the pitch and yaw axes. The bottom end of the strut is press fit to a precision shaft that attaches to two double ended flexure pivots from C-flex on a lower aluminum base plate under the tunnel floor. An upper base plate is flush with the tunnel floor and is the mounting platform for a fairing that shields the strut, wires, and static pressure port plumbing from the freestream flow. The slot is made adjustable through use of an internal Velmex traverse mounted in the model forebody. This traverse moves the entire aftbody of the model to adjust the slot gap size.

In building a fairing, the main goal was to cause as little disruption of the flow as possible so as to reduce the effect on the flow over the model. NACA 0012 and NACA 0015 airfoil shapes were run through a 2-D incompressible boundary layer code called CEBSMITH, with chords varying from 6 inches to 10 inches assuming turbulent flow, to determine the size and shape of the fairing. The NACA 0012 with a 10 in chord was chosen for the fairing shape shown in Figure 8 because it could accommodate all the wires and plumbing, and it was unlikely to have enough of an adverse pressure gradient to cause flow separation until $95 \%$ of the chord. The fairing was constructed with four ribs and four spars, with the top rib being made of thick balsa to allow it to be shaped to the contour of the model. The top of the fairing sits about 0.125 inches below the bottom of the model and the strut is positioned so as not to touch the fairing. It is important that the fairing not touch the strut or the model so that it does not influence total axial force measurements through added friction. Some of the ribs were trimmed in model assembly to make larger openings around the strut to ensure its free movement. 

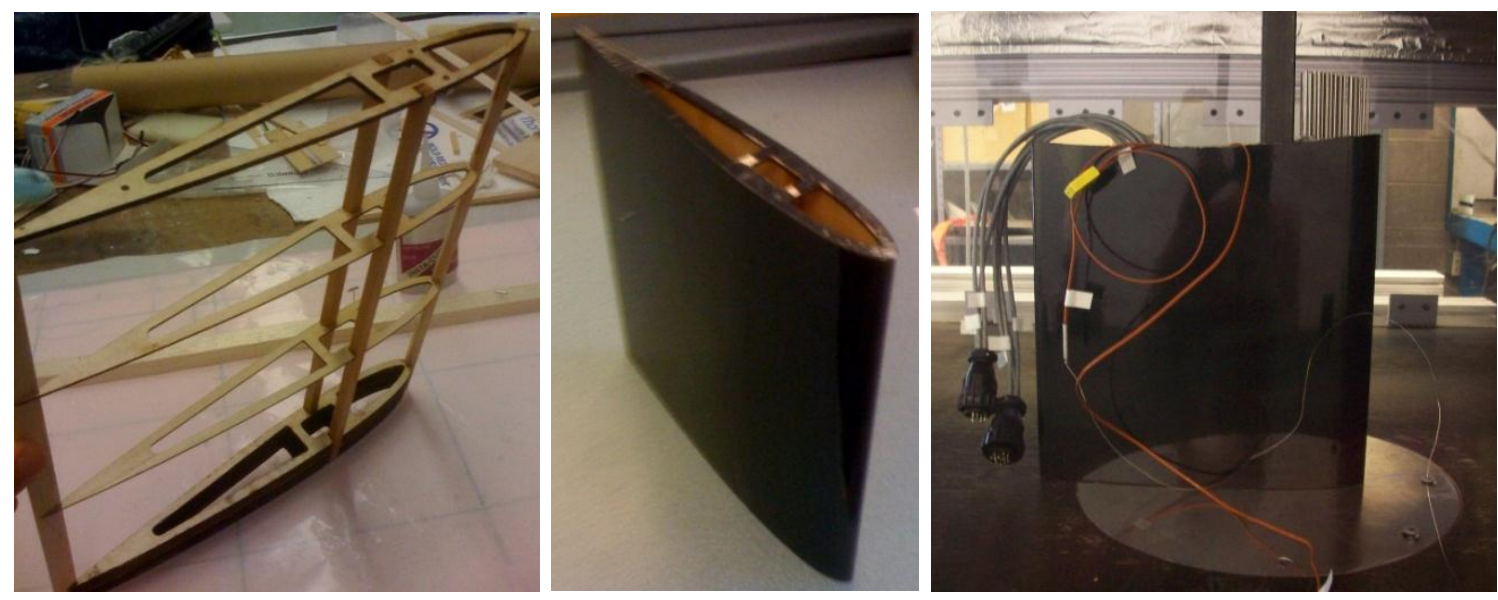

Figure 8. Photographs of the fairing a) internal ribs and spars, b) final assembly, and c) mounted in the wind tunnel test section housing the strut, electrical wiring, and pressure tubing.

Aluminum was chosen as the main manufacturing material because it is relatively inexpensive, light, and easy to work with. Additional aluminum parts were manufactured to separate the forebody and aftbody skins and to provide internal structure to the model. An aluminum bowl closes off the back end of the forebody, Figure 9. Its shape is a result of the necessity to maintain constant flow area throughout the slot. Constant mass flow is desired, so because circumference decreases as flow moves radially inward from the slot, the gap must become larger in order to maintain constant area, hence the bowl shape. Another aluminum face caps off the front of the aftbody skin and mounts the fan. 


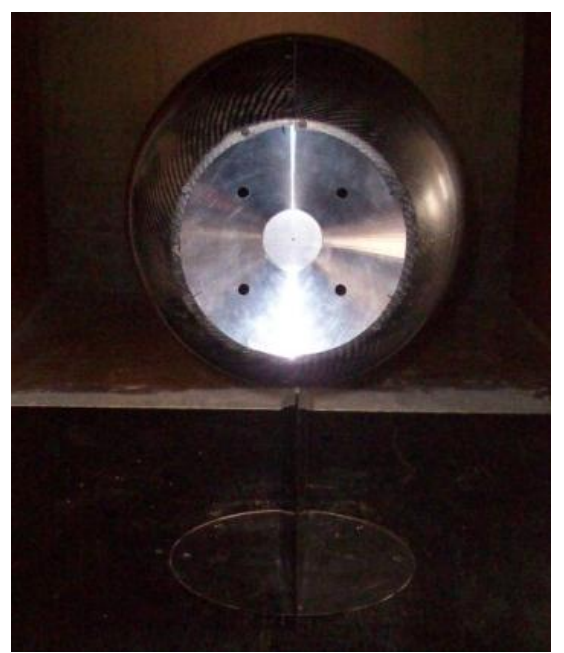

Figure 9. Aluminum forebody closure shield, formed in a bowl shape to maintain constant volume in the suction slot.

\subsubsection{Cusp Design and Manufacture}

The first cusp shape was based purely from a diagram of the cusp profile used in the 1981 Goldschmied wind tunnel test. There are no references available that describe the shape of the cusp geometries used in the previous wind tunnel tests or any information to justify why those particular shapes were chosen. Several reports reference a paper by Friedrich Ringleb that discusses trapped vortices and potential flows, however there is no mention of suction or use of a cusp with suction. ${ }^{7}$ Although Goldschmied refers to his cusps as "Ringleob cusps" after Friedrich Ringleb, it is unknown how he developed those designs. Cusp A, or the original cusp has a shape that is based off of the diagram in Figure 10. The other two cusp geometries, B and C, are simply versions of the original with modifications in how much the cusp protrudes into the suction flow. The variation in cusp geometries can be seen in Table 2 and Figure 11. Cusps for the current tests are machined out of aluminum to provide consistency and precision in the shapes. Although the cusp shapes are not mathematically determined, the results of the current tests aim to provide some insight into the important aspects of the shape. 


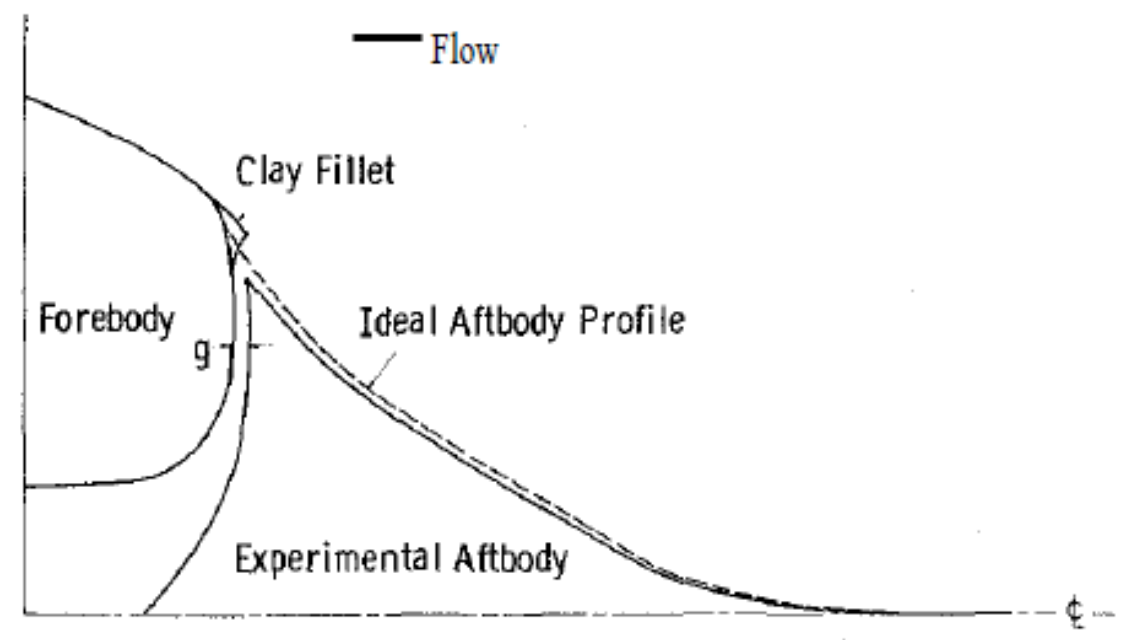

Figure 10. Diagram of the clay cusp used in the 1981 wind tunnel test. ${ }^{8}$

Table 2. Cusp geometry variables.

\begin{tabular}{|c|c|c|}
\hline Cusp & X (inches) & $\theta$ \\
\hline A & 0.05 & $52^{\circ}$ \\
\hline B & 0.1 & $46^{\circ}$ \\
\hline C & 0.15 & $39^{\circ}$ \\
\hline
\end{tabular}

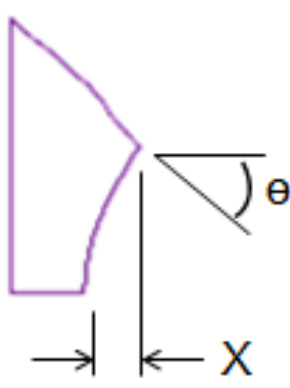

Cusp B
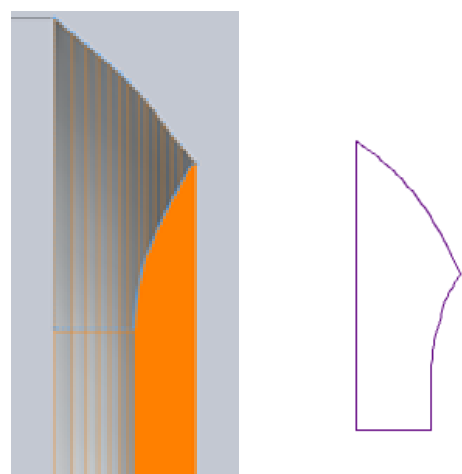

Cusp A

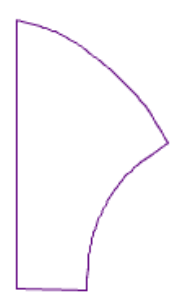

Cusp C

Figure 11. Orıgınaı cusp geometry imitated for current tests, and otner cusp geometries with different $X$ and $\theta$ values.

In designing the cusps, it was important to determine a way to attach the cusps that would make them easy to attach and remove without interfering with the outer mound 
line of the specific shape. Due to the physical size of the cusp, there is not enough material to screw the cusps on directly without putting the screws right through the point, and because of the aluminum bowl closing off the end of the forebody, the cusps could not be screwed in from the back side. The solution was to use a tab and groove mechanism that twists into a locked position. A connection ring was first designed to permanently attach to the forebody skin. The connection ring is a small aluminum ring that contours to the shape of the forebody and has four grooves for the cusp tabs to lock into. The three cusps each have four tabs on the back side that lock into the connection ring as seen in Figure 12. Not only does this system allow for the cusps to be easily interchangeable, but also makes a crisp, flat edge at the mating point of the forebody and cusp which makes for a smoother transition between the two. All of the cusps and the connection ring were cut in half so as to be able to separate the two halves of the model without removing the entire aftbody. The transitions between the forebody to the connection ring and the connection ring to the cusp were filled and smoothed out with red wax before data collection. The installed connection ring and Cusp C can be seen in Figure 13.

Slot width was varied in testing. Depending on the suction flow rate, the slot width changed to maintain maximum efficiency. If the slot width is too large, the flow may not be able to smoothly cross the slot and attach to the aft body which eliminates any improvements in drag. If the slot is too narrow, pressure in front of the fan will increase and create too great of a pressure difference across the fan causing its efficiency to decrease. This investigation aimed to determine these points during operation. 

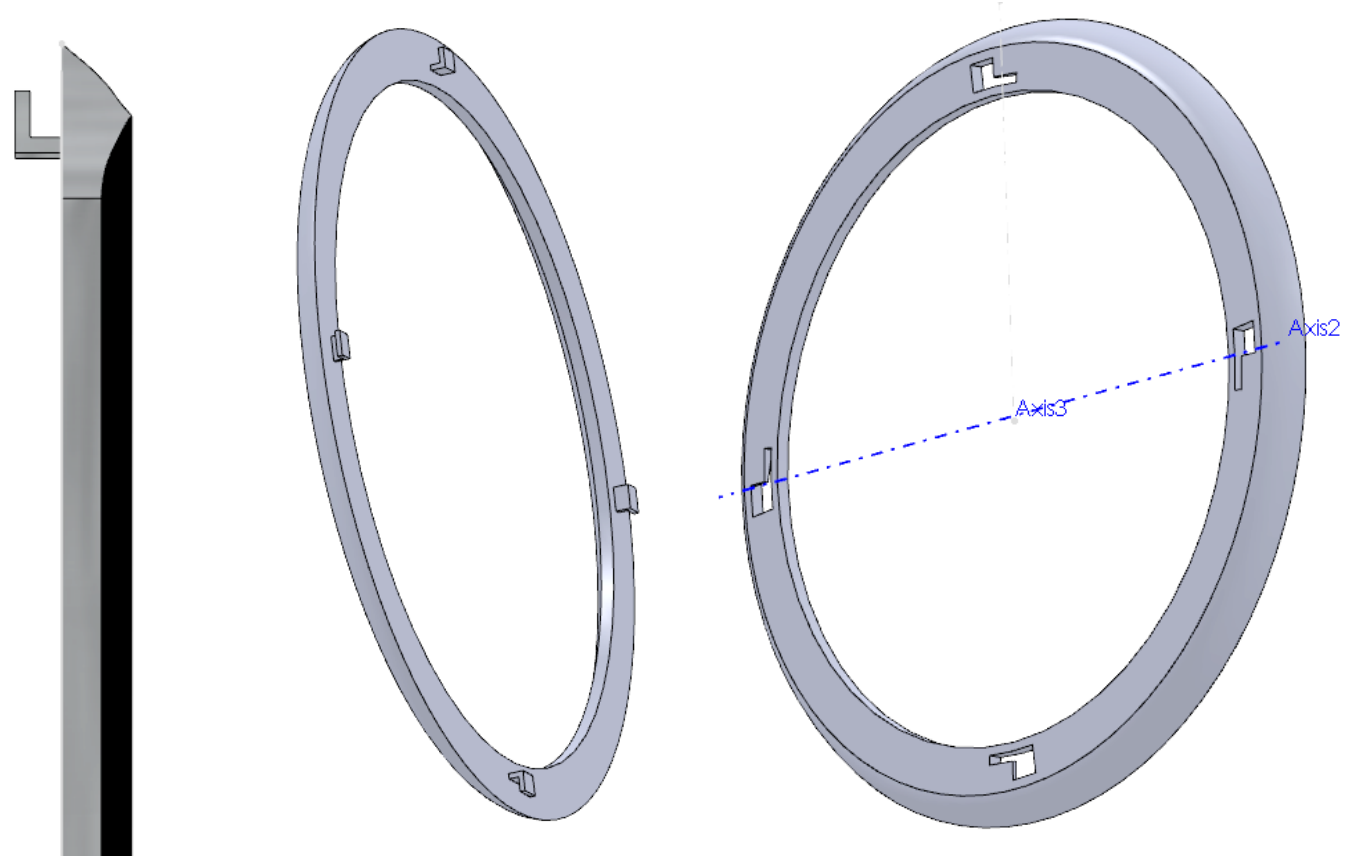

Figure 12. Solid model images of Cusp A a) with cusp shape visible and connection tabs, b) the full ring with connection tabs, and c) connection ring where the cusp geometries snap in to attach to the back of the forebody.
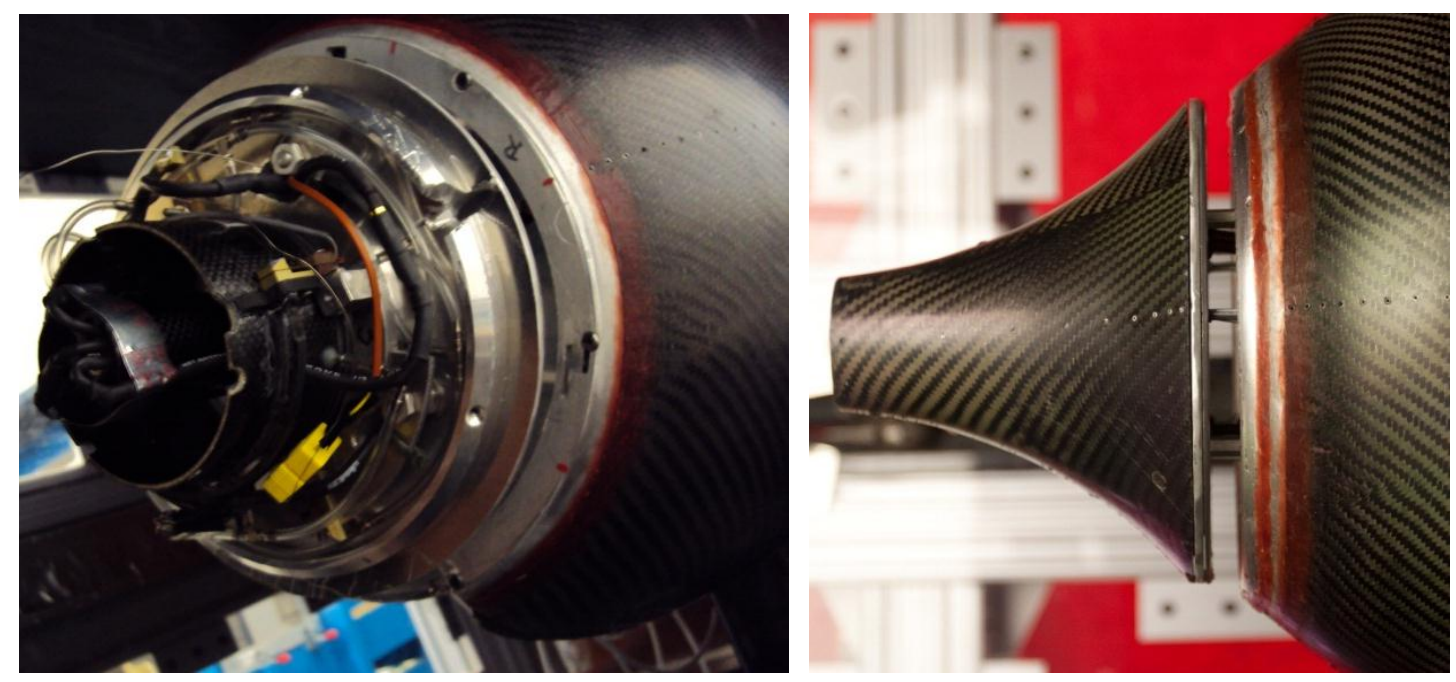

Figure 13. Photographs showing a) installed aluminum connection ring for cusp attachment with transition smoothed with red wax and b) installed Cusp $C$ with all transitions smoothed with red wax. 


\subsection{Data Acquisition System}

The data acquisition system consists of 5 subsystems, Figure 14 . These are the pressure measurement system, the USB data acquisition device, the PCI data acquisition card, and the two traverses.

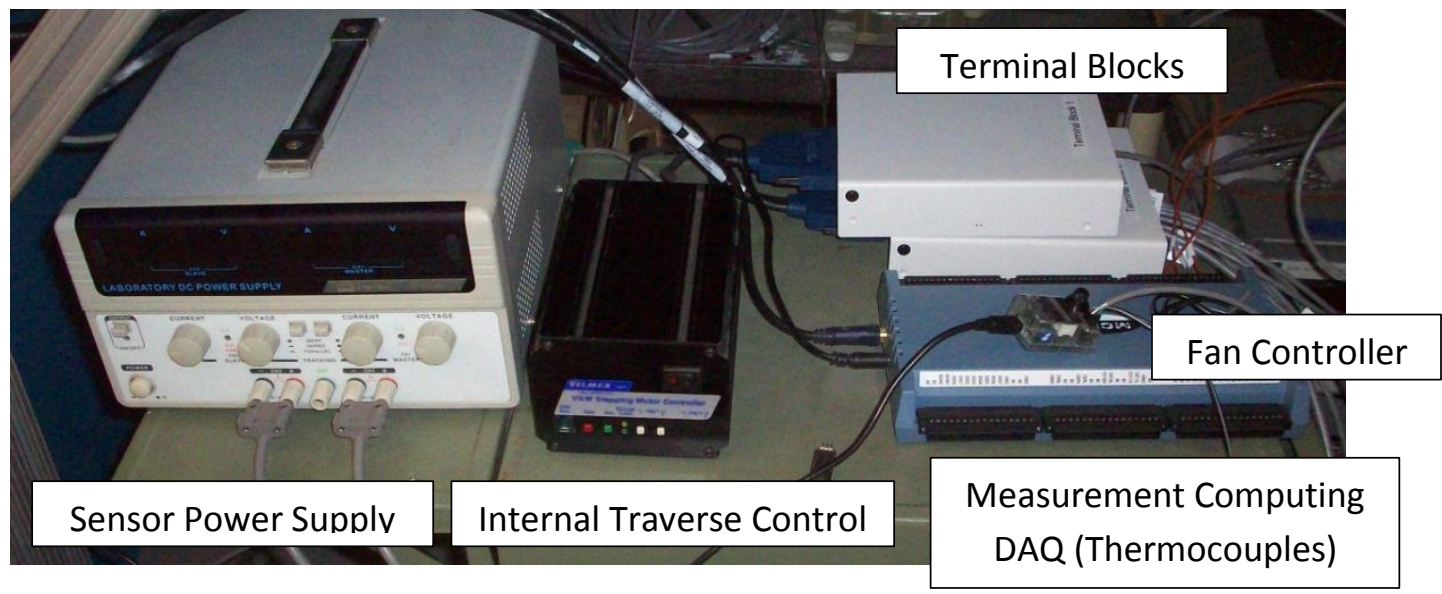

Figure 14. Data Acquisition System including the power supply for the model sensors, the terminal blocks for sensor connections to be sent to the PCl card in the computer, the Measurement Computing DAQ, the controller for the internal traverse, and the controller for the model fan motor that is programmed through the computer. (Pressure measurement subsystem not pictured).

There are a total of eight sensors in the model and one potentiometer on the external traverse outside the model, plus three thermocouples. The eight sensors in the model include five load cells, one $25 \mathrm{lb}$ load cell and four $1 \mathrm{lb}$ load cells, a linear potentiometer, and two accelerometers.

\subsubsection{Measurement Computing USB Data Acquisition Device}

The USB data acquisition device is a Measurement Computing USB-2416 multifunction I/O module. The module has up to 32 single-ended channels (16 differential channels), a maximum input voltage of 30 volts, and a maximum data rate of 3,750 samples per second, but the actual throughput varies with the number of channels being used. Three $\mathrm{K}$ type thermocouples are connected to double-ended screw terminals for 
Channels $0-2$ on this module. A program called InstaCal is used to self-calibrate the USB-2416, and recommended to be done anytime the ambient temperature changes by more than $10^{\circ} \mathrm{C}$.

\subsubsection{PCI Data Acquisition Card}

The PCl data acquisition card is a high speed multifunction system with a 16-Bit resolution, a data rate of up to 1.25 million samples per second, and contains up to 80 analog channels. This PCl card read all the sensors in the model besides the thermocouples. The sensors and their typical lab DC power supply are connected to two terminal blocks that are then fed to the PCI DAQ card in the back of the computer.

\subsubsection{Internal and External Traverses}

Both the internal traverse that controls the aftbody movement and the external traverse that controls the pitot-static probe for wake measurement are controlled by their own systems. The internal traverse is a single axis traverse made by Velmex, Inc. It has a straight line accuracy of $0.001 " / 10$ ", a travel length of 4 inches, limit switches, and an advances/turn of $0.025 \mathrm{in}$. The traverse is controlled by a VXM stepper motor controller and a brushless motor. During the experiment the traverse was controlled manually through the VXM controller. With the cusps attached to the slot entrance, slot gap size was measured from the tip of the cusp to the edge of the aftbody.

The external traverse is a two axis Isel traverse. An Isel microstep controller with a processor card, three output stages, and an AC power supply run the traverse. During the experiment the external traverse was controlled through the use of a hand remote. 


\subsubsection{Pressure Transducers and Static Pressure Ports}

Pressure data was acquired using a Scanivalve ZOC33/64Px-X1 pressurescanning module. This module has 64 differential pressure ports; 32 ports with a pressure range of 0.36 Psid and another 32 ports with a range of 1.0 Psid. The accuracy of all ports is $+/-0.20 \%$ full-scale reading. An internal temperature sensor compensates for temperature changes in the module. Before use, the module is simply allowed to reach a constant temperature and then zeroed. A RAD3200 A/D unit amplifies and samples the signal from the pressure scanner and relays the information through a USB hub to the computer. The software program ScanTel v1.01 is used as the communication software and can set the scan rate and sample time of the RAD3200 A/D. Pressure data is output to a file in the unit of psf. Figure 15 and Figure 16 below show the components of the Scanivalve system and its typical layout. The static pressure of the upstream pressure ring is used as a reference for all pressure measurements. The operational valve logic can be seen below in Table 3 .

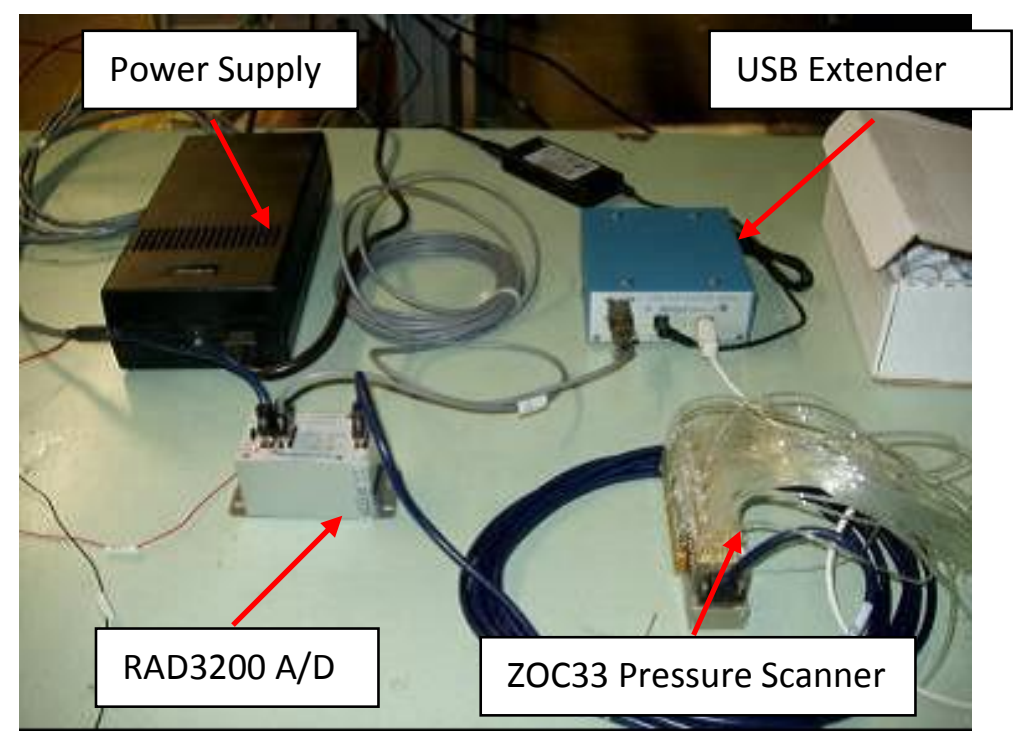

Figure 15. Pressure measurement subsystem is the Scanivalve system made up of a power supply, a USB extender, the RAD3200 analog to digital converter, and the ZOC33 pressure scanner. 


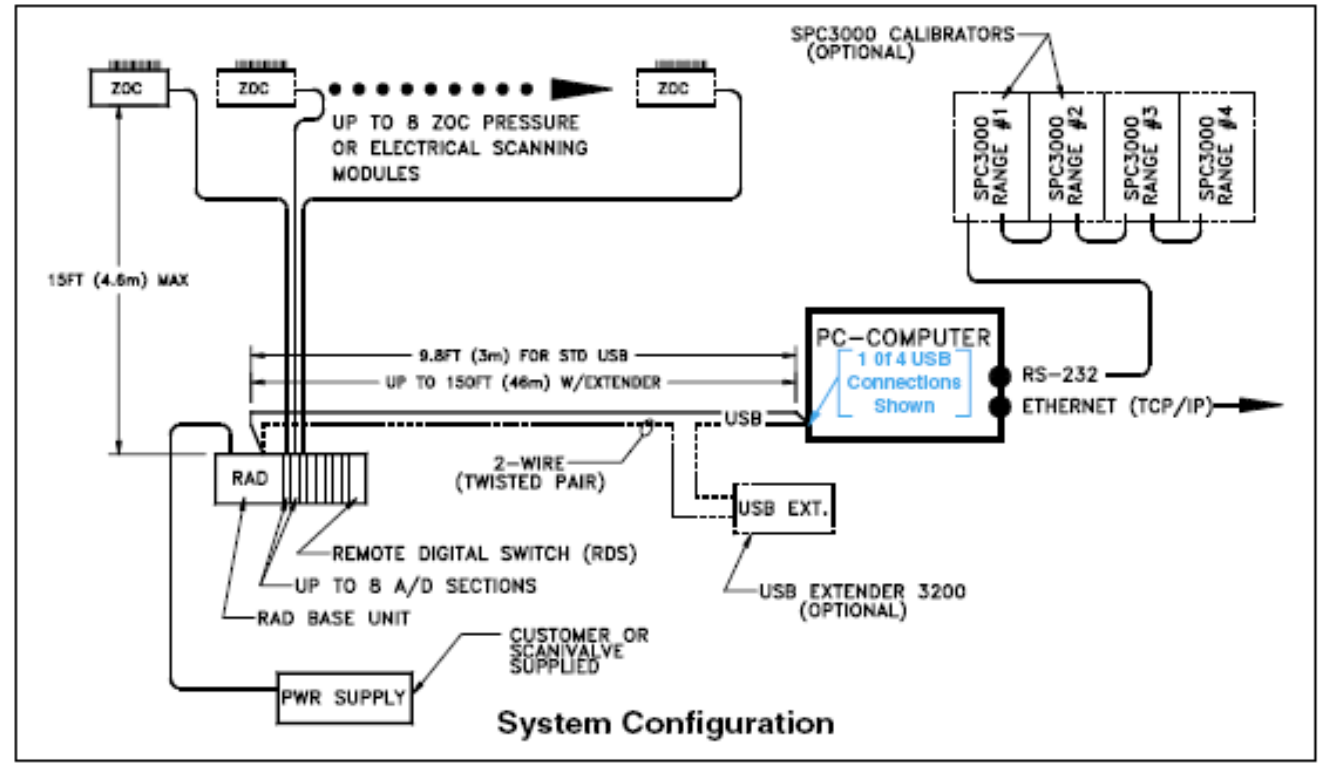

Figure 16. Typical Scanivalve System Configuration. ${ }^{10}$

Table 3. Scanivalve Valve Logic

\begin{tabular}{||l|c|c||}
\hline \hline \multicolumn{1}{||c|}{ MODE } & PXCTL & CAL CTL \\
\hline OPERATE & $\mathrm{X}$ & $65 \mathrm{psi}$ \\
\hline CALIBRATE & $65 \mathrm{psi}$ & $\mathrm{X}$ \\
\hline PURGE & $\mathrm{X}$ & $\mathrm{X}$ \\
\hline ISOLATE & $65 \mathrm{psi}$ & $65 \mathrm{psi}$ \\
\hline \hline
\end{tabular}

There are 58 static pressure ports on the surface of the model shown in Figure 17,49 on the forebody and 9 on the aftbody made of $1 / 16$ " OD steel tubing. The ports are clustered near the nose and the slot where the greatest pressure gradients were expected, Figure 18. There is also a ring of four static ports at the fan entrance and another ring just after the fan to measure the pressure difference across the fan. This not only gives a measure of the work done on the flow, but also indicates fan performance parameters. The four static ports that form a ring are connected to a single pressure transducer to allow for an averaged reading by the Scanivalve. Another ring of four static 
ports just under the cusp lip and a single static port at the center of the slot plenum measure the static pressure at the slot entrance and inside the slot to indicate how the suction flow changes as it travels through the slot and prepares to enter the fan. The last two ports available on the 64 port Scanivalve system are taken by the tunnel static pressure and tunnel total pressure measurements. Due to a change in mass flow rate calculation strategies, two more static pressure ports were needed to measure static and total pressure from a pitot static tube taking wake surveys at the aftbody exit. Forebody surface ports 29 and 31 were commandeered for this purpose.

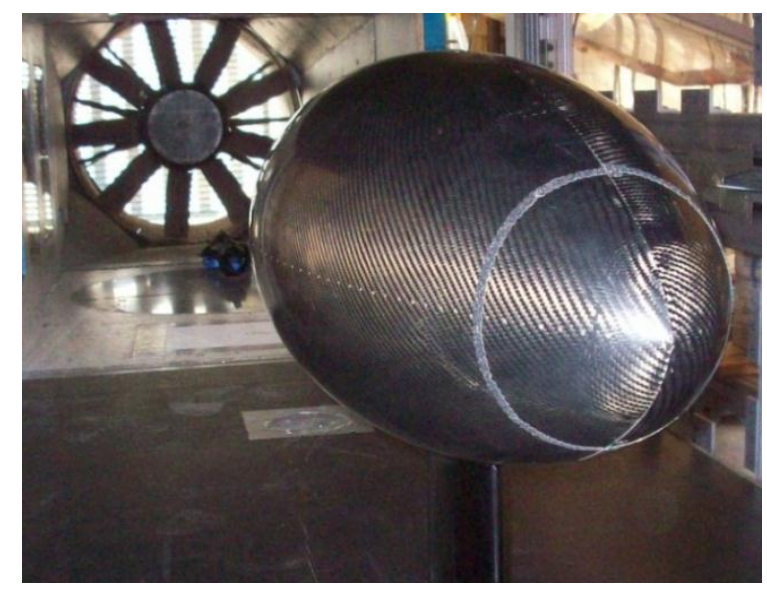

Figure 17. Photograph showing a view of the forebody surface static pressure ports.

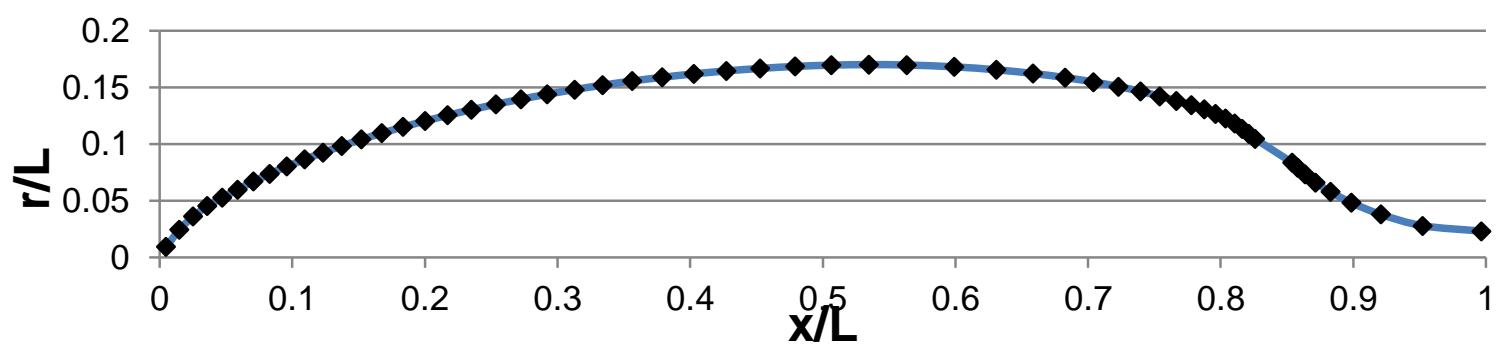

Figure 18. Distribution of 58 surface static pressure ports along the propulsor.

In order to collect the true data and filter out noise, 3000 points were collected by the Scanivalve and averaged for each data point. Several setting were changing from 
the default to increase the number of readings, to decrease the amount of time in collecting data, and to format the recorded files correctly for importing into Matlab. The changed settings are as follows:

\section{Period 50}

Ifc 00

\section{FM 2}

Fps1 3000

Chan1 1-1..1-64

\subsubsection{LabVIEW}

All the USB-2416 and the PCI DAQ card signals are displayed and recorded in a LabVIEW version 9.0 vi. The front panel displays graphs of sensor voltages reading and thermocouple temperature readings for health monitoring during testing. The vi also organizes the signals into text files. All the sensors are set to average 3000 readings per point at rate of $3 \mathrm{~Hz}$. The thermocouples are set to average 100 readings per point. The front and a portion of the back panel of the vi are pictured in .

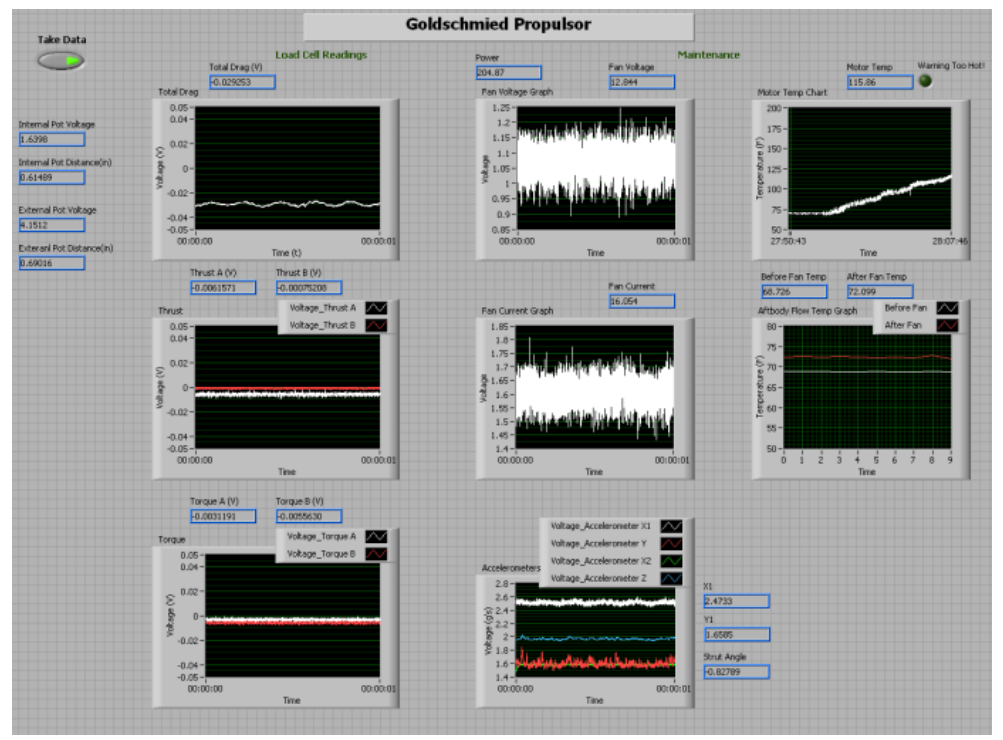

Figure 19. Front panel of LabVIEW vi for collecting and monitoring Goldschmied propulsor model sensor data. 


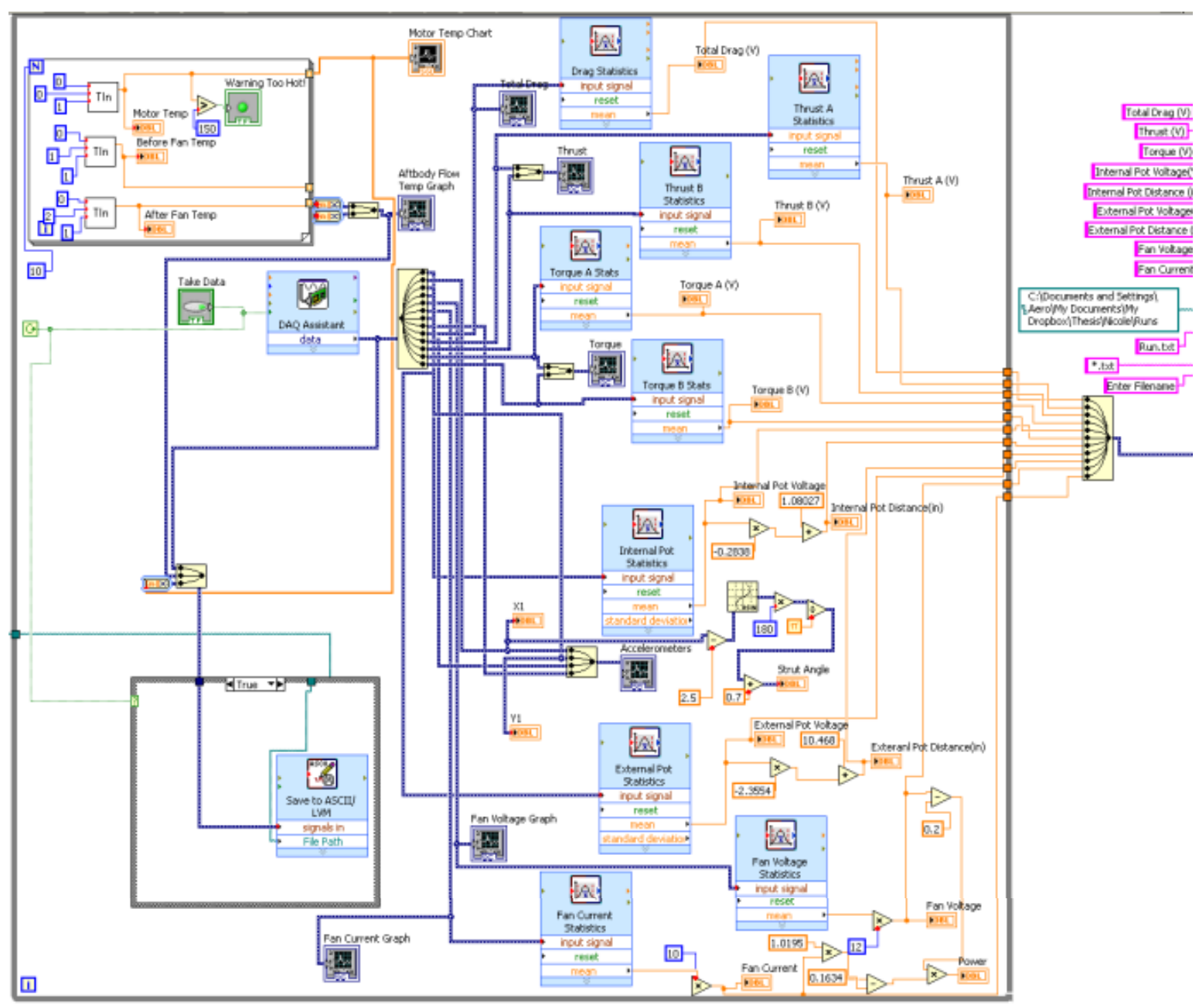

Figure 20. Back panel of LabVIEW vi used to collect and display Goldschmied propulsor model sensor data.

\subsubsection{Mass Flow Measurement}

Mass flow rate was originally going to be measured during the experiment through a correlation of differential pressure through the suction slot. However, this proved to be a problem during calibration because the differential pressure between the edge and center of the slot was not always large enough to allow for a correlation with the velocity of the air exiting the aftbody. It was also found that the differential pressure varied greatly between cases when the tunnel airspeed was zero and when the tunnel 
airspeed was greater than zero. The lack of a constant parameter to compare between cases disqualified this method of mass flow measurement as an option.

The adopted method for measuring mass flow was a wake survey. A pitot-static tube was used to horizontally survey the exit air at the end of the aftbody. Six data points were collected from the center of the exit area to the edge of the aftbody skin and then integrated to determine the velocity of the air at the aftbody exit and the mass flow rate. This method added considerable time to data collection.

\subsubsection{Total Axial Force Measurement}

Total axial force on the propulsor is measured by an Omega LCEB-25 lb load cell with a $\pm 0.06 \%$ FS accuracy that is mounted to push against a strut that holds the model. The strut rotates on an axle connected to double-ended flexure pivots on each end, creating a pivot point. The double ended flexure pivots made by C-Flex are frictionless and have no stiction, allowing for accurate and repeatable drag measurement by the load cell.

\subsubsection{Fan Thrust and Fan Torque Measurement}

Two Omega LCL-454G load cells with a 0-1 lb range measure thrust of the model fan and two other Omega LCL-454G load cells measure the model fan torque. The individual load cell measurements are added to obtain the total measurement. Figure 21 is a photograph showing where the load cells are mounted to the model fan. 


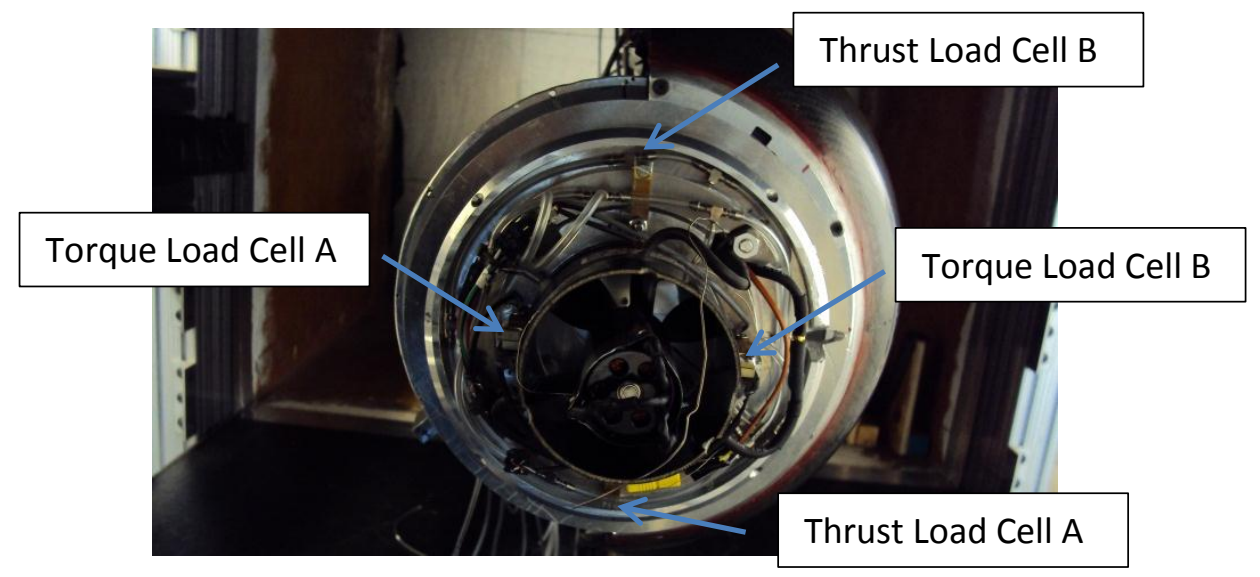

Figure 21. Photograph of the load cells measuring fan thrust and fan torque in the model aftbody. Two $1 \mathrm{lb}$ load cells measure thrust at the top and bottom of the fan and two $1 \mathrm{lb}$ load cells measure torque at the right and left side of the fan.

\subsubsection{Fan Power}

Fan voltage and current are measured for each run through the back of the $\mathrm{Hp}$ VDC power supply. Through initial system testing and setup it was determined that the LabVIEW reading through the computer was not correct most likely due to line losses, but the current had a direct correlation to the exact readings measured with an ampmeter and the voltage was simply offset from the voltmeter reading. Therefore the LabVIEW data for fan current and voltage was corrected with the following correlations, where $x$ is the LabVIEW measurement and $y$ is the corrected measurement.

$$
\text { Voltage: } y=x+0.2
$$

$$
\text { Current: } y=1.0195 x-0.1634 \mathrm{v}
$$

In order to compare data for each run, a correlation needed to be determined for fan throttle and power. Fan power is calculated using the fan voltage and fan current measurements, however, the measured fan power does not correspond to the fan power that the ESC records. Also, the computer controller for the fan does not have a readout for power to allow for that metric to be used as a control. The computer controller adjusts 
fan speed through a throttle setting. Therefore, the throttle settings of the controller were correlated to the measured fan power through the following correlation, where $x$ is the LabVIEW measurement and $y$ is the corrected measurement.

Table 4 lists the throttle settings for expected fan powers at optimum fan conditions.

$$
y=-0.0021 x^{2}+2.5853 x+1198
$$

Table 4. Throttle settings for fan power at specified performance conditions.

\begin{tabular}{|c|c|}
\hline Throttle & Power \\
\hline 1198 & 0 \\
\hline 1322 & 50 \\
\hline 1436 & 100 \\
\hline 1539 & 150 \\
\hline 1631 & 200 \\
\hline 1713 & 250 \\
\hline 1785 & 300 \\
\hline 1846 & 350 \\
\hline 1896 & 400 \\
\hline 1936 & 450 \\
\hline 1966 & 500 \\
\hline
\end{tabular}

Schubeler makes the $30 \mathrm{~cm}$ ducted fan (2.43inch diameter) with an ultralightweight carbon-aluminium-diagonal-rotor unit running resonance- and vibration free. This fan operates in a thrust range of 3.5 to $17 \mathrm{~N}$ and a power range of 0.1 to $0.95 \mathrm{~kW}$. Static efficiency is rated at $73 \%$. The fan features a low tip clearance for greater total efficiency. Figure 22 is the performance measurements from the manufacturer Schubeler Jets. 


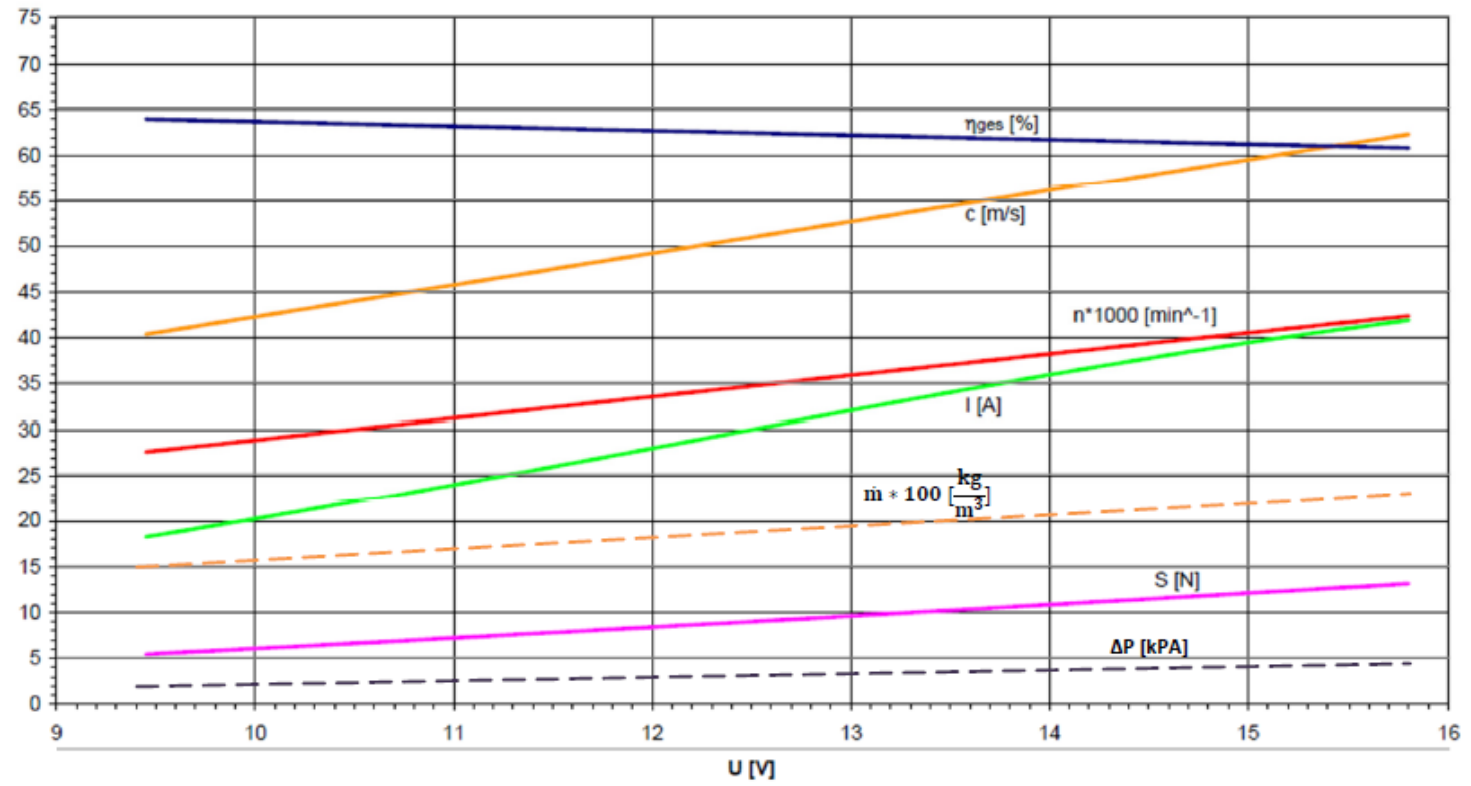

Figure 22. Schubeler $30 \mathrm{~cm}^{2}$ ducted fan performance chart. ${ }^{12}$

\subsubsection{Fan Temperature and Pressure Change}

A ring of four static pressure ports average the pressure before the fan blades and another ring averages the static pressure just after the fan blades to allow for measurement of the pressure rise across the fan at different fan speeds and slot gap sizes. Figure $23 a$ is a photograph of the Schubeler carbon fiber ducted fan with the static pressure ring measuring static pressure after the fan blades. Figure $23 \mathrm{~b}$ is a diagram of the fan arrangement in the aftbody and the flow path through the aftbody. 

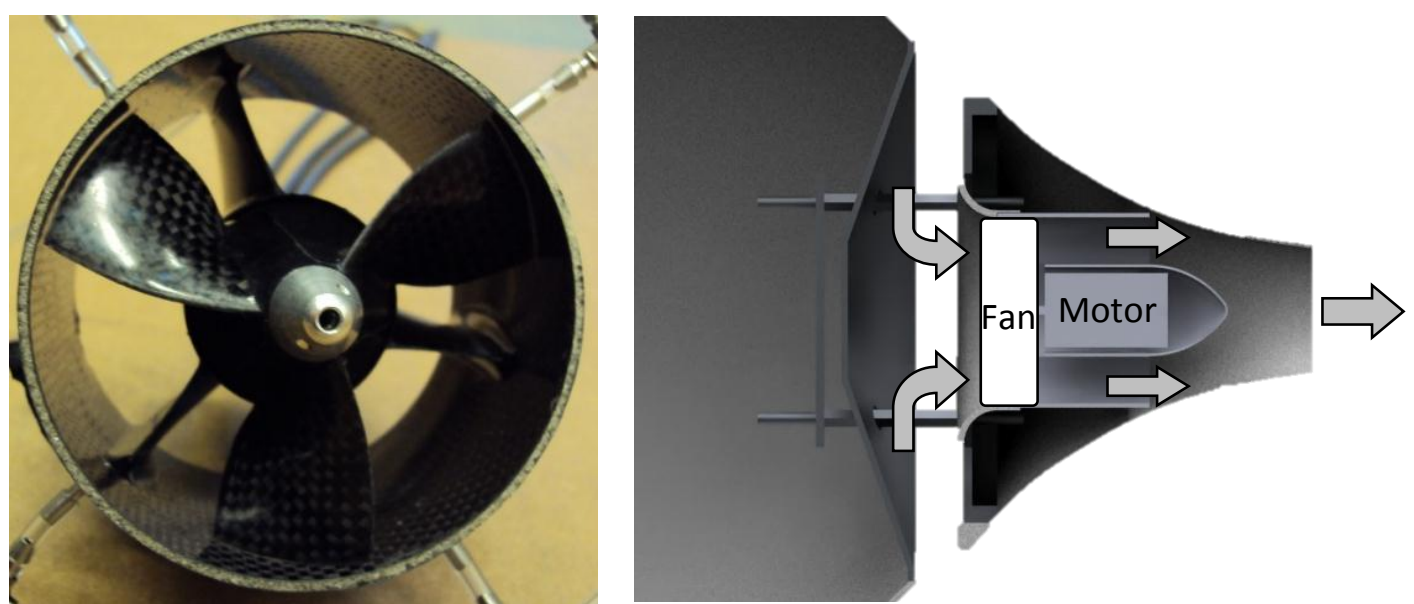

Figure 23. a) Schubeler $30 \mathrm{~cm}^{2}$ ducted fan with static pressure taps to measure pressure before the fan blades. b) Diagram of fan placement in aftbody and flow directionality through the suction slot and the aftbody.

Three Type $\mathrm{K}$ thermocouples are mounted in the aftbody to measure temperature of the flow before the fan, at the exit, and to monitor the temperature of the fan motor.

\subsubsection{Health Monitoring}

Two dual axis accelerometers measure model movement in the $\mathrm{x}, \mathrm{y}$, and $\mathrm{z}$ directions. The $\mathrm{X} 1$ and $\mathrm{Y}$ axis accelerometer was mounted to the aluminum strut mount in the forebody and the $\mathrm{X} 2$ and $\mathrm{Z}$ axis accelerometer was mounted to the underside of the internal traverse mount. The accelerometers were incorporated to indicate if something came loose in the model to cause significant vibration that could then affect sensor measurements.

A Type $\mathrm{K}$ thermocouple measured fan motor temperature to monitor that the temperature didn't rise above the rated safety temperature for proper operation of the motor. 
A linear potentiometer sits on the internal traverse mount and measures slot gap size. It has a 1.56 inch mechanical travel range and is powered at $5 \mathrm{~V}$. The other potentiometer measures the movement of the external traverse that moves the pitotstatic probe for wake survey measurements and has a range of 10 inches. Table 5 lists all the measured parameters for the current wind tunnel tests.

Table 5. Measured parameters for the Goldschmied propulsor model.

\begin{tabular}{|ll|}
\hline \multicolumn{1}{|c|}{ Parameter } & \multicolumn{1}{c|}{ Sensor/Measurement Device } \\
\hline Suction Mass Flow Rate & Pressure ports/Scanivalve \\
\hline Pressure Drag & 58 Static pressure ports/Scanivalve \\
\hline Total axial force & $\begin{array}{l}\text { Omega LCEB-25 load cell ( } \pm 25 \mathrm{lb} \text { range, } \pm 0.06 \% \mathrm{FS} \\
\text { accuracy) }\end{array}$ \\
\hline Fan Power & Fan current and fan voltage \\
\hline Fan Thrust and Torque & Omega LCL-454G load cells (0-1lb range) \\
\hline $\begin{array}{l}\text { Fan Pressure and Temperature } \\
\text { Change }\end{array}$ & $\begin{array}{l}\text { Pressure Ports/Scanivalve } \\
\text { Thermocouples }\end{array}$ \\
\hline Wake Survey & Pitot-static probe/Scanivalve \\
\hline Health Monitoring & Accelerometers (vibration) \\
& Linear Potentiometers (traverse position) \\
& Thermocouple (motor temp., elec. temp) \\
\hline
\end{tabular}




\section{$3 \quad$ Experimental Procedure}

\subsection{Test Conditions}

All test cases were carried out at a Reynolds number of 2.3 million for Round 2 of the investigation. Round 1 was carried out in order to establish continuity between the previous Goldschmied tests and the current work. Once the agreement with the initial work was found to be satisfactory in comparison with original work, force and pressure data was taken with added complexity to the suction slot geometry.

Round 2 of testing maintained all the same control and variable parameters as Round 1 of testing mentioned previously, with the addition of one more primary test variable, slot geometry. The slot geometry was modified in each run by the addition of a cusp at the entrance of the suction slot. The cusp varies in the distance it protrudes into the suction flow and in the angle it takes from the suction slot entrance edge. The range of slot widths that are cycled through with each run is also increased to a range from 0.1 to 0.6 inches. Figure 24 Figure 24 . Round 2 test plan for investigating influential parameters of slot geometry.illustrates the Round 2 test plan.

\begin{tabular}{|c|c|c|c|c|c|c|c|c|}
\hline \multicolumn{7}{|l|}{$\operatorname{Re} \times 10^{6}$} & \multicolumn{2}{|l|}{2.3} \\
\hline \multicolumn{5}{|l|}{ Slot Geometry } & \multicolumn{2}{|c|}{ Cusp A } & Cusp B & Cusp C \\
\hline \multicolumn{3}{|l|}{ Slot Width (\% of L) } & 0.25 & 0.52 & 0.78 & 1.04 & 1.30 & 1.56 \\
\hline Fan Power (Watts) & 0 & 100 & 200 & 300 & 400 & & & \\
\hline
\end{tabular}

Figure 24. Round 2 test plan for investigating influential parameters of slot geometry. 


\subsection{Calibration}

Five load cells, measuring total axial force, thrust, and torque needed to be calibrated for each test set to determine the repeatability of measurement with the load cells and to find the equations for converting voltage readings to force. All were done using pulley systems and precision weights. The total axial force load cell set-up is shown in Figure 25a. A rod that has freedom to rotate was connected to one end of an L-bracket with weights on the other end of the bracket. The rod was also attached to the aftbody skin via a clamping system show in Figure 25b. The mechanism allowed for the model to be both pushed and pulled to calibrate for both thrust and drag on the load cell. With the model center of gravity being behind the strut, a moment is created on the strut that pulls it backwards onto the load cell even when there is zero drag. The moment is large enough that it still creates a force on the load cell even when the model is experiencing a small amount of thrust. In this fashion, drag and thrust can be measured with the single load cell. Three one pound weights were placed in the nose of the model to offset the weight of the aftbody assembly and move the center of gravity closer to the strut. Figure 26 is the calibration curve for total axial force, converting voltage to pounds. In the calibration curve there seems to be some hysteresis causing the readings to shift and vary slightly when comparing loading vs. unloading the load cell. To minimize this as much as possible, the load cell was cycled by loading the load cell with a $2 \mathrm{lb}$. weight for 30 seconds, three times at the beginning of each test set to erase any memory. A trend line between the up and down loading curves was also used as the calibration curve. 

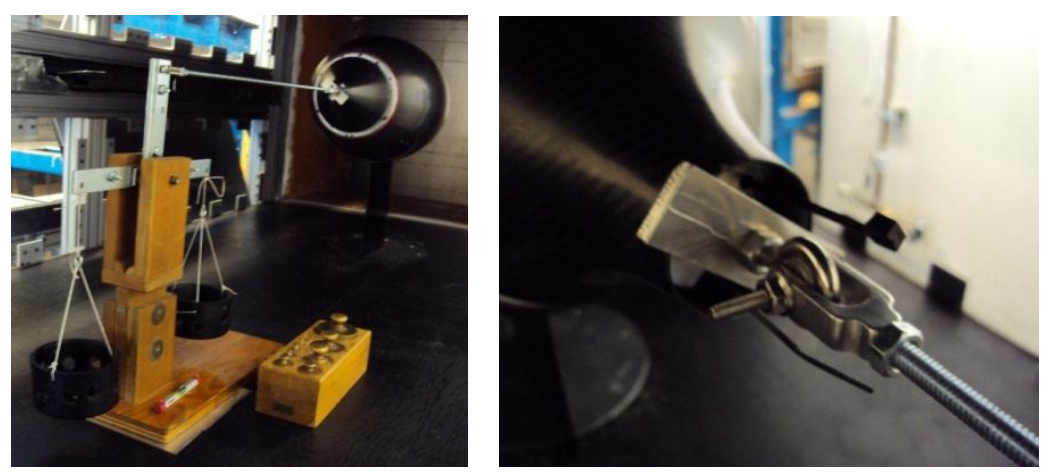

Figure 25. Photographs of a) the total axial force calibration set-up and b) the total axial force calibration clamping assembly.

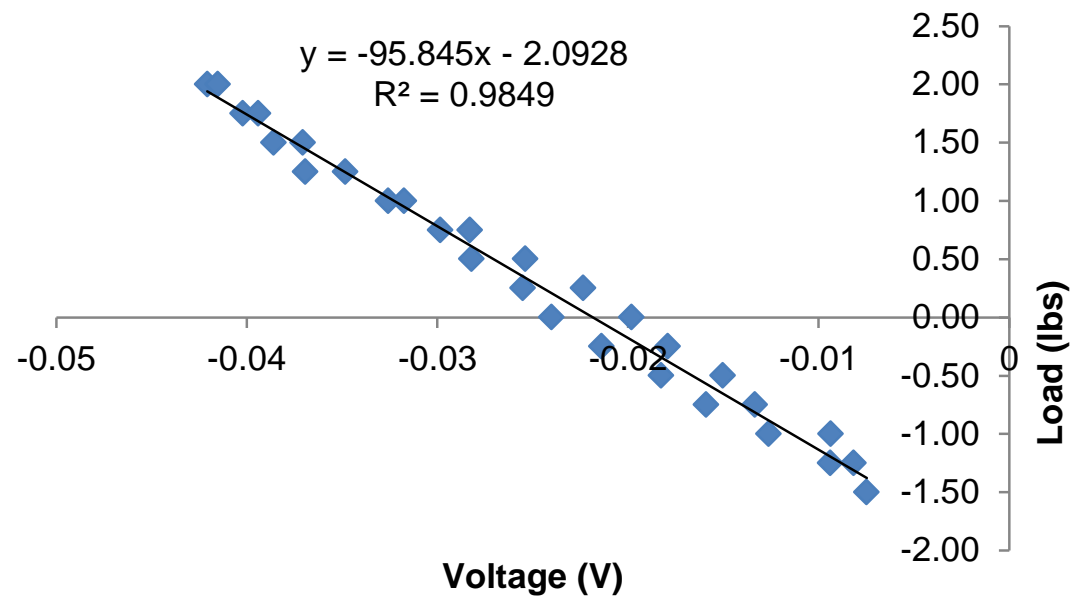

Figure 26. Total axial force load cell calibration curve.

The two thrust load cells are located at the top and bottom of the fan and were calibrated using an apparatus that pushes on the center of the fan. The apparatus shown in Figure 27a consists of a rod on an L-bracket. The bracket gets pulled by the addition of weights and causes the rod to push on the fan. Torque was calibrated with the setup shown in Figure 27b, pulling the fan in a counter clockwise direction to counter the direction that the fan spins. Calibrations curves for thrust and torque are shown in Figure 28 and Figure 29, converting voltage to pounds. 

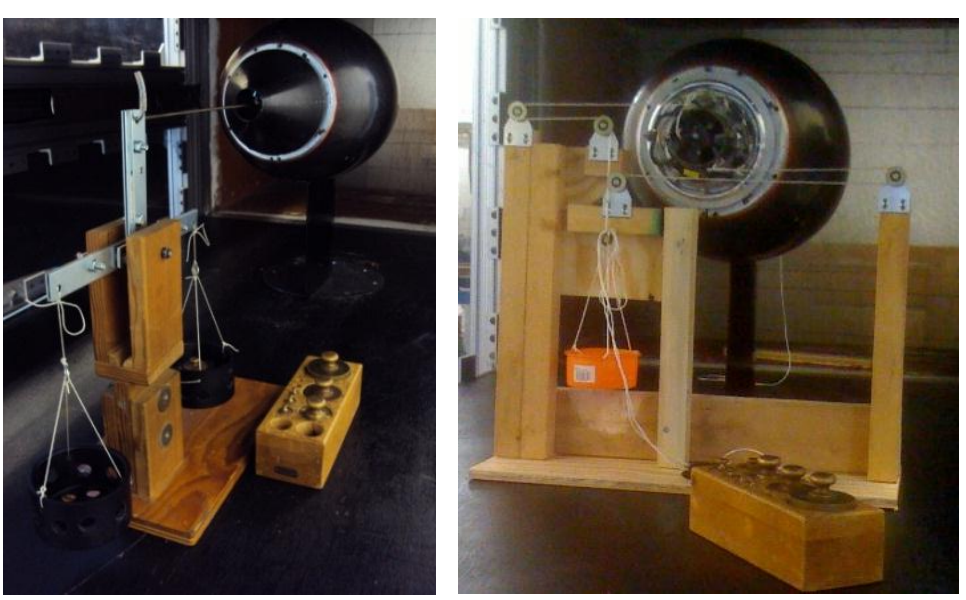

Figure 27. Photographs of a) the thrust calibration set-up and b) the torque calibration setup highlighting the calibrated weight and the pulley system.

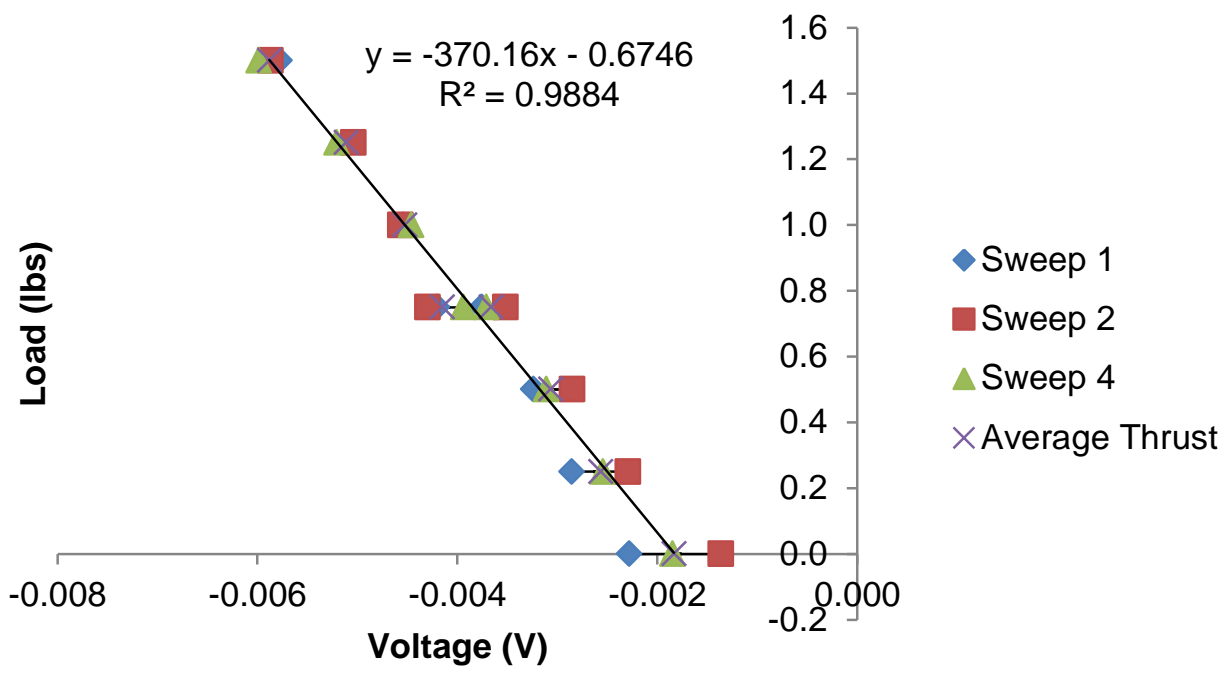

Figure 28. Thrust load cell calibration curve. 


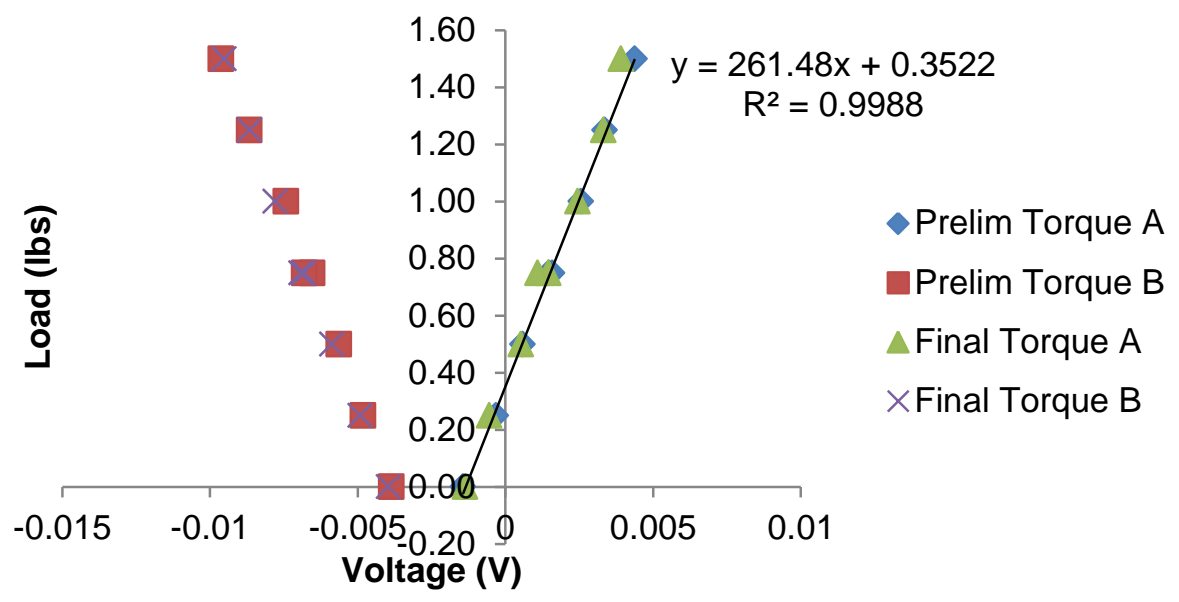

Figure 29. Torque load cell calibration curve.

Each test set included six runs that tested a different slot width and ran through four different fan throttle settings. Data was taken for the wind off case for each run and at a zero point between throttle settings in each run. For the wind on case, the tunnel fan was on and the model fan was off, giving a zero fan power data point. For the zero case, both the tunnel fan and the model fan were off. 


\section{$4 \quad$ Data Acquisition and Post Processing}

Simple actuator disk theory can be used to analyze the flow through the aftbody of this Goldschmied Propulsor model. Figure 30 illustrates one control volume and the stations in the aftbody.

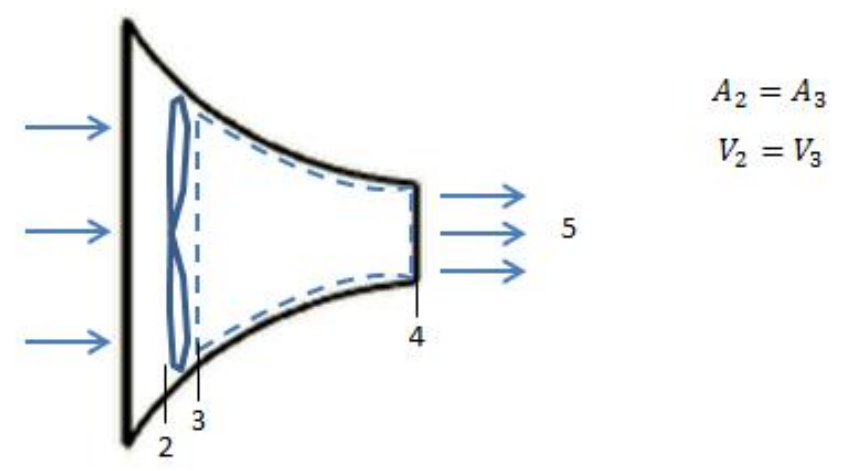

Figure 30. Aftbody stations diagram.

\subsection{Pressure Measurements}

Pressure measurements were sampled at a rate of $45-\mathrm{kHz}$ with 3000 samples per port and saved to a data file. This was accomplished with the Scanivalve Rad 2.10 and the ScanTel data acquisition software. Two Matlab programs were then used to average the data, organize the data, apply static pressure corrections, resolve $C_{p}$ values, and calculate force coefficients.

\subsection{Tunnel Corrections}

The walls of a wind tunnel affect the measurements taken during testing.

Boundary layers on the tunnel walls change the airspeed of the tunnel causing airspeed to increases from the inlet to the outlet, changing readings based on the location where they were collected. The physical presence of a model in the wind tunnel test section also changes how the air flows through the test section. Many factors of testing in a wind 
tunnel cause variation in wind tunnel data versus a model in open air. In order to compare wind tunnel data to a self-propelled model traveling through the atmosphere, corrections must be added.

\subsubsection{Pressure Corrections}

The need for a static pressure correction arises because the downstream pressure ring was used as a static pressure reference; however it is not exactly the tunnel static pressure. A survey of the test section allowed for the calculation of corrections for the tunnel total, static, and dynamic pressure.

$$
\begin{aligned}
& q_{c}=1.0332 \\
& p_{c}=1.0332 \\
& P_{c}=1.0880 \\
& q=q_{c}\left(p_{\infty}-p\right) \\
& p_{\infty}=p_{\infty, u} p_{c} \\
& C_{p}=\frac{p-p_{\infty}}{q}
\end{aligned}
$$

Where $q_{c}$ is the freestream dynamic pressure correction, $p_{c}$ is the static pressure correction, and $P_{c}$ is the freestream total pressure correction. The following tunnel corrections are presented by Barlow, Rae, and Pope. ${ }^{14}$

\subsubsection{Buoyancy}

Buoyancy is caused by boundary layer growth on the walls of the working section reducing the working section area equivalent to a contraction. This causes flow acceleration and a drop in static pressure, which artificially increases the drag. A 
buoyancy correction is dependent on the longitudinal pressure gradient and the volume of the body.

The longitudinal pressure gradient is

$$
-\frac{d p}{d l}=-k \frac{\rho V^{2}}{2 h}
$$

Where $\mathrm{k}$ is measured for each specific wind tunnel and ranges from 0.016-0.040, $\rho$ is density, $\mathrm{V}$ is freestream velocity, $\mathrm{h}$ is the height of the working tunnel section. The static pressure gradient should be measured in the tunnel along the working section. For cases where the longitudinal pressure gradient is constant, the buoyancy correction is

$$
\Delta D_{B}=\frac{d p}{d l} V_{B}
$$

$V_{B}$ is the volume of the model body. This correction for buoyancy is typically very small in the case of wings, but for fuselages it becomes more significant. For the case of a fuselage or our axisymmetric Goldschmied body, the buoyancy correction is more accurately calculated in segments to accommodate the significant changes in cross sectional area along the length of the body. Four segments were used to calculate the buoyancy force in this paper, 0-0.2, 0.2-0.4, 0.4-0.6, and 0.6-0.9779 meters along the model length. For one segment the resulting buoyancy force is

$$
\Delta D_{B}=\left(p_{1}-p_{2}\right)\left[\frac{1}{2}\left(S_{1}+S_{2}\right)\right]
$$

The total buoyancy force can then be calculated by

$$
D_{B}=\int_{0}^{l} S(x) p^{\prime}(x) d x
$$

Where $S$ is the cross sectional area of the model, $\mathrm{p}$ is the static pressure, and 


$$
p^{\prime}(x)=\frac{d p}{d x}
$$

The longitudinal pressure gradient was measured to be $-0.06802 \mathrm{lb} / \mathrm{ft}^{2} / \mathrm{ft}$ along a $1.97 \mathrm{ft}$ length of the working section and the total buoyancy drag was calculated as

$$
D_{B}=0.1652 \mathrm{lbs}
$$

\subsubsection{Solid Blockage}

The presence of a model in the tunnel reduces the area through which air can flow in that section of the tunnel, thereby increasing the freestream velocity over the model. This affect can be corrected by increasing the effective wind tunnel airspeed.

$$
\begin{aligned}
& \varepsilon_{s b}=\frac{\Delta V}{V}=\frac{K_{3} \tau V_{B}}{C^{3 / 2}} \\
& \varepsilon_{s b}=\frac{1.02 * 0.81 * 1.905 f t^{3}}{\left(11.02 f t^{2}\right)^{3 / 2}} \\
& \varepsilon_{s b}=0.04302
\end{aligned}
$$

Where $K_{3}=1.02$ for an axisymmetric body, $\tau$ is 0.86 for the Cal Poly tunnel, $V_{B}$ is the volume of the model body, and $\mathrm{C}$ is the working section area of the tunnel.

\subsubsection{Wake Blockage}

In order to maintain a constant mass flow, the airspeed inside the wake must be lower than freestream and the airspeed outside the wake must be greater than freestream. This affect can be corrected by adjusting the tunnel airspeed. For the Goldschmied body where there is separated flow, a wake blockage equation for a bluff body is used

$$
\varepsilon_{w b}=1+\theta C_{D u}\left(\frac{S}{C}\right)
$$




$$
\theta=\frac{-1}{C_{p b c}}
$$

Where $C_{p b c}$ is the corrected base pressure coefficient, $\mathrm{S}$ is the model frontal area, $\mathrm{C}$ is the test section area, and $C_{D u}$ is the uncorrected 2-D drag coefficient. Base pressure was measured from tunnel wind on, model fan off cases where there was known to be separation.

For cases with the model fan on, there is assumed to be not a substantial amount of separated flow so the equation used is

$$
\varepsilon_{w b}=\frac{\Delta V}{V_{u}}=\frac{S}{4 C} C_{D u}
$$

\subsubsection{Total Corrections}

Static pressure and total pressure to determine tunnel speed are measured upstream of the working section, therefore the tunnel parameters need to be corrected with the solid blockage and wake blockage corrections. The total correction is

$$
\varepsilon=\varepsilon_{s b}+\varepsilon_{w b}
$$

Listed are the tunnel parameters where total corrections are applied
Airspeed
$V=V_{u}(1+\varepsilon)$
Dynamic Pressure
$q=q_{u} q_{c}(1+\varepsilon)^{2}$
Reynolds Number
$R e=R e_{u}(1+\varepsilon)$ 


\subsection{Mass Flow Rate}

Determining mass flow rate through the aftbody is an important point of comparison between test cases to illustrate the ability of the fan to create suction. The standard equation for density is

$$
\rho=\frac{p}{R T}
$$

$\mathrm{R}$ is the gas constant equal to $287.058 \mathrm{~J} / \mathrm{kg}^{*} \mathrm{~K}$ and $p$ is the absolute static pressure. The exit velocity is found through

$$
V_{4}=\sqrt{\frac{2\left(P_{T, 4}-p_{4}\right)}{\rho}}
$$

And finally mass flow is found by integrating the velocity profile at the exit.

$$
\dot{m}=2 \pi \rho \int_{0}^{R} V_{4} r d R
$$

\subsubsection{Density}

Density is calculated at position 2 (as shown in Figure 30) just before the fan where temperature and static pressure are measured. Density is assumed constant throughout the aftbody.

The absolute static pressure is found by adding the measured static pressure from the Scanivalve to the barometric pressure (atmospheric pressure). The mass flow rate can then be determined with the measured dynamic pressure at the aftbody exit and the exit area

\subsection{Suction Coefficient}

The suction coefficient is calculated with the following equation 


$$
C_{q}=\frac{Q}{V_{0} V_{B}{ }^{0.66}}=\frac{\dot{m}}{\rho V_{0} V_{B}{ }^{2 / 3}}
$$

Where $V_{0}$ is freestream velocity and $V_{B}$ is the volume of the body.

\subsection{Force Measurements}

All the load cells can be sensitive to atmospheric changes and the metals they are made of can tend to creep over time which causes their readings to shift over time and when exposed to large loads. These changes in the load cell readings need to be recognized and corrected to insure accurate measurements.

\subsubsection{Calibration Corrections}

A correction needs to be incorporated into the calibration equation to account for shifts in the total axial force readings from creep or shifts. To do this, the zero run cases were averaged within a round of data to get a wind off value, $V_{F, \text { off }}$. The averaged zero run value was then subtracted from the average zero load value from the calibration to get a correction factor

$$
\Delta V_{F, \text { corr }}=V_{F, \text { calibration }}-V_{F, \text { off }}
$$

Finally, the corrections were added to the raw voltages before they were put into the calibration equation.

$$
F=m\left(V_{F}+\Delta V_{F, c o r r}\right)+b
$$

\subsubsection{Additional Drag}

Once the measured drag from the load cell is converted to a force, it needs to be corrected to account for other factors that may artificially inflate the drag reading. These other factors include drag due to buoyancy and drag due to interference from the fairing. 
Drag due to buoyancy was discussed in the Tunnel Corrections Section 4.2, and is subtracted from the drag force measurements after the calibration equations have been applied.

Drag from interference of the flow from the fairing onto the flow around the model was found by taking a drag measurement with the model in its typical configuration and tunnel wind on, then subtracting that measurement from another drag measurement taken with a dummy fairing added above the typical configuration. The difference in the voltage measurement is the drag due to the presence of the fairing and must be subtracted from the raw drag measurements before the calibration equation is applied. The fairing interference drag was $0.006 \mathrm{~V}$ and the zero shift correction ranges from 0.001 to $0.004 \mathrm{~V}$. The equation for the corrected axial force equation is then

$$
F_{A}=-95.845\left(-0.0317197+\Delta V_{D, \text { corr }}-V_{D, \text { fairing }}\right)-2.0928-D_{B}
$$

Total axial force can then be non-dimensionalized using the corrected dynamic pressure.

$$
C_{A}=\frac{F_{A}}{q V_{B}^{2 / 3}}
$$

\subsection{Pressure Drag}

The total pressure drag is found by summing the pressure on each panel. The panels are the exposed surface area between each pressure port. 


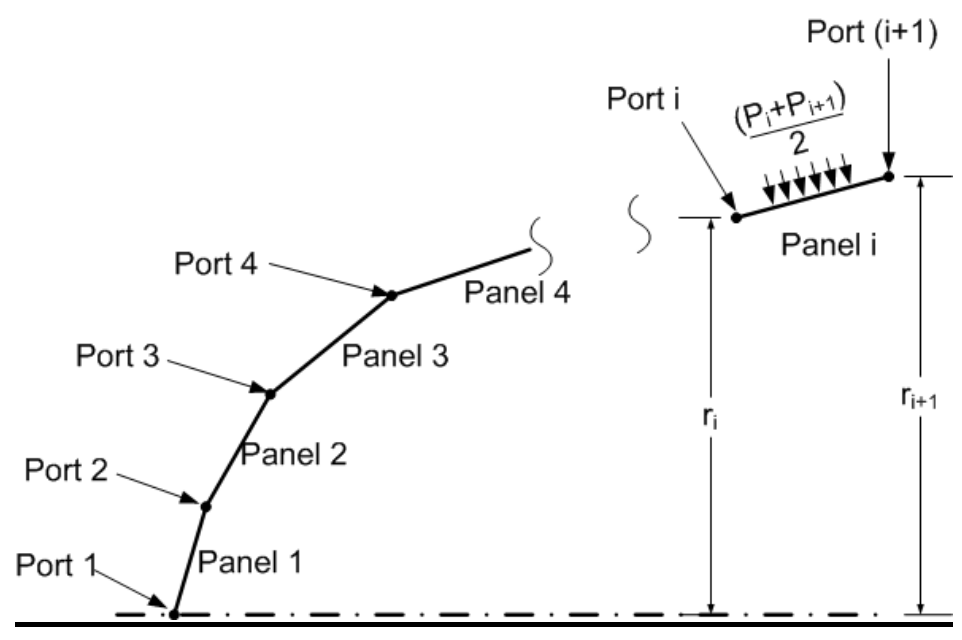

$$
\begin{gathered}
D_{p}=\sum_{i=1}^{N-1} p_{i, a v e} A_{i} \sin \left(\varepsilon_{i}\right) \\
\left.D_{p}=\sum_{i=1}^{N-1}-\frac{\left(p_{i}+p_{i+1}\right)}{2}\left[2 \pi r_{i+1}\left(r_{i+1}-r_{i}\right)-\pi\left(r_{i+1}-r_{i}\right)^{2}\right)\right]
\end{gathered}
$$

Pressure drag is non-dimensionalized with the same volume coefficient equation as total axial force.

$$
C_{d, p}=\frac{D_{p}}{q V_{B}^{2 / 3}}
$$

\subsection{Fan Speed/RPM}

Fan Speed was measured by the Castle ESC housed in the model. The fan speed data points for a specific throttle setting were averaged throughout the run. The standard deviation of the fan speed in a run varied from 30 to $180 \mathrm{RPM}$, which is a minimal error of $1 \%$ for the worst case. 


\section{$5 \quad$ Results and Discussion}

A trip strip was placed at $10 \%$ of the model length, where the Reynolds number was greater than 600 to allow for transition to fully turbulent flow. The original Goldschmied models also had transition strips at $10 \%$ of the length. Transition of the boundary layer from laminar to turbulent was confirmed with a stethoscope that was moved along the surface of the model. Through this method it was also evident that turbulent flow was maintained completely along the model surface and laminar flow was not re-established downstream, which would then have required a second trip strip to be added further downstream.

Recall as the results are presented, that for each cusp, slot gaps of 0.1 to 0.6 inches were tested with 5 fan throttle settings for each slot gap.

\subsection{Cusp A}

Cusp A produced a drag from zero to $0.54 \mathrm{lbs}$ and in some configurations reached a thrust of up to $0.17 \mathrm{lbs}$. As expected, when the model/propulsor fan is off, the model experiences greater total axial force as the slot gap increases. With the model fan on, slot gaps of 0.5 and 0.6 inches produce the lowest drag throughout the range of fan speeds tested, Figure 31 where the total axial force coefficient is plotted against fan speed. Drag seems to be sensitive to slot gaps up to 0.5 inches showing variance up to $0.2 \mathrm{lbs}$. After 0.5 inches, Figure 31 suggests that drag becomes insensitive to this variable. Error bars are shown on slot gap sizes of 0.1 and 0.5 inches only so that data points and trends are still visible. It can be seen that the smallest slot gap of 0.1 inches produces the highest drag. This may be due to a large momentum drag. Keep in mind that positive total axial force is defined as in the direction of flow, indicating drag. Figure 32 displays mass flow rate through the aftbody and does not illustrate the trend seen in 
the total axial force plot. There doesn't appear to be any clear trend, and it seems that overall mass flow rate doesn't vary much between fan speeds or slot widths. In fact all the mass flow rates fall within the same error region and therefore are not significantly different. This result is curious because an increase in flow rate would be expected with an increase in fan speed even with the ducted fan.

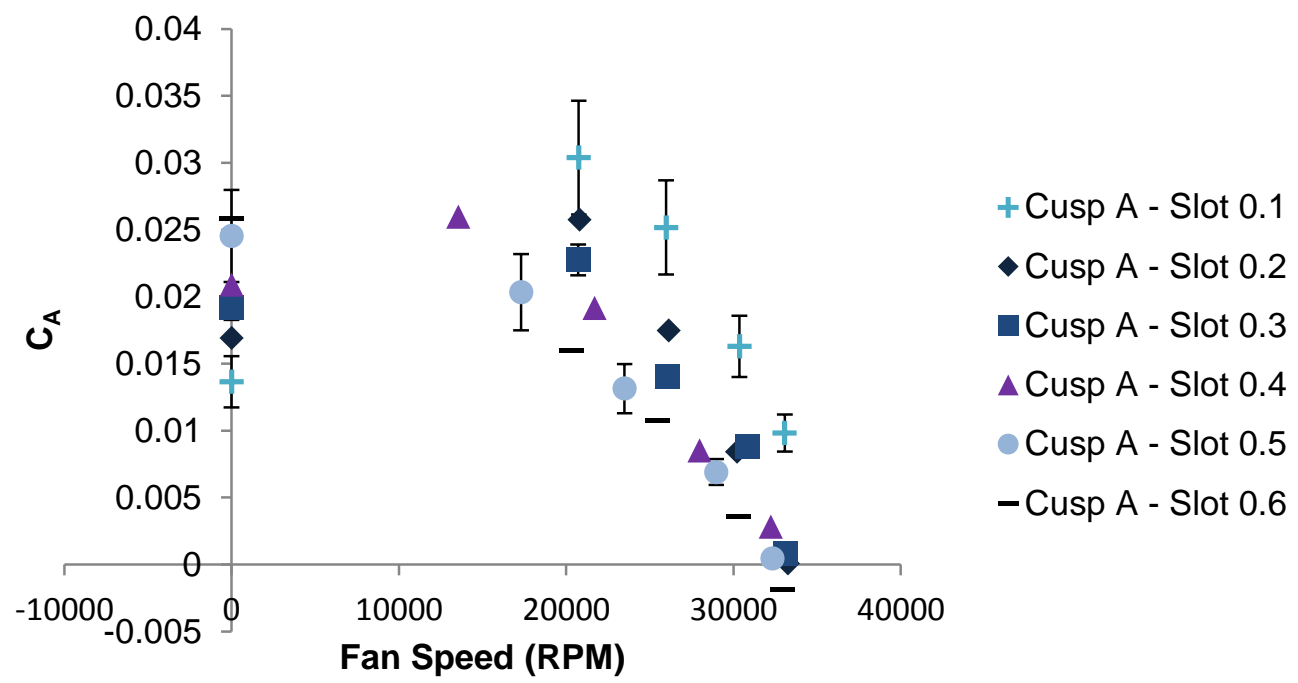

Figure 31. Total axial force coefficient vs fan speed in RPM with Cusp A attached at the suction slot.

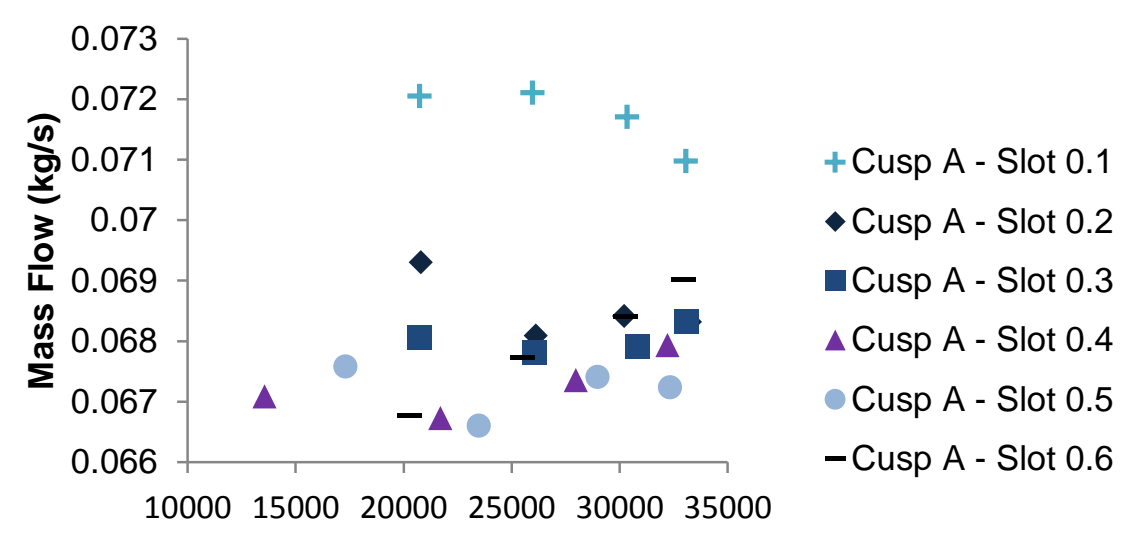

Fan Speed (RPM)

Figure 32. Mass flow rate in $\mathrm{kg} / \mathrm{s}$ vs fan speed in RPM comparison at different slot gaps with Cusp A geometry attached to suction slot. 
Pressure data reveals that there is an adverse pressure gradient seen after port 32 which is about $57 \%$ of the length. Pressure coefficient distributions and flow visualization confirm that separation does not occur despite this adverse pressure gradient. Smoke was used for flow visualization of the flow around the model when the model fan was off and for visualization at the slot with the model fan on. Although flow visualization was only done with Cusp $\mathrm{C}$, the photographs show generally what one would expect for all three cusps and so are shown here to enhance the understanding of the results. Figure 33 shows that when the model fan is off, the flow separates towards the end of the forebody. In this case, the turbulent boundary layer is not able to overcome the adverse pressure gradient, causing the separation. This is also visible in the pressure distribution shown in Figure 34. The constant $C_{p}$ after about $79 \%$ of the length indicates flow separation. This pressure distribution can be compared with Figure 35 and Figure 36 where the model fan was on.

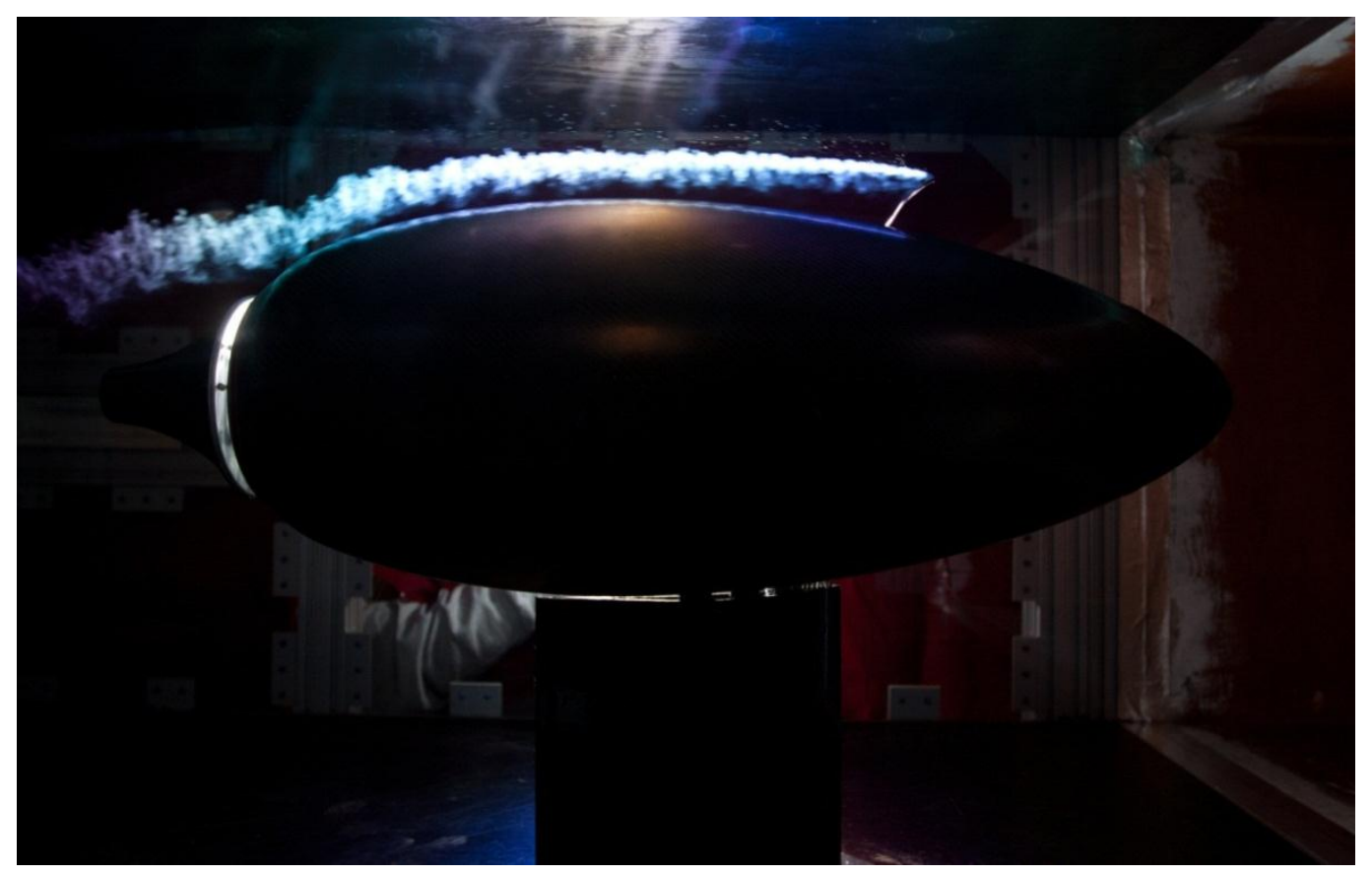

Figure 33. Smoke flow visualization with the model fan off and Cusp C slot geometry. 


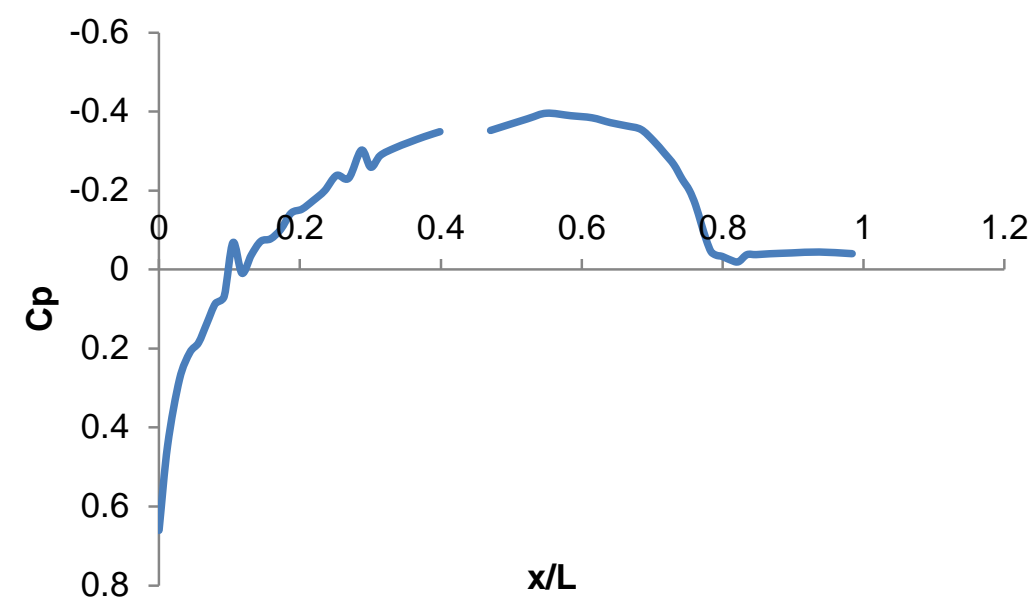

Figure 34. Pressure distribution over Goldschmied body with Cusp A slot geometry and slot gap of 0.5 inches.

The pressure distributions show no flat region that would indicate separation for the fan on cases. An interesting thing to note is that there seems to be a great deal of pressure recovery with the pressure around the back of the model rising back above atmospheric. The distributions in Figure 36, at high fan speed, are greater than in the plot at low fan speed, Figure 35, because the suction flow rate is large enough to affect the flow equally at all slot gap sizes, rendering slot gap size insignificant for this range. Less severe adverse pressure gradients are also seen in the high fan speed pressure distribution. 


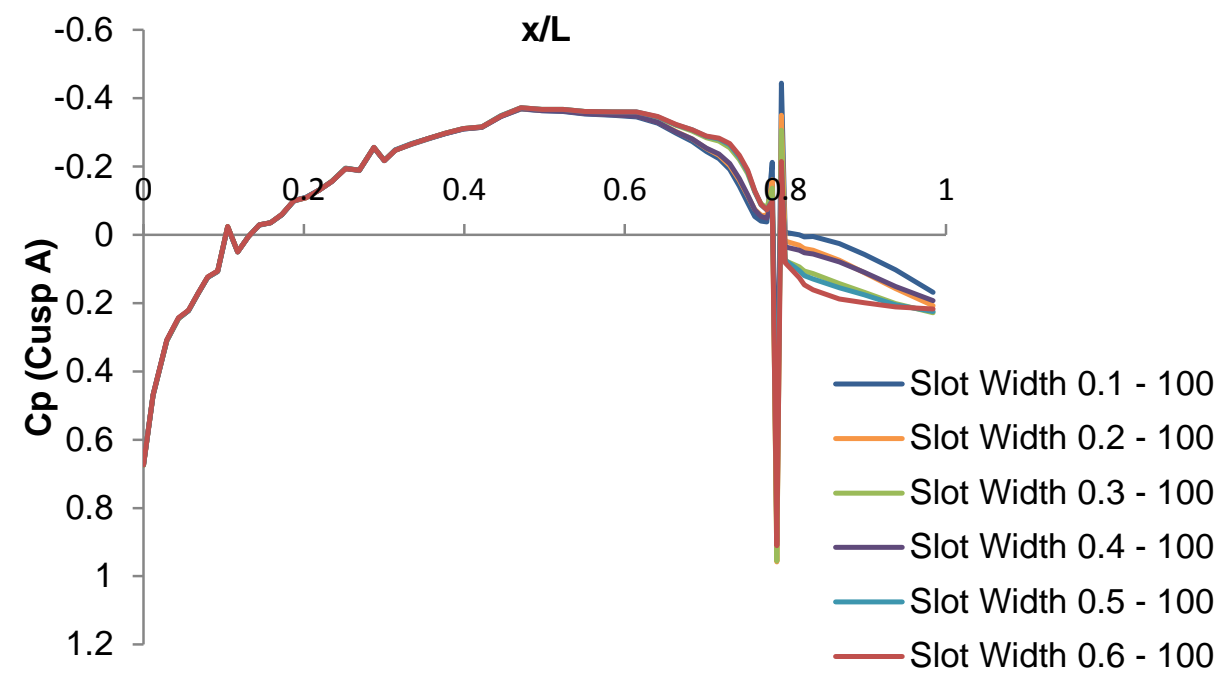

Figure 35. Pressure distributions over Goldschmied body with Cusp A slot geometry and constant throttle setting (fan speed $\sim 20700$ RPM).

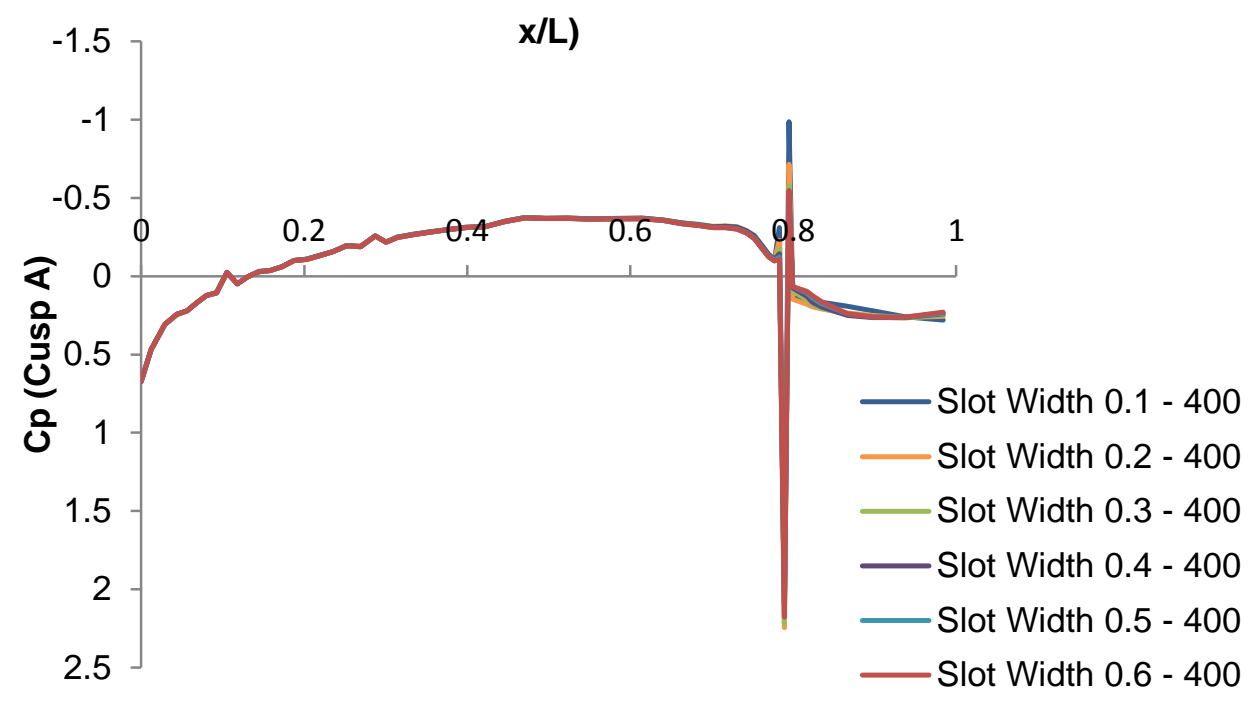

Figure 36. Pressure distributions over Goldschmied body with Cusp A slot geometry and constant throttle setting (fan speed $\sim 32500$ RPM).

Flow visualization at the slot with the model fan on also indicates that separation is prevented. Figure 37 shows that the flow remains attached up to the slot with Cusp C slot geometry and a fan speed of 26000 RPM. The image also appears to show the boundary layer re-growing after the slot on the aftbody. Figure 38 is another flow 
visualization image with Cusp C slot geometry, but fan speed is 33000 RPM. Both photographs confirm that when the model fan is on, even at low speeds, full flow attachment is achieved.

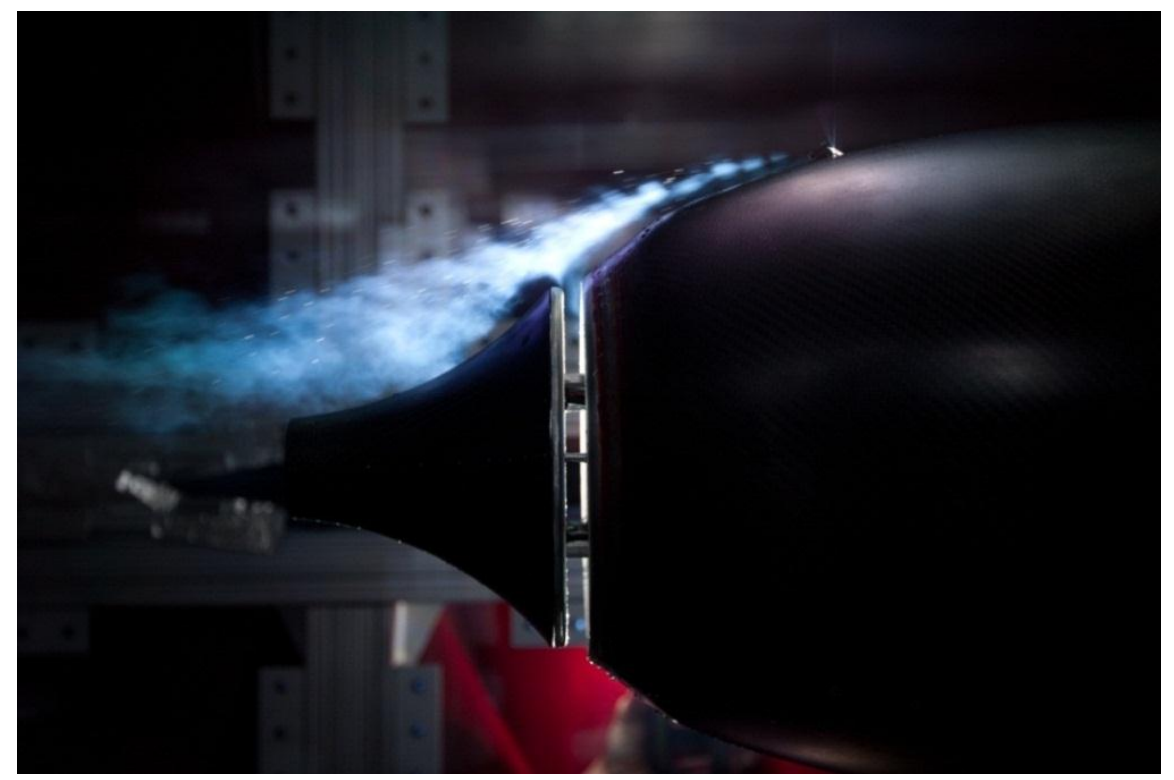

Figure 37. Smoke flow visualization with Cusp C and model fan speed of 26000 RPM.

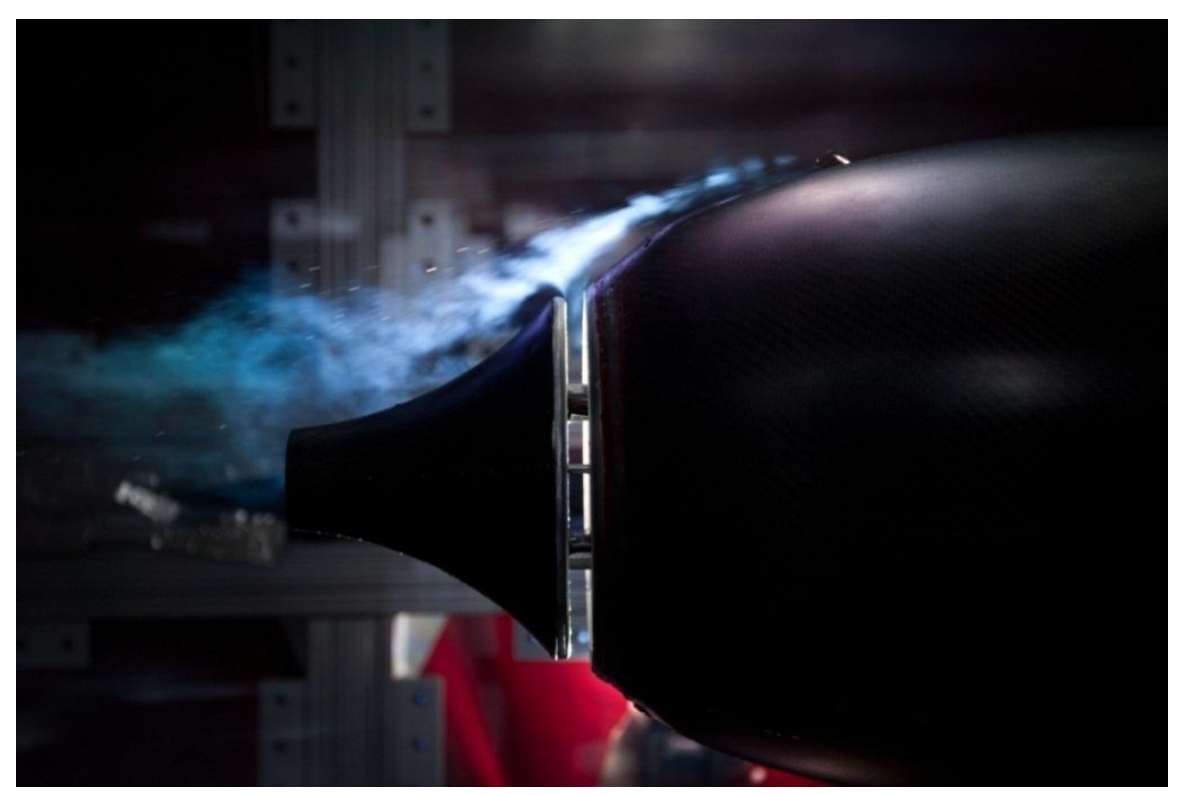

Figure 38. Flow visualization with Cusp C and fan speed of 33000 RPM. 
Looking initially at how the suction coefficient changes with the pressure recovery step across the slot in Figure 39, we see that the smaller suction coefficients display a smaller pressure recovery at the slot. A large pressure recovery step indicates that there is a large pressure increase after the slot. The more pressure recovery, the greater the reduction in pressure drag. However, the difference in suction coefficient is insignificant just as with mass flow rate and the error on this calculation is about $20 \%$, so in actuality there is no appreciable difference in required suction for each cusp geometry.

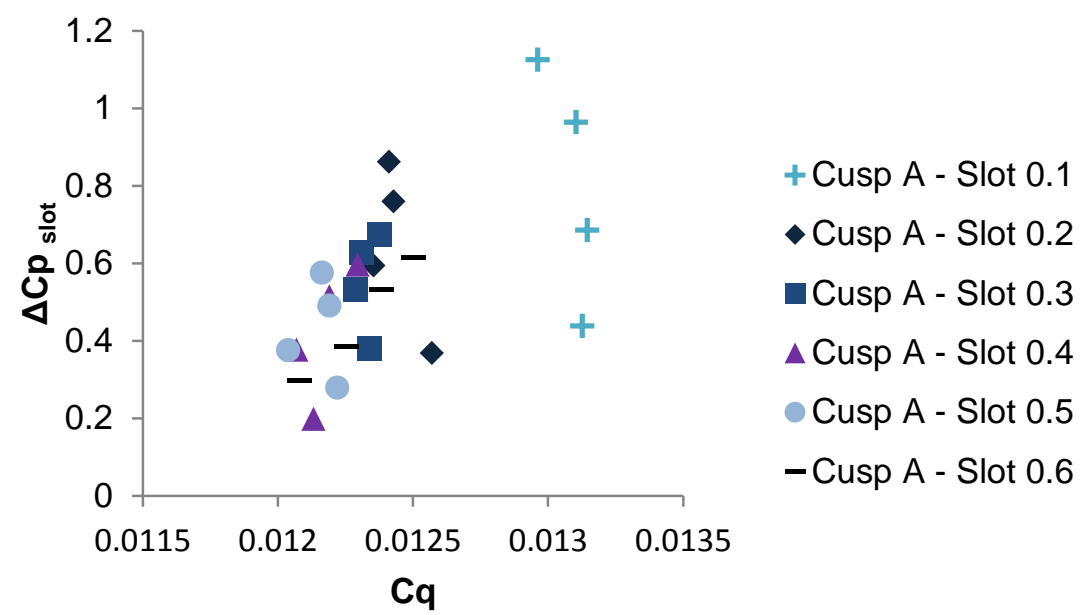

Figure 39. Pressure recovery step vs suction coefficient for Cusp A.

Figure 40 shows that the pressure drag is the lowest at the slot gap of 0.1 inches which had the greatest pressure recovery in Figure 39. In fact, the pressure drag values in Figure 40 are actually all pressure thrust. The suction slot at all the tested fan speeds was able to recover enough pressure to create a pressure gradient around the Goldschmied body that inclines it to move forward from the high pressure at the back end to the lower pressure upstream. A body that is able to create this favorable surrounding pressure gradient is effectively eliminating pressure force as a hindrance to its movement. It is interesting that across all fan speeds the 0.1 inch slot gaps produces 
the most pressure thrust, however results in the greatest total axial force. In this case, although wake drag was effectively eliminated, the momentum drag increased so much as to become an even greater obstacle to the propulsor's forward motion.

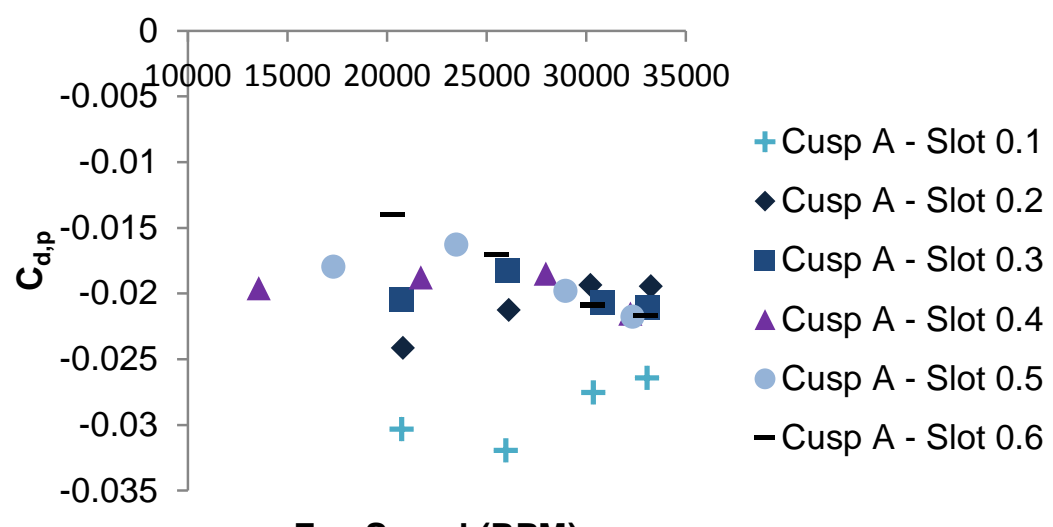

Fan Speed (RPM)

Figure 40. Pressure drag vs fan speed for Cusp A.

When suction is off, total axial force is expected to be very close to the measured pressure drag. Figure 41 clearly shows that pressure drag is clearly not the only component of force being measured by the total axial force load cell. Drag due to skin friction could be the reason for the difference in the two measurements. Also, as total axial force increases with slot gap size, pressure drag does not.

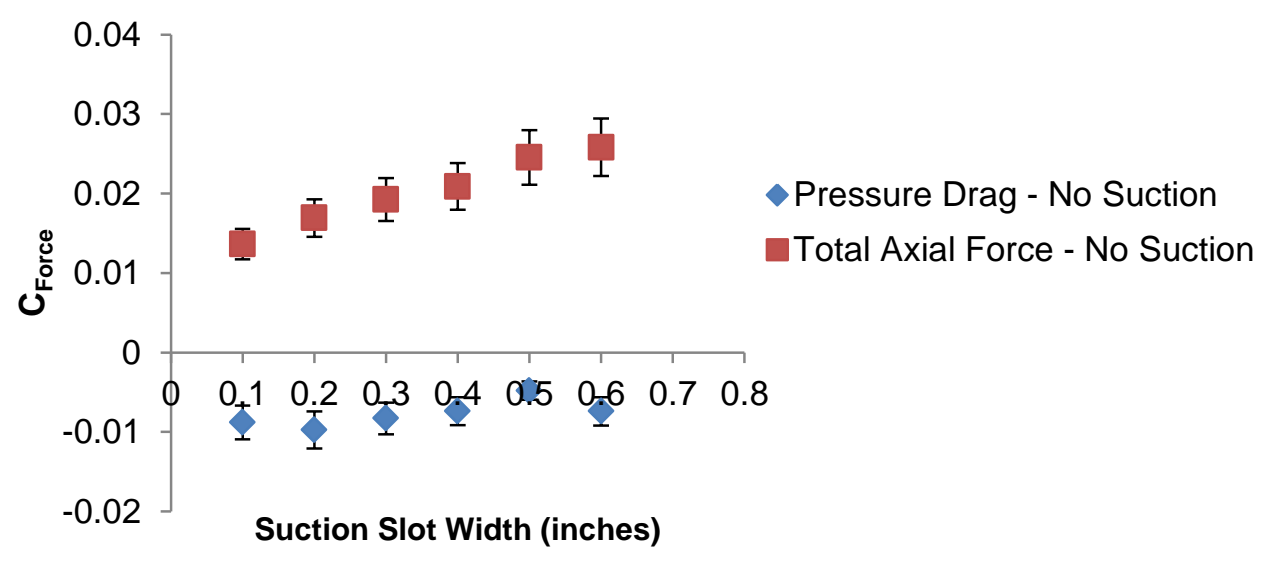

Figure 41. Total axial force and pressure drag plotted against slot gap size at a fan speed of 20750 RPM.

Page 59 
Figure 42 displays how pressure rise across the fan increases with fan speed.

The smallest slot gap of 0.1 inches causes the greatest change in pressure especially at higher fan speeds, while all the other slot gaps seem to follow the same curve. Around 25000 RPM pressure rise starts to increase much quicker with each additional RPM.

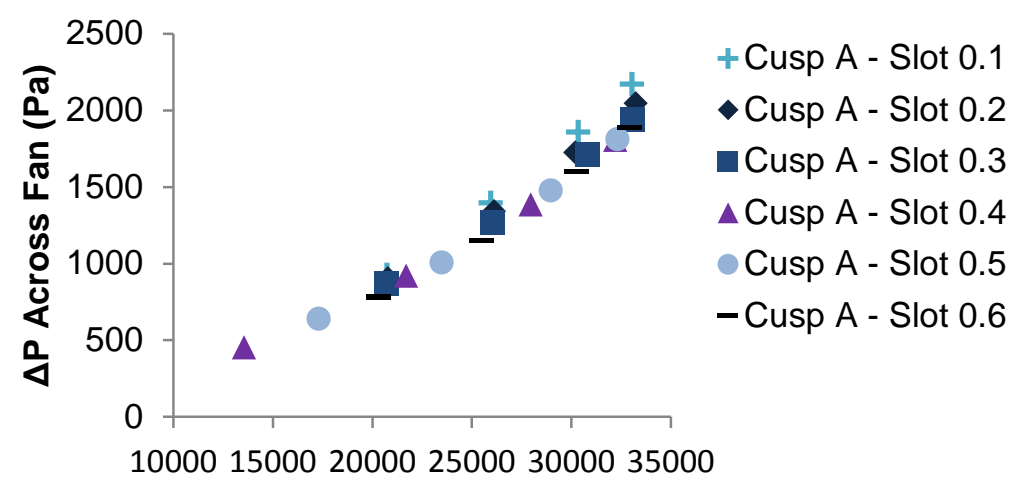

Fan Speed (RPM)

Figure 42. Pressure loss across the fan with increasing fan speed for Cusp A.

Fan Power shows a similar trend as pressure rise across the fan, Figure 43. All slot gap sizes follow the same curve correlating fan power and fan speed. At higher fan speeds, the power requirement becomes proportionally much greater than at slower fan speeds.

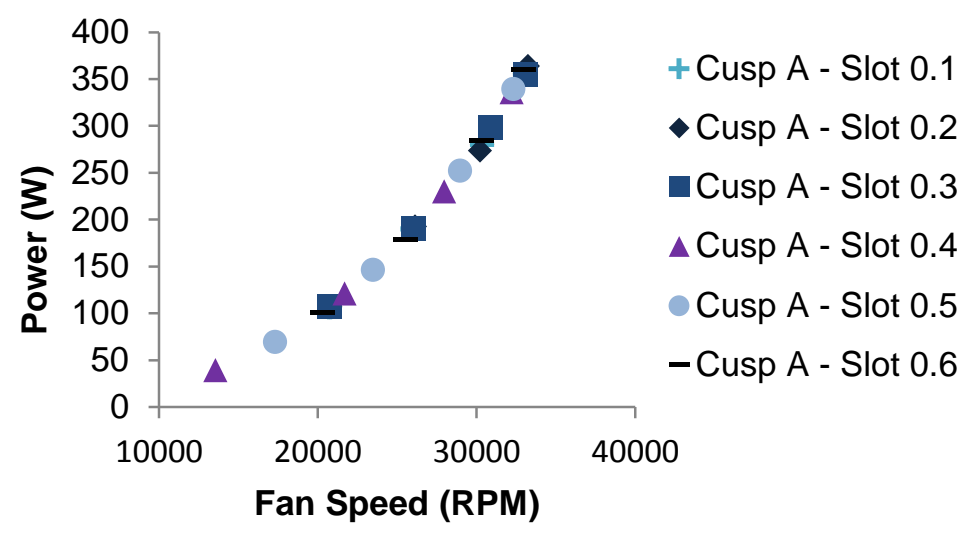

Figure 43. Fan power vs fan speed with Cusp A slot geometry. 
Fan thrust and torque, shown in Figure 44 and Figure 45, vary independently from slot gap size. Thrust increases with fan speed and torque decreases with fan speed. The nonlinearity of data for specific slot gaps is most likely due to problems in the mounting of the sensors rather than real changes in the system. The placement of the load cells in the model and their close proximity to the fan, wiring, and the aftbody skin makes it difficult to ensure completely free movement of the fan within the aftbody housing. For this reason we will only use the general trend of this data rather than the actual values as part of the results.

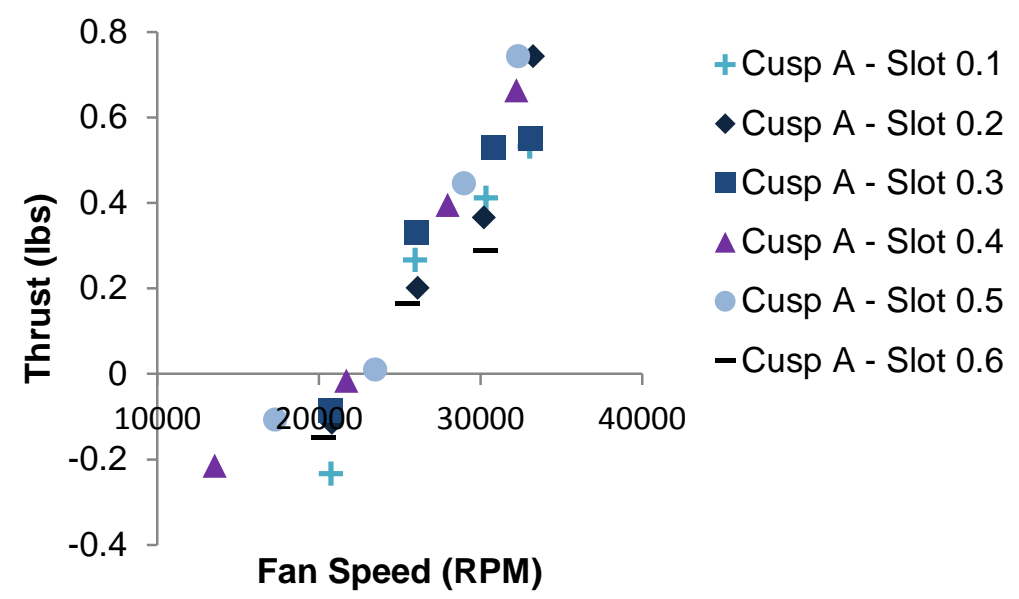

Figure 44. Fan thrust at varying fan speeds and different slot gaps with Cusp A.

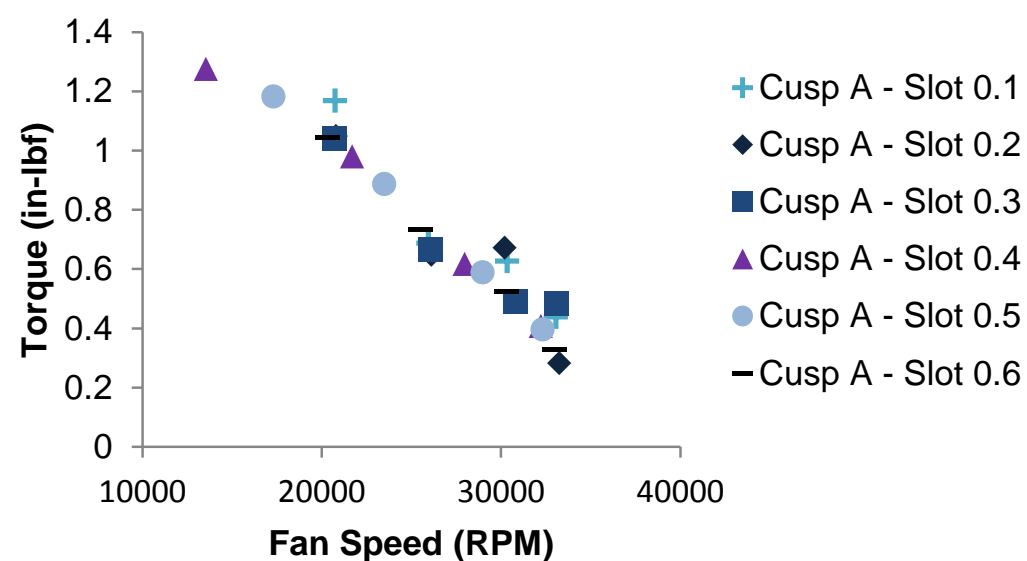

Figure 45. Fan torque at varying fan speeds and different slot gaps with Cusp A. 
Fan power, pressure rise across the fan, and fan thrust all are shown to increase with fan speed. These are the expected tends and provide confidence in those measurements. Looking back at mass flow rate through the aftbody, there still seems to be no clear reason for that to not also increase with fan speed. Although a six point integration of velocity measured from a pitot static tube should be a sufficient way to calculate mass flow rate, these results leave doubts as to the reliability of this measurement. One possible reason that this mass flow measurement technique could be suspect is if there is a significant amount of swirl and angularity to the flow that the pitot-static probe isn't able to pick up.

\subsection{Cusp B}

Cusp B is the geometry based off of the diagram from the original 1981 Goldschmied test and displays the same basic trends as Cusp A. The Cusp B slot geometry shows less sensitivity to slot size with the total axial force curves being close together. Figure 46 shows that slot gaps from 0.3 to 0.6 inches all result in drag forces that are at the low end of the range for this configuration. The drag forces produced with the Cusp B configuration are still within the same range as seen with Cusp A, displaying drag up to $0.54 \mathrm{lbs}$ and thrust up to $0.17 \mathrm{lbs}$. As seen with Cusp A, the smallest slot gap of 0.1 inches produces considerably higher drag than the other slot gaps. 


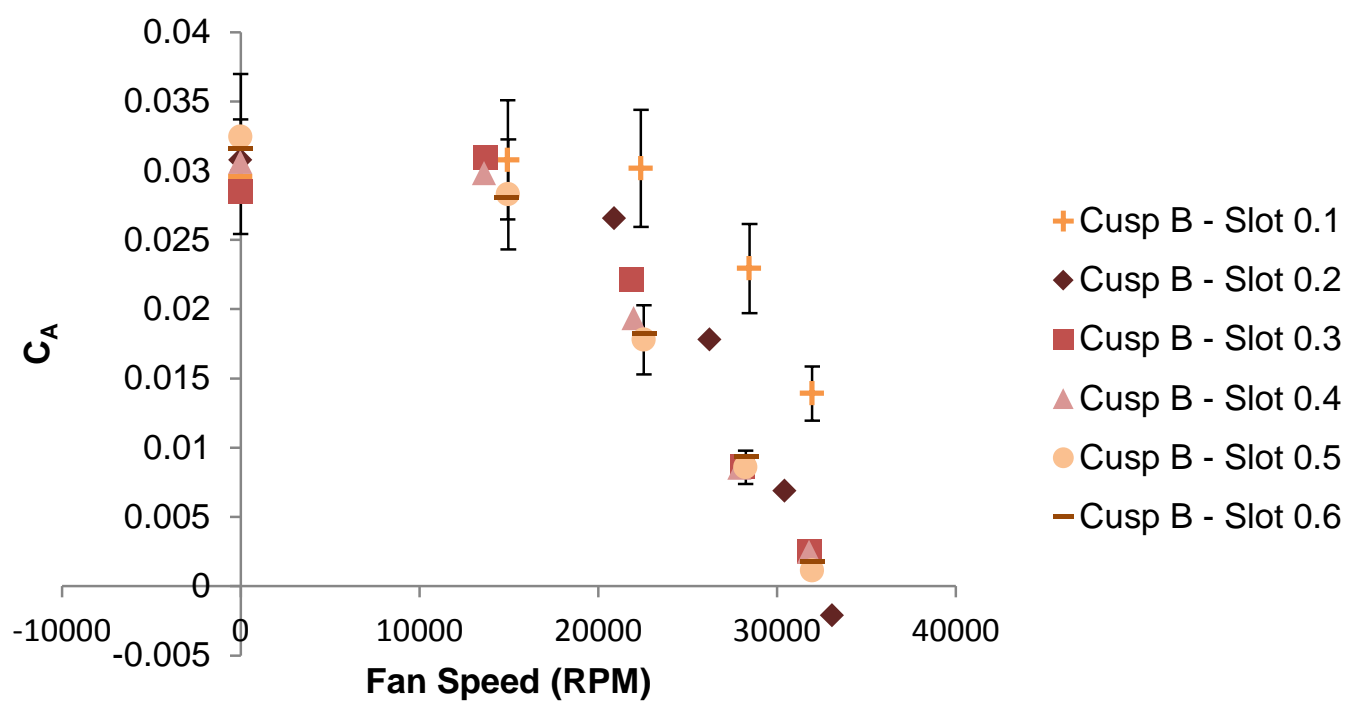

Figure 46. Total axial force vs fan speed for Cusp B slot geometry.

Thrust, torque, and fan power vs fan speed all show the same trends discussed for Cusp A. Thrust increases with fan speed, Figure 47, torque decreases with fan speed, Figure 48, and fan power follows a power curve requiring much greater power to reach the higher fan speeds, Figure 49.

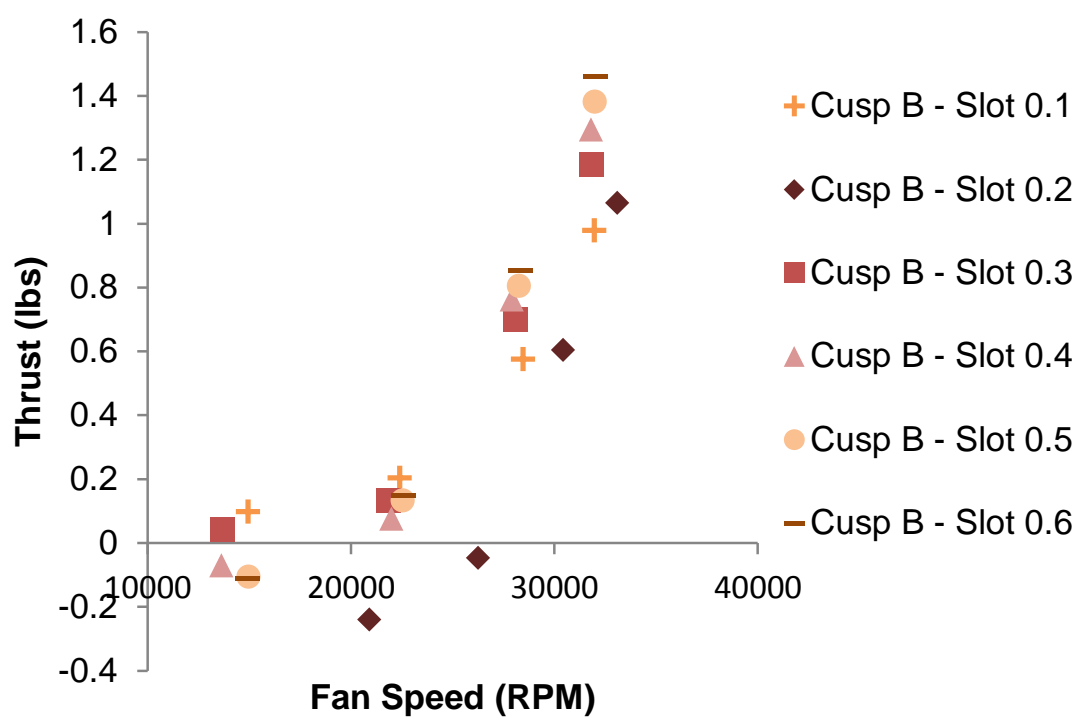

Figure 47. Fan thrust vs fan speed for Cusp B slot geometry. 


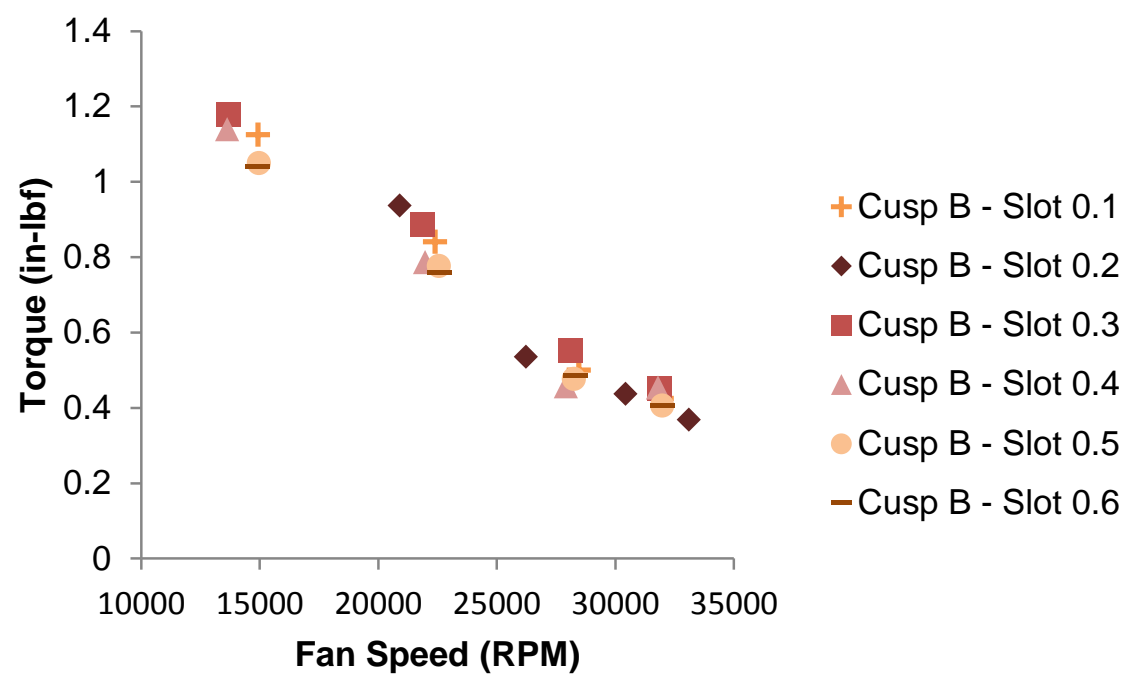

Figure 48. Fan torque vs fan speed for Cusp B slot geometry.

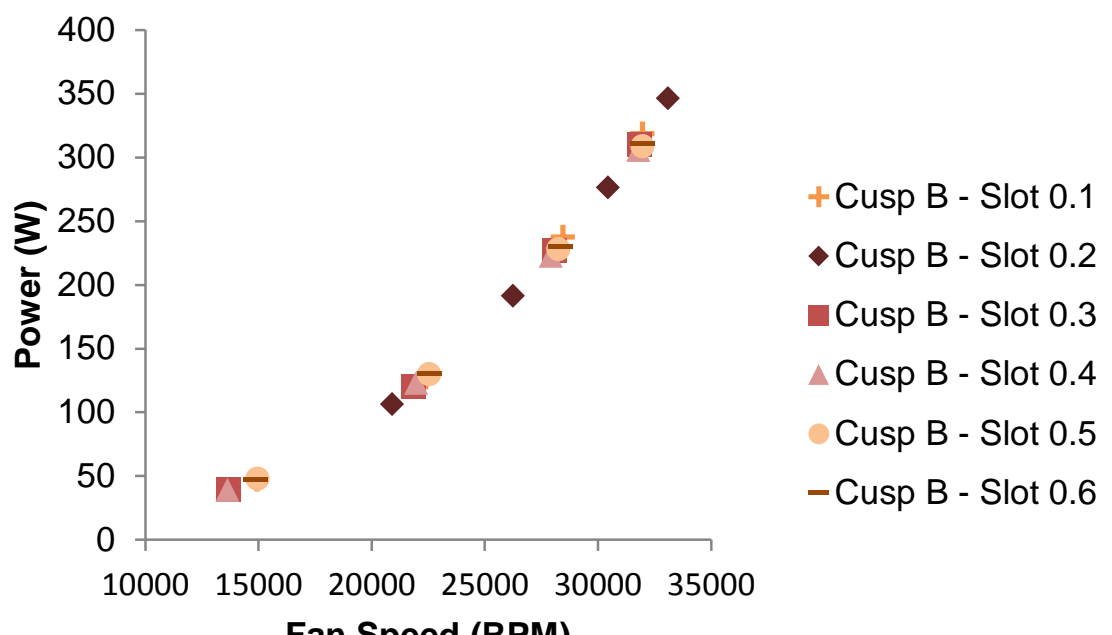

Figure 49. Fan power vs fan speed for Cusp B slot geometry.

Mass flow rate shows no particular trend and all points fall within the same error indicating that mass flow rate doesn't vary, Figure 50. Again, this is curious because mass flow rate could be expected to increase with fan speed. 


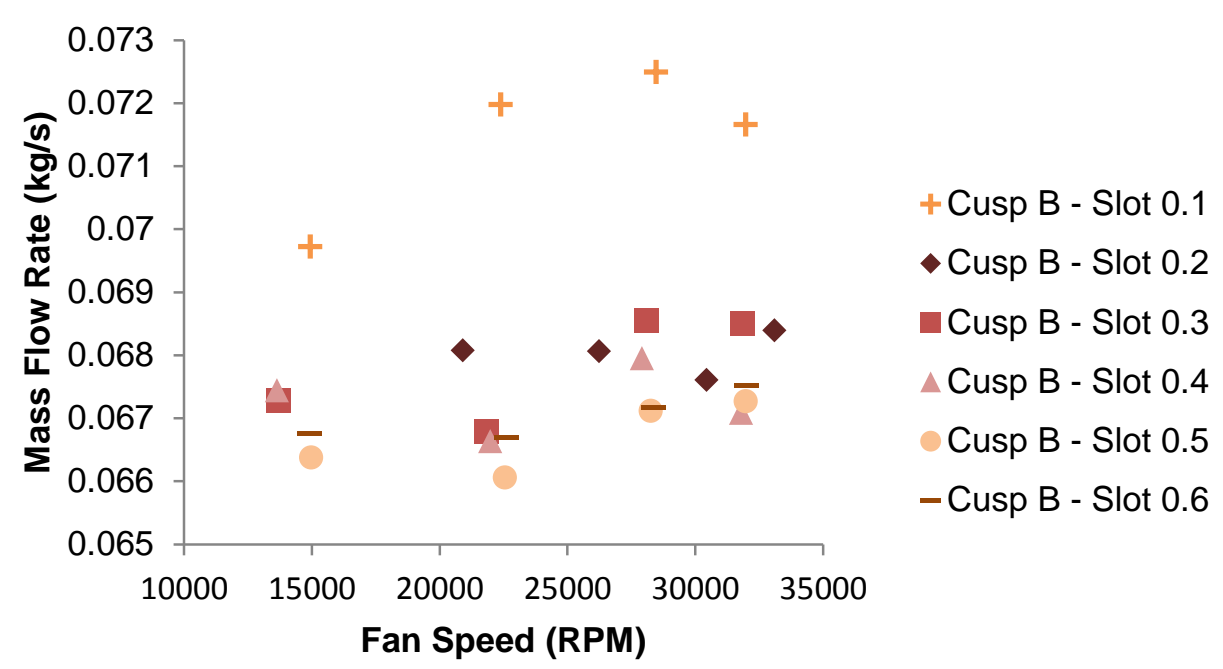

Figure 50. Mass flow rate through aftbody with Cusp B slot geometry.

The interesting results from the Cups B configuration can be seen in Figure 51. All slot gap sizes display similar pressure drag, or rather pressure thrust, except the slot gap of 0.1 inches which is higher. Slot gap sizes of 0.2 and 0.3 inches also show a trend of reducing pressure thrust with increasing fan speed.

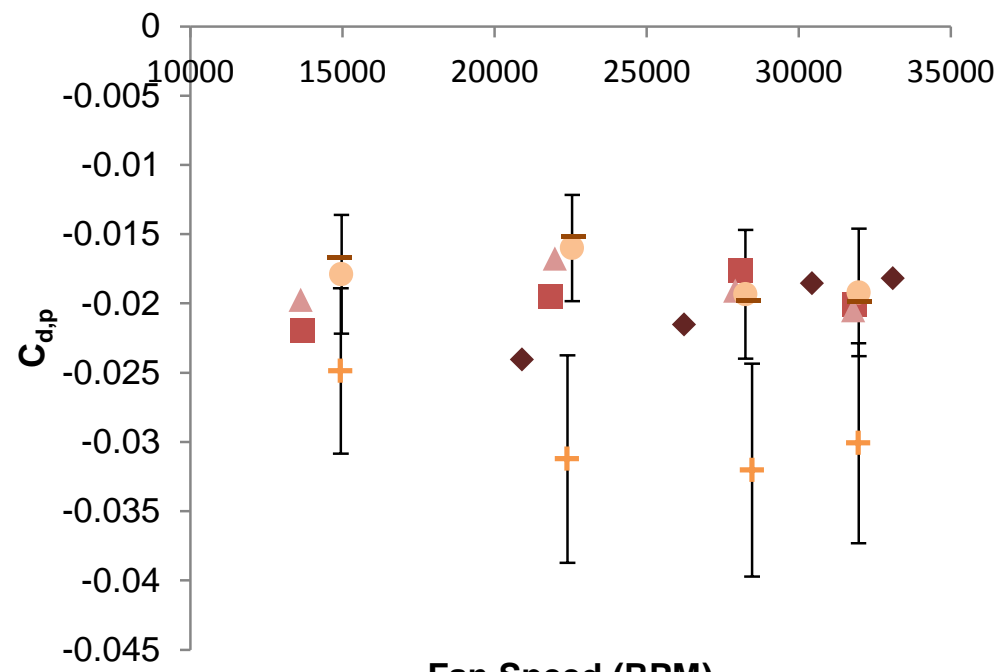

+ Cusp B - Slot 0.1

$\rightarrow$ Cusp B - Slot 0.2

Cusp B - Slot 0.3

$\triangle$ Cusp B - Slot 0.4

Cusp B - Slot 0.5

- Cusp B - Slot 0.6

Fan Speed (RPM)

Figure 51. Pressure drag vs fan speed for Cusp B slot geometry. 
As discussed with Cusp A, the pressure recovery step versus suction coefficient points plotted in Figure 52 displays no change in suction coefficient with slot gap size or cusp geometry. The slot gap of 0.1 inches displays the highest pressure recovery and pressure thrust, but again suffers with a high total axial force due to large momentum drag, Figure 53.

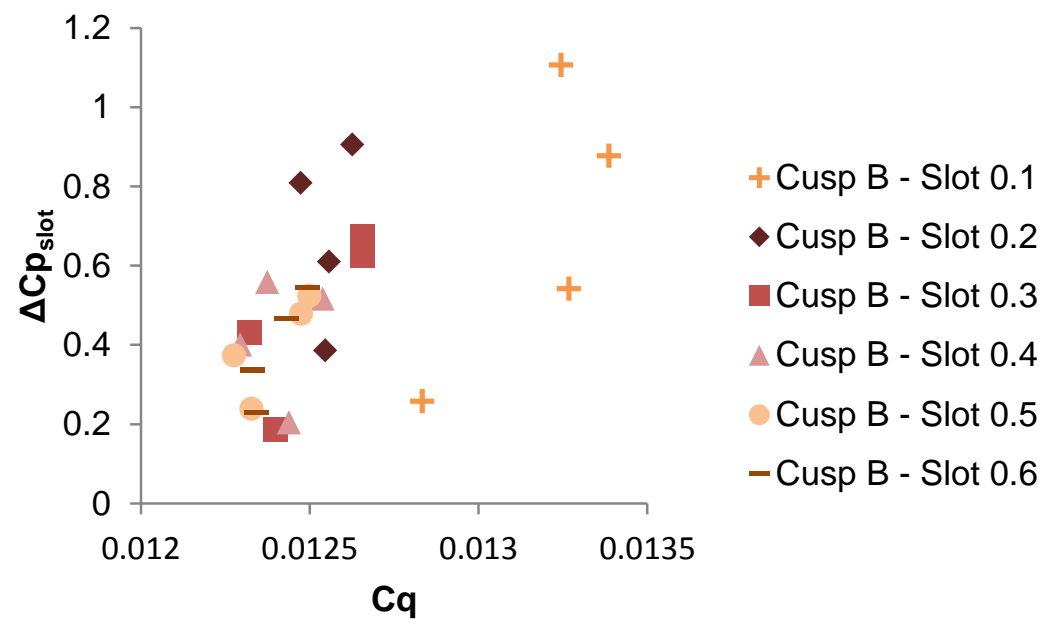

Figure 52. Pressure change across suction slot vs suction coefficient with Cusp B slot geometry.

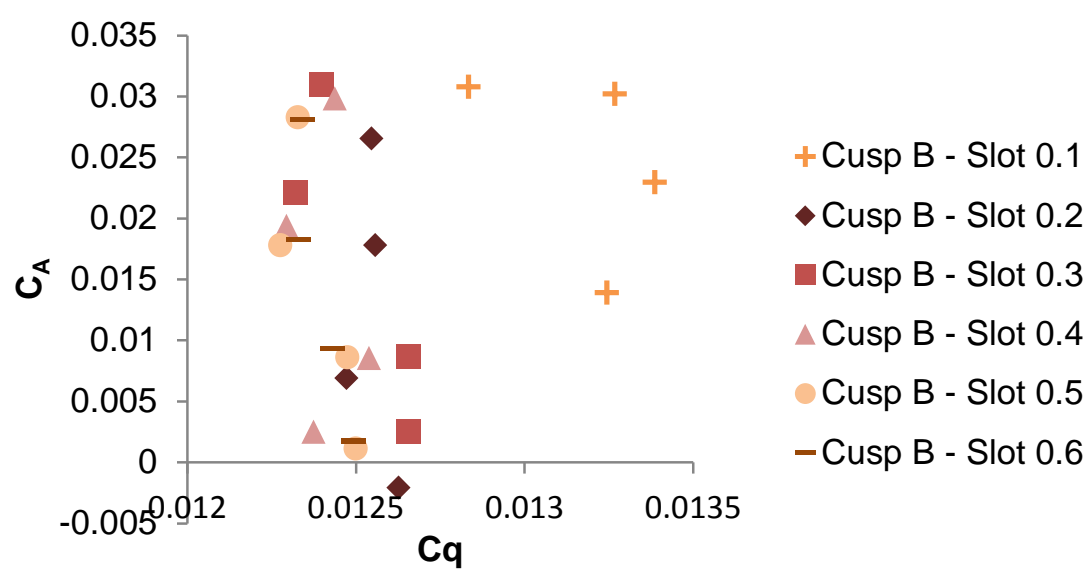

Figure 53. Total axial force vs suction coefficient for all slot gap sizes with Cusp B slot geometry. 
Pressure distributions over the Goldschmied model show that at lower fan speeds there is a steeper favorable pressure region and slot gap size has a greater effect on the pressure recovery both before and after the slot, Figure 54. At higher fan speeds the favorable pressure region is less dramatic and all slot gap sizes produce similar results, Figure 55. At the high fan speed, the medium slot gap sizes have slightly better pressure recovery while the extreme gap sizes don't do as well.

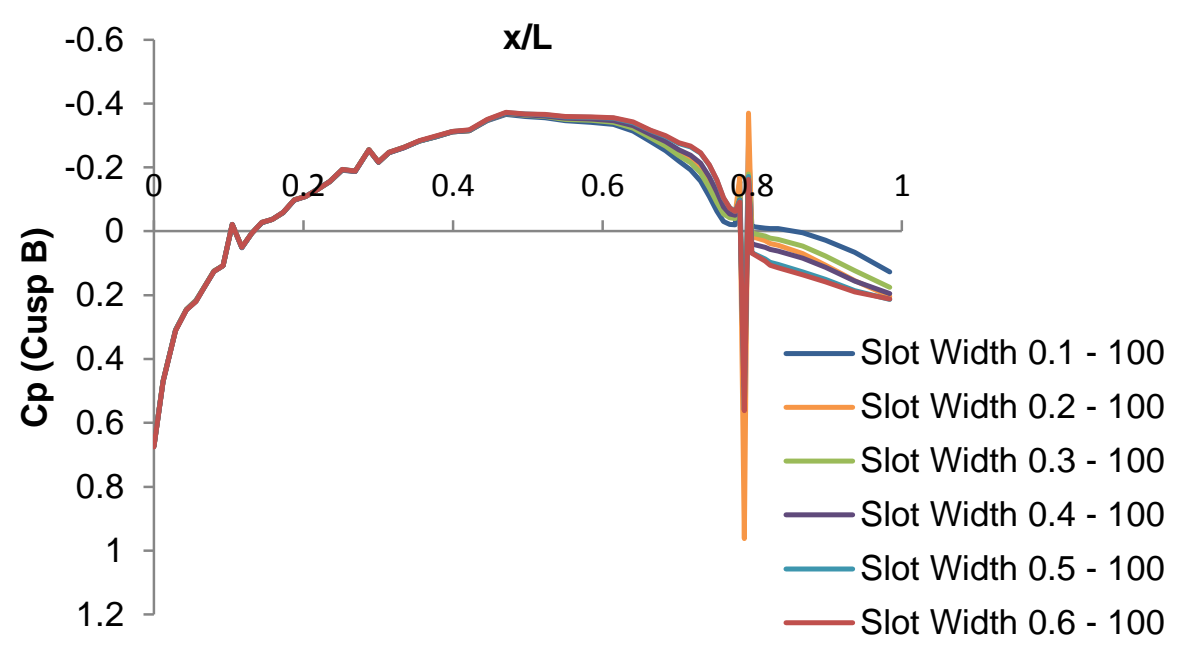

Figure 54. Pressure distribution over Goldschmied body with Cusp B slot geometry and constant throttle setting (fan speed $\sim 15000$ RPM).

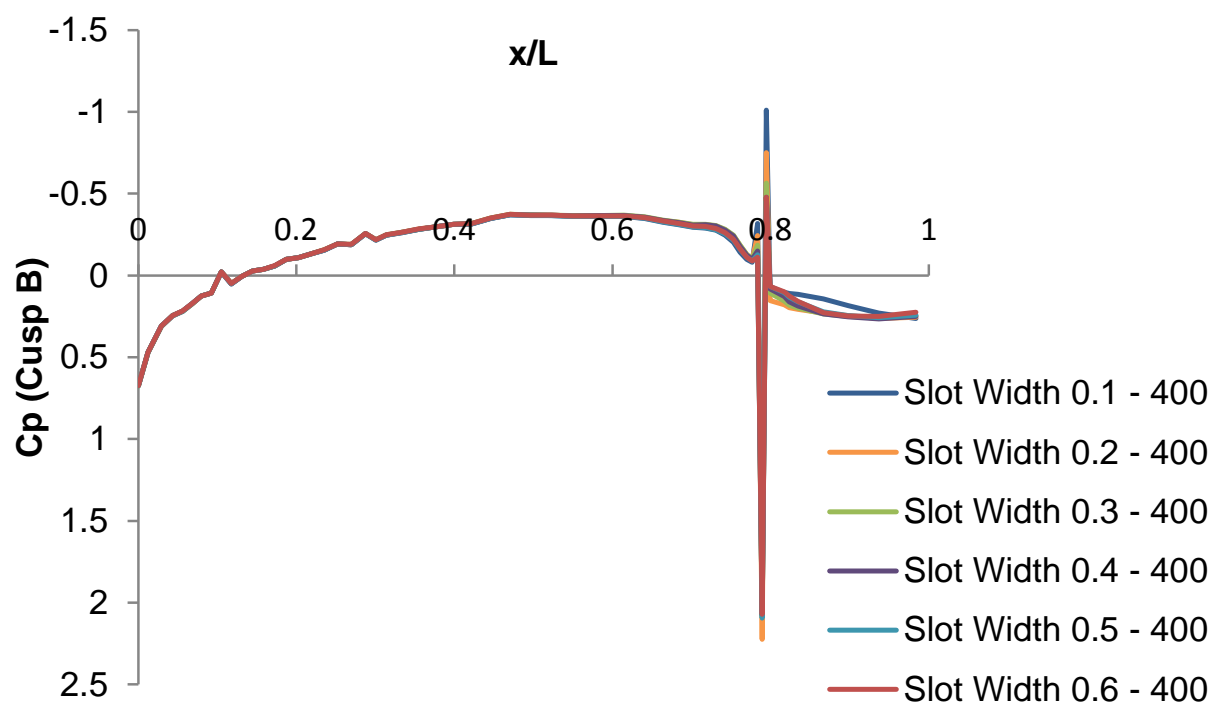

Figure 55. Pressure distribution over Goldschmied body with Cusp B slot geometry and constant throttle setting (fan speed $\sim 32500$ RPM)

Page 67 
As with Cusp A, pressure rise across the model fan increases with fan speed. The smaller slot gaps display a trend that looks like a power curve, causing greater pressure rise per RPM at higher fan speeds, Figure 56.

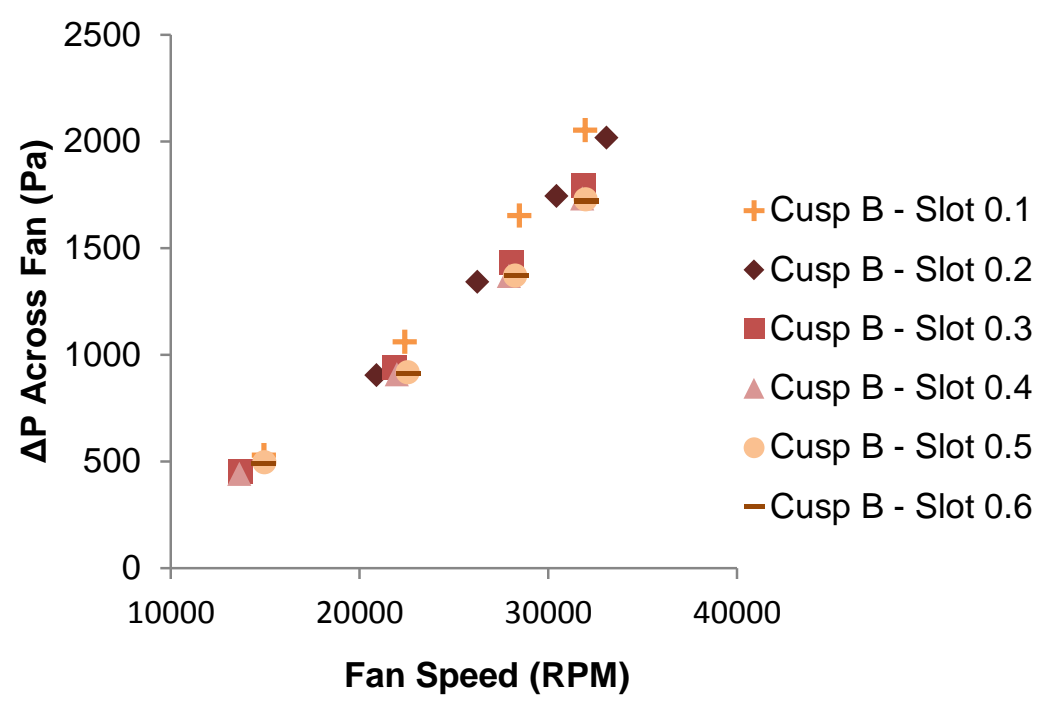

Figure 56. Pressure rise across the model fan with Cusp B slot geometry.

\subsection{Cusp C}

The third configuration tested in Round 2 of testing features the Cusp C slot geometry. This configuration produced the worst of the three sets of drag results with the highest fan on drag of $0.68 \mathrm{lbs}$ and only reaching a thrust at slot gaps of 0.4 and 0.5 inches with the maximum thrust being $0.11 \mathrm{lbs}$, Figure 57 . The smallest slot gap of 0.1 inches displays the highest total axial force, where positive axial force is defined in the direction of the flow. 


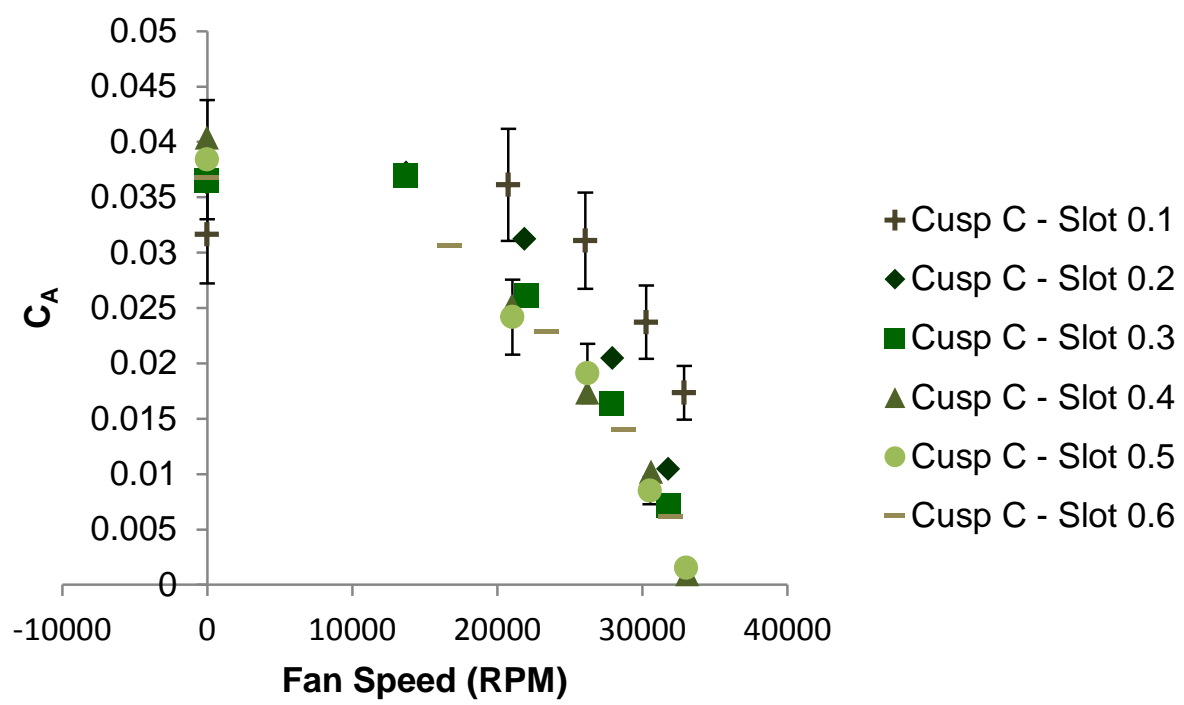

Figure 57. Total axial force vs fan speed with Cusp C slot geometry.

The smallest slot gap of 0.1 inches produces the lowest pressure thrust in Figure 58 while all the larger slot gaps display pressure drag values that don't significantly differ between the different slot gaps or with fan speed. Figure 59 displays no significant difference in suction coefficient between cusps or slot gap sizes. The smallest slot gap of 0.1 inches does produce the greatest pressure recovery.

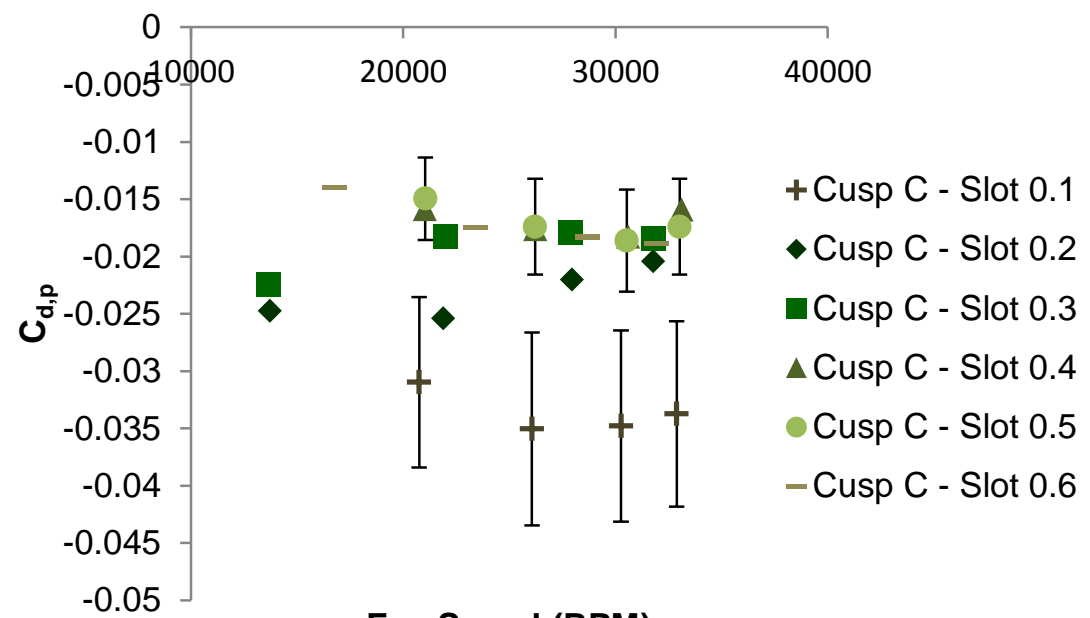

Fan Speed (RPM)

Figure 58. Pressure drag vs fan speed with Cusp C slot geometry. 


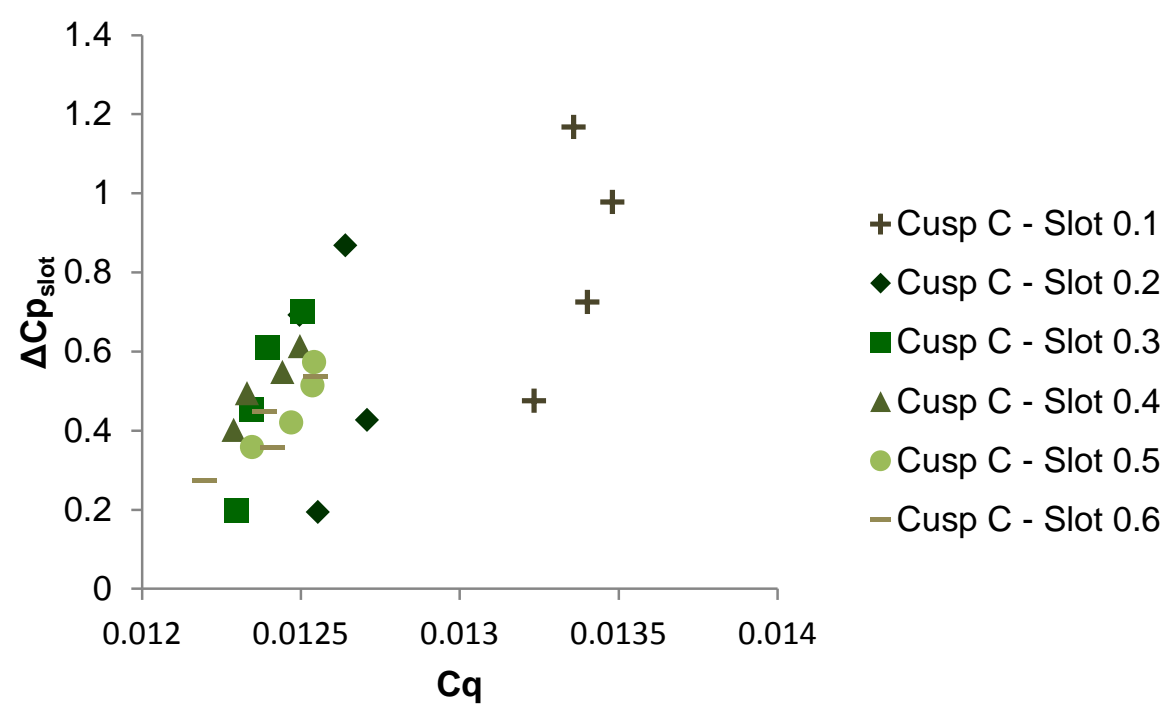

Figure 59. Pressure recovery across suction slot vs suction coefficient with Cusp C slot geometry.

The expected increase in mass flow rate with fan speed increase is not visible in Figure 60. This the same lack of trend seen in the mass flow rate data from Cusp A and Cusp B .

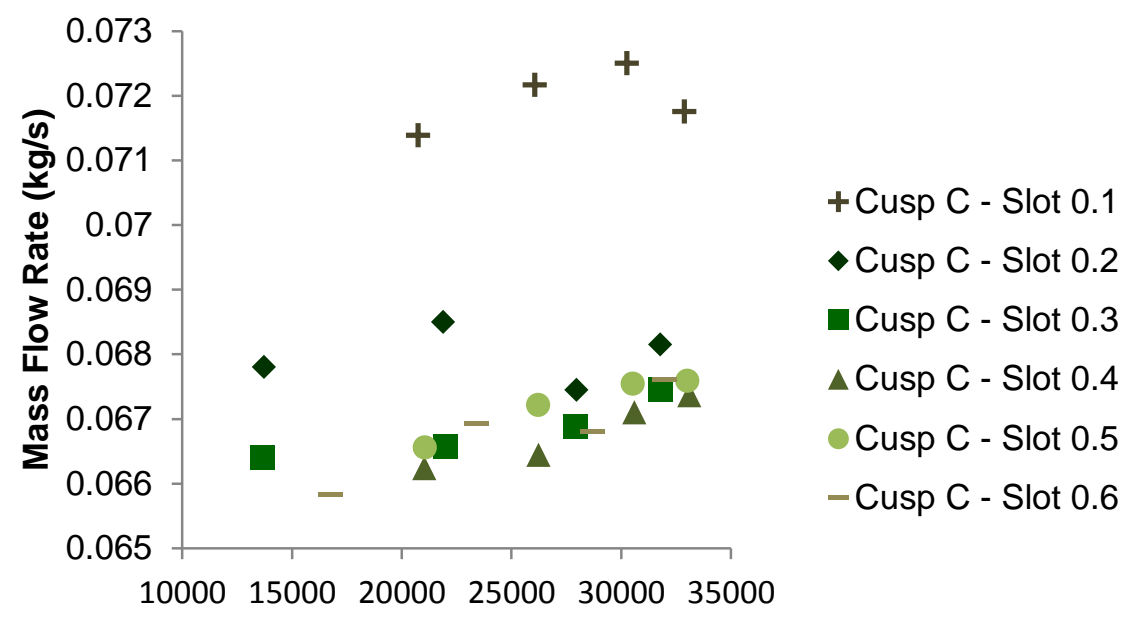

Fan Speed (RPM)

Figure 60. Mass flow rate through the aftbody of the Goldschmied propulsor with Cusp C slot geometry. 
Figure 61 and Figure 62 are pressure distributions over the Goldschmied body. The pressure gradient seen by the aftbody is significantly greater at lower fan speeds than at higher fan speeds. Slot gap size is also a greater factor in pressure recovery at lower fan speeds.

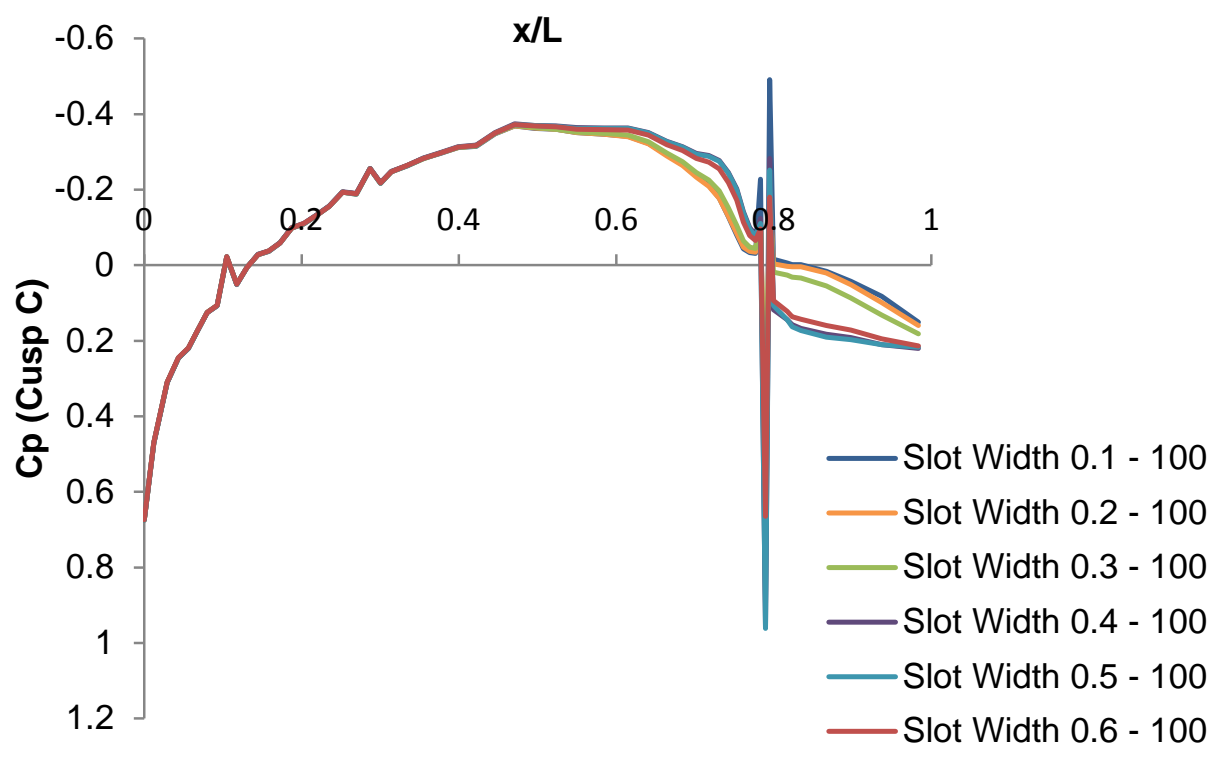

Figure 61. Pressure distribution over a Goldschmied body with Cusp C slot geometry and constant throttle setting (fan speed $\sim 17000$ ).

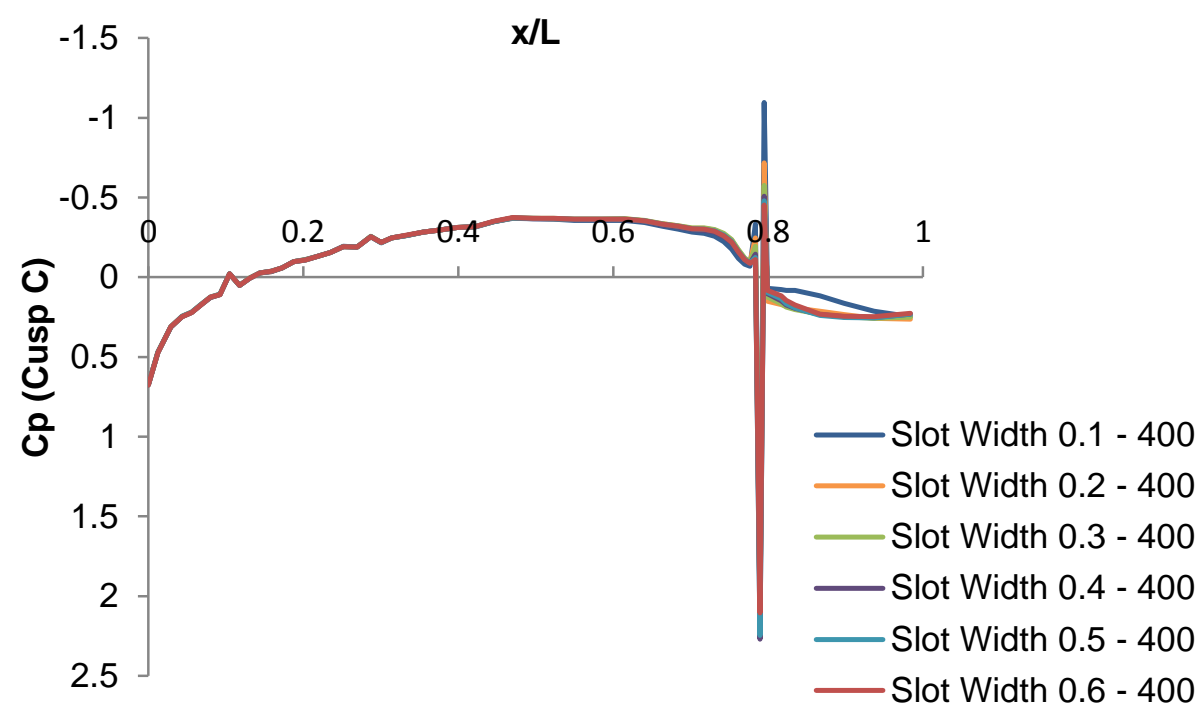

Figure 62. Pressure distribution over a Goldschmied body with Cusp C slot geometry and constant throttle setting (fan speed $\sim 32800$ ). 
Fan thrust, fan torque, pressure rise across the fan, and fan power vs. fan speed all show the same trends as seen with Cusp A and Cusp B. Thrust increases with fan speed and torque decreases with fan speed, Figure 63 and Figure 64. Both seem to be unaffected by slot gap size. Pressure rise across the fan is greatest with the smallest slot gap of 0.1 inches at higher fan speeds, Figure 65 . Figure 66 is the plot of fan power vs fan speed, with fan power following a power curve.

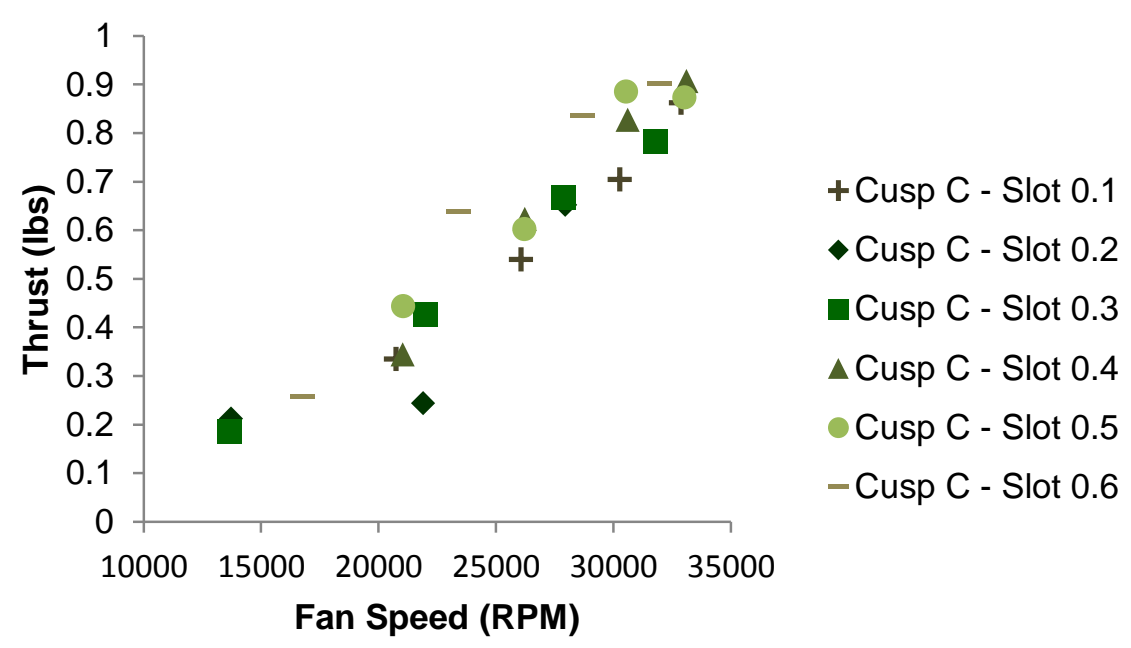

Figure 63. Fan thrust vs fan speed with Cusp C slot geometry.

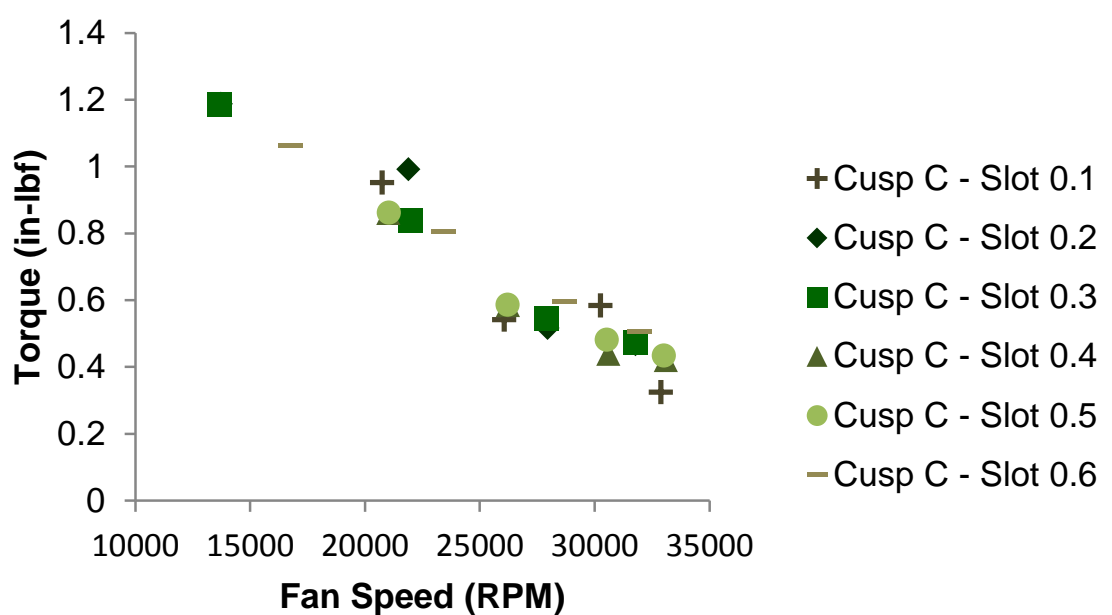

Figure 64. Fan torque vs fan speed with Cusp C slot geometry. 


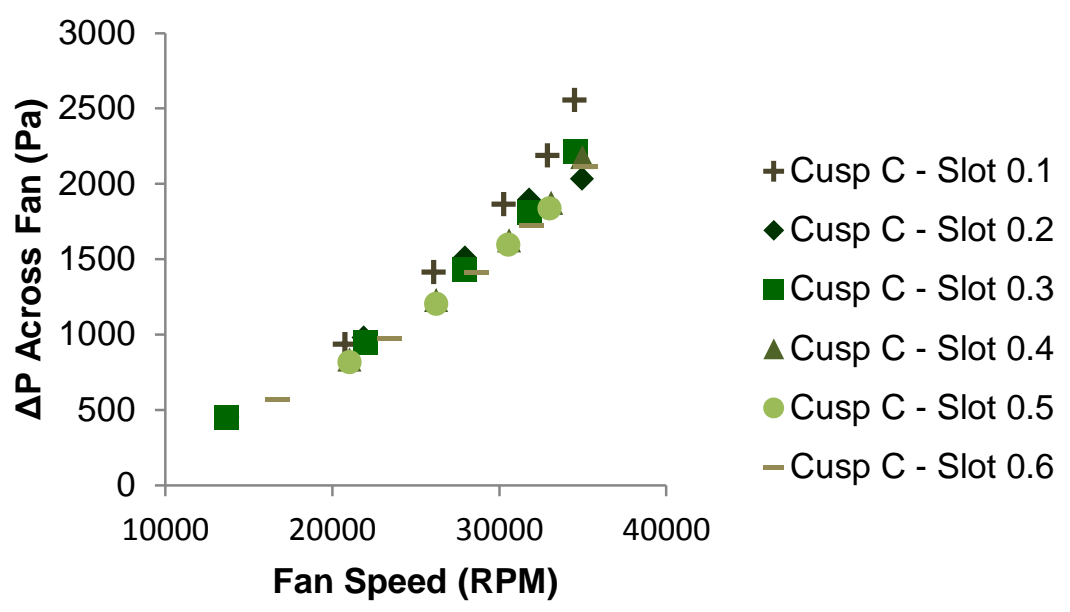

Figure 65. Pressure rise across the model fan vs fan speed for Cusp C slot geometry.

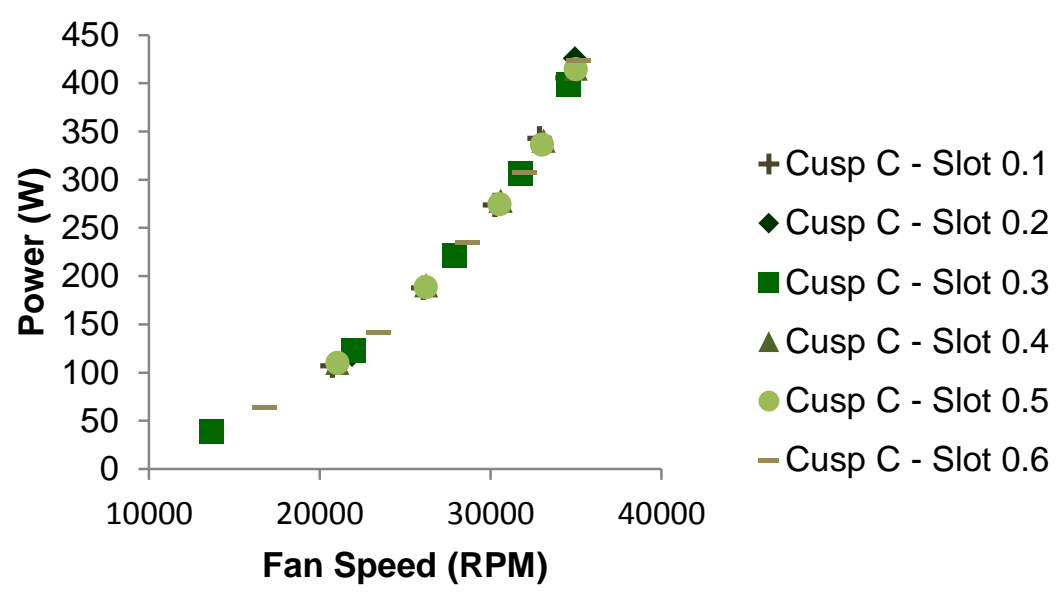

Figure 66. Fan power vs fan speed for Cusp C slot geometry.

\subsection{Comparison}

Comparison of the three cusp geometries at the suction slot and how they perform vs no cusp is the main purpose of this round of wind tunnel tests. The objective is to determine if a cusp improves suction slot performance and if so, which cusp allows for the greatest total axial force reduction and requires the least amount of power in doing so. It then makes sense that we first compare the drag seen with each cusp. 
Figure 67 shows the total axial force for all cusps at the larger slot widths where the lowest drag values were recorded. It is clear in this comparison that Cusp C performed the worst with the highest total axial force values across all slot gap sizes and fan speeds. At lower fan speeds, Cusp A produces the lowest total axial force values with slot gaps of 0.5 or 0.6 inches. At higher fan speeds, Cusp B total axial force data begins to match up with the Cusp A total axial force data. Despite all the original Goldschmied reports insisting on the need for a cusp at the suction slot entrance, Figure 67 displays that no cusp produces the lowest total axial force values. The no cusp drag values plotted are only preliminary values not the final reported values from the Round 1 testing report. Cusp C can be ruled out as a viable slot geometry, as it seems to protrude too far into the flow to give us the desired drag reduction and may perform better at higher fan power, but increasing fan power with the current fan would require significantly more power for the result we get at a lower power with Cusps A and B.

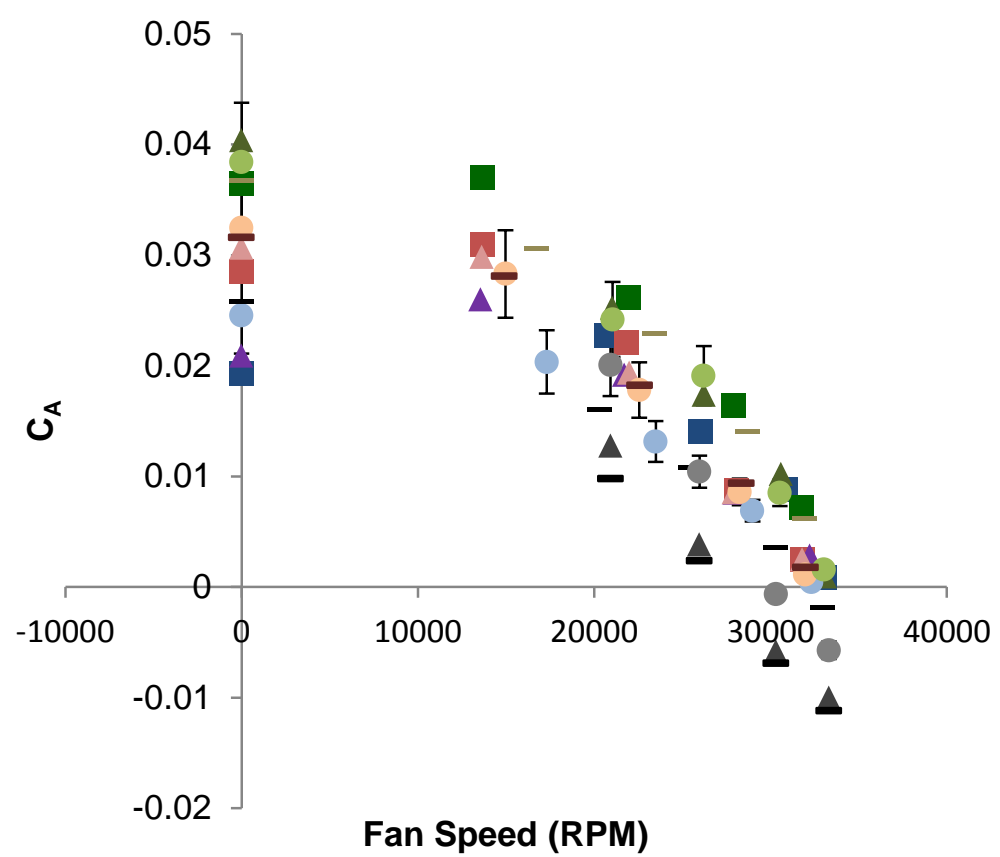

- Cusp A - Slot 0.3

- Cusp B - Slot 0.3

- Cusp C - Slot 0.3

$\triangle$ Cusp A - Slot 0.4

$\triangle$ Cusp B - Slot 0.4

$\triangle$ Cusp C - Slot 0.4

- Cusp A - Slot 0.5

- Cusp B - Slot 0.5

- Cusp C - Slot 0.5

- Cusp A - Slot 0.6

-Cusp B - Slot 0.6

- Cusp C - Slot 0.6

$\Delta$ No Cusp - Slot 0.38

- Noc Cusp - 0.5

-No Cusp - Slot 0.6

Figure 67. Total axial force of Goldschmied Propulsor with different cusp geometries at the suction slot. 
Pressure drag is a large contributor to the total axial force of an axisymmetric body such as this Goldschmied body. If the suction slot can increase pressure recovery over the body, it can greatly reduce pressure drag and as Goldschmied suggested, could create pressure thrust. Figure 68 compares the pressure drag with each of the different cusps. The errors make it clear that between the different cusps and the different fan speeds, there is no meaningful difference in the pressure drag. Figure 68 suggests that adding a cusp to the suction slot creates no meaningful reduction in drag.

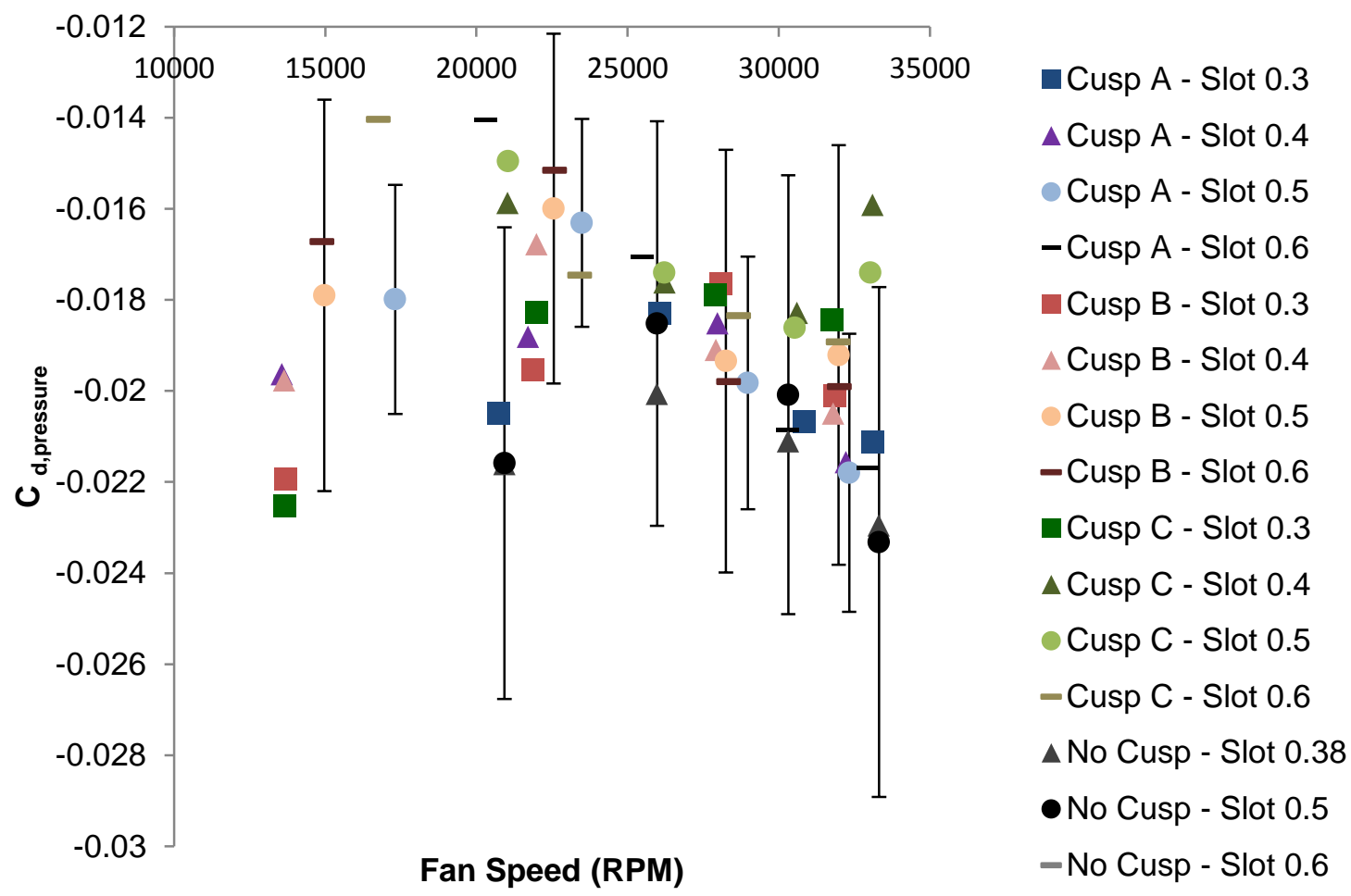

Figure 68. Pressure drag on a Goldschmied body with different suction slot geometries.

Figure 69 appears to show that Cusp A could provide the desired pressure recovery with the lowest suction flow rate. However with inspection, the difference in suction coefficients is not significantly different and therefore none of the cusps display any meaningful difference in the suction required to keep attached flow over the 
Goldschmied body. Figure 69 clashes with Fabio Goldschmied's claim that the addition of a cups reduces the suction requirements.

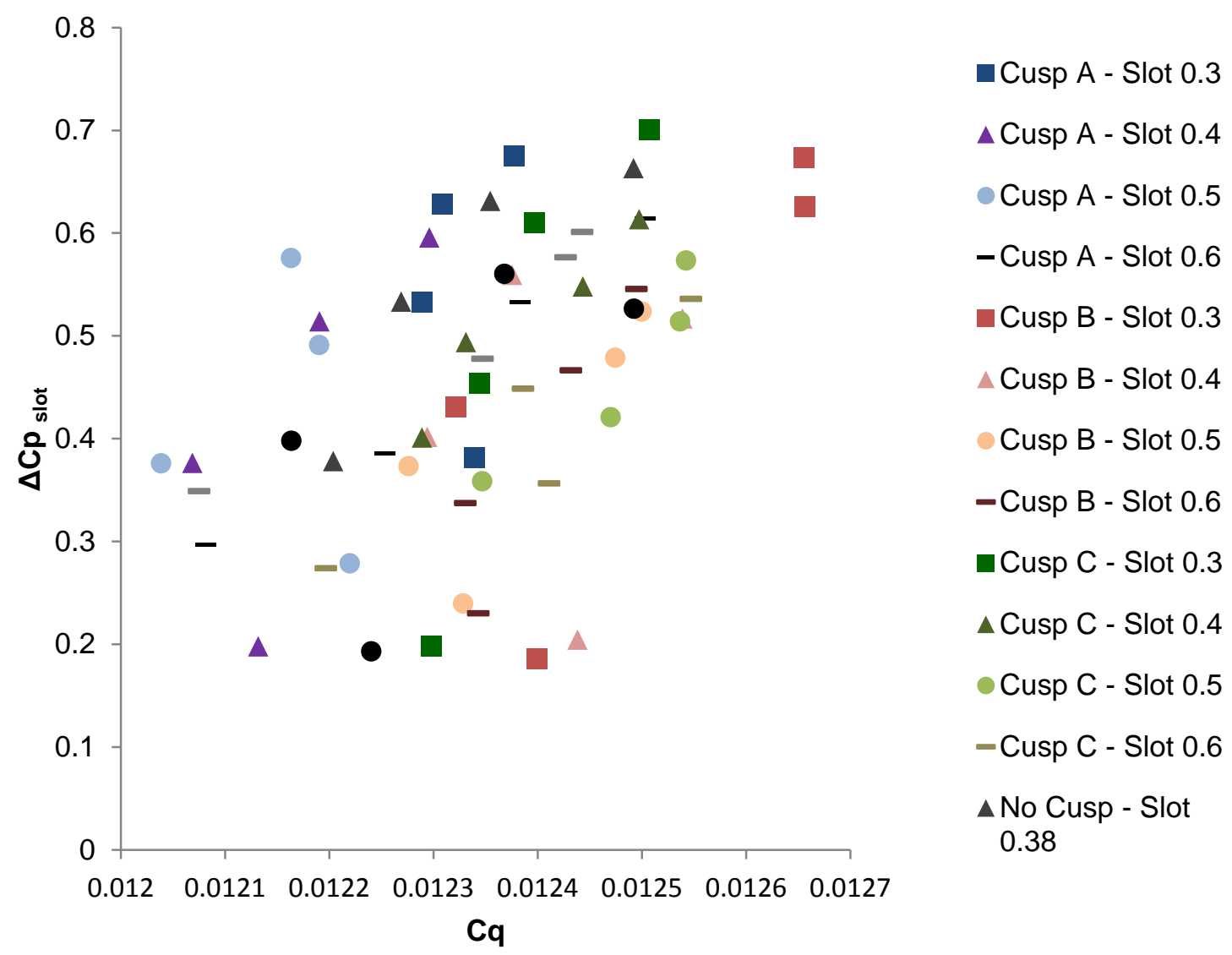

Figure 69. Pressure change across the suction slot vs suction coefficient for three slot geometries.

Figure 70 shows that the cusp geometries at the slot did not affect the power curve of the fan, and Figure 71 shows that the pressure rise across the fan was not affected by the slot geometries either. It appears that under the current test conditions the fan was able to operate at its best performance conditions. 


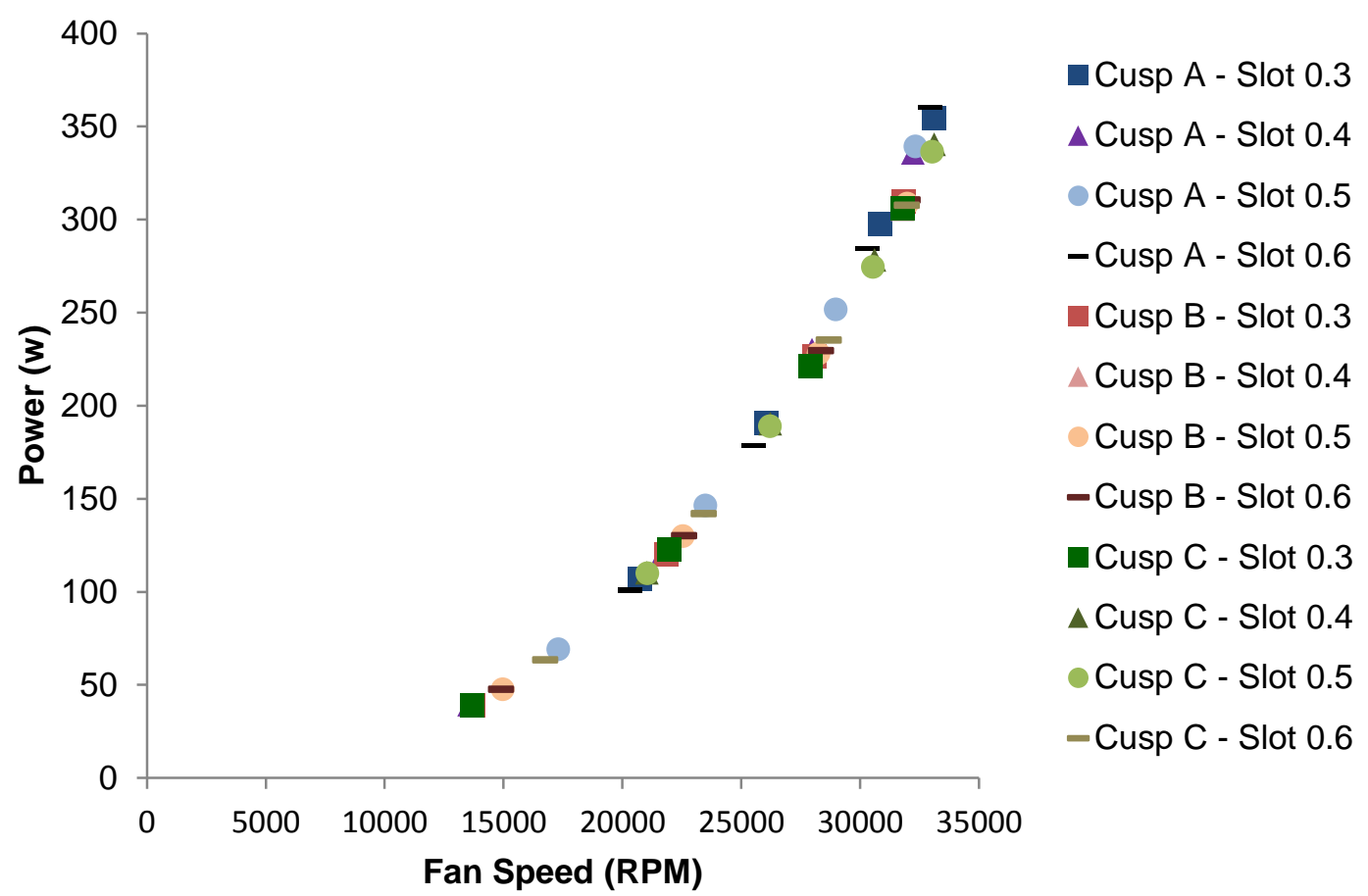

Figure 70. Fan power vs fan speed for three different slot geometries.

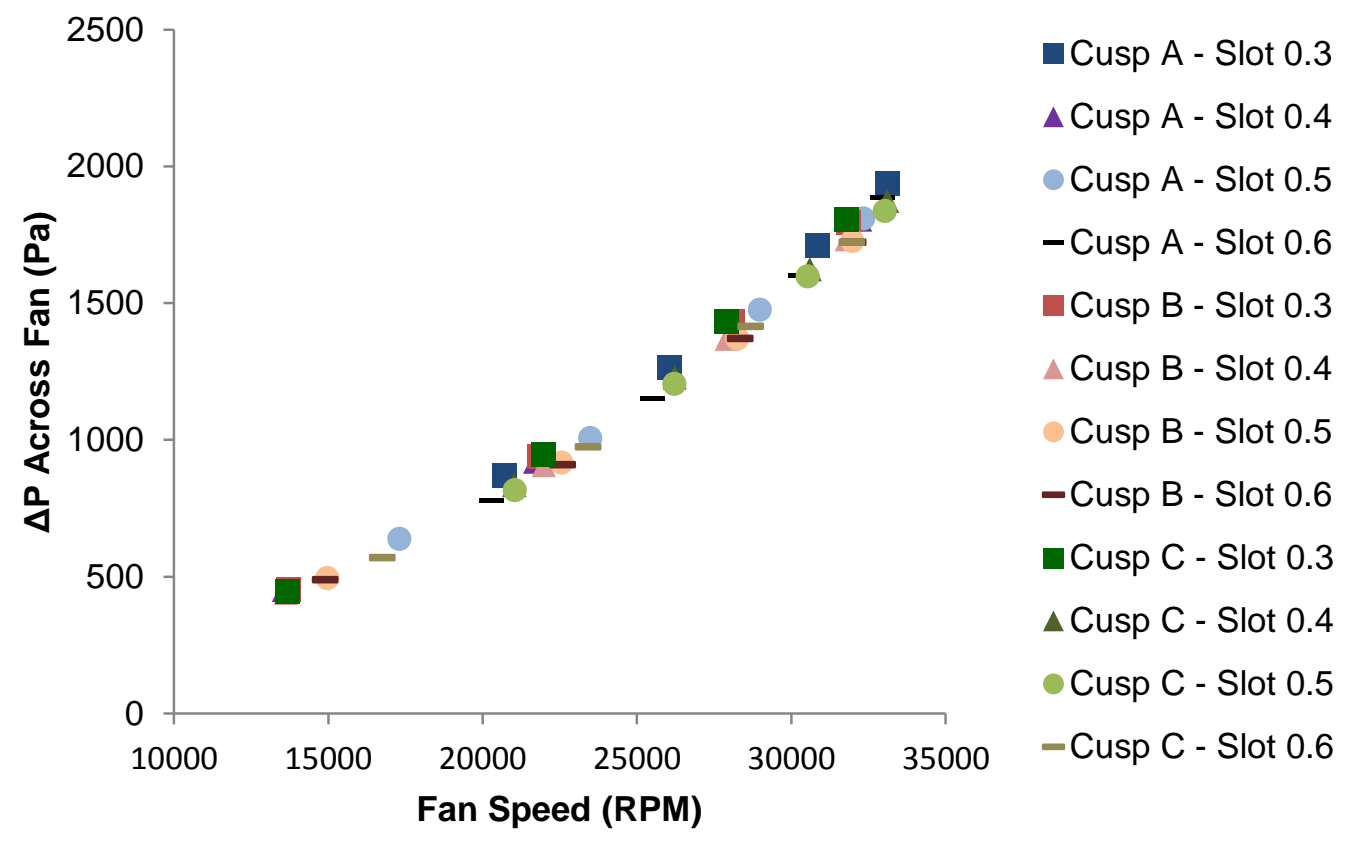

Figure 71. Pressure rise across the fan during testing of three different suction slot geometries. 


\section{Conclusions}

Three different cusp geometries were developed to change the suction slot geometry on a Goldschmied Propulsor to test how they affect the performance of the system. The cusps varied in the distance they protrude into the incoming suction flow and in the angle they take from the lip into the suction slot. Results show that of the three cusp geometries, Cusp A produced the greatest reductions total axial force for the fan speeds tested. When compared to the no cusp condition, Cusp A did not produce any significantly lower total drag or require any less suction to maintain attached flow over the model. These results question Goldschmied's claims that a cusp is a necessary component of a Goldschmied Propulsor design, as there is no noticeable system improvement seen in this set of data. 


\section{$7 \quad$ References}

${ }^{1}$ Goldschmeid, F. R., "Integrated Hull Design, Boundary-Layer Control, and Propulsion of Submerged Bodies," AIAA Second Propulsion Joint Specialist Conference, 13-17 June 1966, Vol. 1, No. 1.

${ }^{2}$ Goldschmeid, F. R., "Wind Tunnel Test of the Modified Goldschmied Model with Propulsion and Empennage: Analysis of Test Results," Report FRG 82-1, February 1986.

${ }^{3}$ Cerreta, Peter A., "Wind-Tunnel Investigation of the Drag of a Proposed BoundaryLayer-Controlled Airship," TID No. TMB AD-3198, March 1957.

${ }^{4}$ Huthmacher, Ryan, "Investigation into the Effect of Boundary Layer Transition on the Massive Separation from a Thick Airfoil," Cal Poly Aerospace Engineering.

5"An Investigation of a Boudary-Layer-Controlled Airship," Goodyear Aircraft Corporation, GER8399, 15 October 1957.

${ }^{6}$ Howe, Harvey J. and Neumann, Benjamin J., "An Experimental Evaluation of a Low Propulsive Power, Discrete Suction Concept Applied to an Axisymmetric Vehicle," David W. Taylor Naval Ship Research and Development Center, DTNSRDC/TM-16-82/02, January 1982.

${ }^{7}$ Goldschmeid, F. R., "Wind Tunnel Demonstration of an optimized LTA system with $65 \%$ power reduction and neutral static stability," Defense Advanced Research Project Agency, 83-1981.

${ }^{8}$ Goldschmeid, F. R., "Jet Propulsion of Subsonic Bodies with Jet Total-head Equal to Free Stream's," AIAA Applied Aerodynamics Conference, 13-15 July 1983.

${ }^{9}$ Goldschmeid, F. R., "Wind Tunnel Test of the Modified Goldschmied Model with Propulsion and Empennage: Analysis of Test Results," Report FRG 82-1, February 1986.

${ }^{10}$ Ringleb, Friedrich, "Separation Control by Trapped Vortices."

${ }^{11}$ Goldschmied, F.R., "Aerodynamic Hull Design for HASPA LTA Optimization," Westinghouse Electric Corporation, Journal of Aircraft, Vol. 15. No. 9, 1978.

12"DS-30-DIA HDT (High Dynamic Thrust): The $69 \mathrm{~mm}$ fan for highest dynamic thrust," Schubeler Jets, Online 3 Feb. 2012, www. shubeler-jets.com.

${ }^{13}$ Goldschmied, F. R., "Fuselage Self-Propulsion by Static-Pressure Thrust: Wind Tunnel Verification," AIAA/AHS/ASEE Aircraft Design, Systems and Operations Meeting, 14-16 September 1987.

${ }^{14}$ Barlow, J.B, Rae, W. H., and Pope, A., "Low-Speed Wind Tunnel Testing," John Wiley \& Sons, New York, 1999.

${ }^{15}$ Goldschmied, F. R., "Wind Tunnel Demonstration of an optimized LTA system with $65 \%$ power reduction and neutral static stability," Defense Advanced Research Project Agency, 83-1981. 


\section{Appendix A: Lessons Learned/ Knowledge Gained}

a) Drag measurements are typically done using a balance rather than a pivot point. This is because bearings will always produce a significant amount of friction to alter the drag reading. Causing issues with drag measurement repeatability. There is also a problem with stiction, which is the static friction force that must be overcome before the pivot can rotate.

b) When designing a system, in this case a wind tunnel model, design changes and parts should always be put in the solid model of the system before manufacturing. This will help ensure that the dimensions are correct, makes it easier to see how the part will fit in the system, and allows for you to see how the part interacts with the rest of the system. Although it may seem like unnecessary time spent on solid modeling in some cases, it can save time in the long run when parts don't need to be rebuilt or modified to fit in the system.

c) Measure twice, cut once. It is incredibly important to measure as accurately as possible especially when working in tight fitting areas. It's better to spend extra time ensuring that you are proceeding correctly, than to waste time later making up for a mistake.

d) Always sanity check data as you go. It is important to make sure that all the instruments are working and that the data being collected is reasonable to what you expect. If you check as you go you ensure that you are collecting quality data. Waiting until after testing to review all data could lead to more time that must be spent retesting. e) When designing a system make sure to design in reference points, or points that can be used to easily take measurements from. This will make it easier make sure components are mounted in the correct place and helps with alignment. 
f) Always plan for things to take longer than you expect. Obstacles and issues will arise that you never expected, so schedule in lots of time to accommodate them.

g) Constantly weigh your options. Throughout a project the plan will change many times and quick decisions will be required. Continuously compare options and weigh decisions to help determine that you are following the best procedure for progression of the project. If a decision seems to be taking you in the wrong direction, be able to weigh your options and redirect to a new path before too much time and effort are wasted.

h) Plan ahead to do things right. Taking shortcuts always comes back to bite you later. Take the extra time to do things right in the beginning so that everything runs smoothly in the end.

i) Organize. It pays to be organized and record everything. It helps you stay on track, reduces stress, and eliminates the need to go back and redo things later.

j) Schedule your time. Making a schedule gives you a clear view of how to proceed and helps you stay on track.

k) Minimize the time for making model alterations between test runs. Design the alteration pieces to be easily removed or installed. This will drastically cut down on testing time, but will also reduce the risk of breaking something in long, complicated install processes.

I) Design things in as few pieces as possible. The more pieces, the more chance for error in proper installation, in proper manufacturing, and more chance of losing pieces.

m) If using plastic tubing for plumbing to pressure ports, use flexible tubing the has the correct ID for your application. This will save you lots of time not having to fix leaks. Stiff plastic tubing does not seal well. Also, try to minimize the number of connection points in one line of tubing. This will also save time in leak checking. 
n) Read the manuals for equipment you're using to follow the recommended settings and procedures.

o) Test all equipment before you are ready to take data. This is important to ensure everything is operating as expected.

p) Do continuity checks of electrical wires to confirm that power and signals are being sent to the appropriate places.

q) Don't expect to know everything when you start, but be prepared to learn as you go.

r) Learn your testing facility in the beginning. Know what the facility has to offer and how to operate equipment before you start. This will also help you identify operations that can be improved or equipment that needs to be sent in to be fixed or calibrated. 


\section{Error Analysis}

Total Pressure:

$P_{T}=P_{\text {measured }}+P_{\text {atm }}$

$\delta P_{\text {measured }}=0.1 \%=-0.00008466 p s i$

$P_{a t m}=29.87 \mathrm{inHg}=14.67 \mathrm{psi}$

$\delta p_{a t m}=0.01 \mathrm{inHg}=0.0049 \mathrm{psi}$

$\delta P_{T}=\sqrt{(0.00008466 p s i)^{2}+(0.0049 p s i)^{2}}=0.0049 p s i=33.79 P a$

Static Pressure:

$p_{\text {static }}=p_{\text {measured }}+p_{\text {atm }}$

$\delta p_{\text {measured }}=-0.0052$

$\delta p_{\text {measured }}=0.1 \%=-0.0000052 p s i$

$\delta p_{\text {static }}=\sqrt{(-0.0000052 p s i)^{2}+(0.0049 p s i)^{2}}=0.0049 p s i=33.79 P a$

Temperature:

$\delta T=0.5^{\circ} \mathrm{F}=127.96 K$

Density:

$\frac{\delta \rho}{\rho}=\sqrt{\left(\frac{\delta p}{p}\right)^{2}+\left(\frac{\delta T}{T}\right)^{2}}=\sqrt{\left(\frac{33.79 P a}{101110.13 P a}\right)^{2}+\left(\frac{127.96 K}{14715.85 K}\right)^{2}}=0.0087=0.87 \%$

Aftbody Exit Velocity:

$\delta \Delta P=\sqrt{(0.0049)^{2}+(0.0049)^{2}}=0.0069296 p s i=47.79 \mathrm{~Pa}$ 
$\delta V_{4}=\sqrt{\left(\frac{2 * \delta \Delta P}{\Delta P}\right)^{2}+\left(\frac{\delta \rho}{\rho}\right)^{2}}=\sqrt{\left(\frac{2 * 47.79 P a}{547.86 P a}\right)^{2}+(0.0087)^{2}}=0.1747 \frac{\mathrm{m}}{\mathrm{s}}$

Dynamic Pressure:

$\frac{\delta q}{q}=\sqrt{\left(\frac{1}{2} \frac{\delta \rho}{\rho}\right)^{2}+\left(\frac{\delta V}{V}\right)^{2}}=\sqrt{\left(\frac{1}{2} * 0.0087\right)^{2}+\left(2\left(\frac{1.05 \frac{m}{s}}{28 \frac{m}{s}}\right)\right)^{2}}=0.0751$

Total Axial Force:

$\delta V_{B}=0.0032258 \mathrm{~m}^{2}$

$\delta F_{A}=0.25 \% F S=0.0625 \mathrm{lb}$

$\frac{\delta C_{D}}{C_{D}}=\sqrt{\left(\frac{\delta F_{A}}{F_{A}}\right)^{2}+\left(\frac{\delta q}{q}\right)^{2}+\left(\frac{2}{3} \frac{\delta V_{B}}{V_{B}}\right)^{2}}=\sqrt{\left(\frac{0.0625 l b}{0.544 l b}\right)^{2}+(0.0751)^{2}+\left(\frac{2}{3} * \frac{0.003226}{0.0539}\right)^{2}}$ $=0.143$

Fan Thrust:

$\delta F_{T}=0.25 \% F S=0.0025 \mathrm{lb}$

Fan Torque:

$\delta F_{q}=0.25 \% F S=0.0025 \mathrm{lb}$

Mass Flow Rate:

$\delta r=0.0625$ in $=0.001588 \mathrm{~m}$

$\frac{\delta \dot{m}}{\dot{m}}=\sqrt{\left(2 \pi \frac{\delta \rho}{\rho}\right)^{2}+6\left(\frac{\delta V_{4}}{V_{4}}\right)^{2}+\left(\frac{\delta r}{r}\right)^{2}}=\sqrt{(2 \pi * 0.0087)^{2}+6\left(\frac{0.001588 m}{0.05 m}\right)^{2}+(6 * 1.05)^{2}}$
$=0.2017$ 
Fan Speed:

$\delta V_{\text {fan }}=125 R P M$

Suction Coefficient:

$$
\begin{aligned}
& \frac{\delta C_{q}}{C_{q}}=\sqrt{\left(\frac{\delta \dot{m}}{\dot{m}}\right)^{2}+\left(\frac{\delta \rho}{\rho}\right)^{2}+\left(\frac{\delta V_{0}}{V_{0}}\right)^{2}+\left(\frac{2}{3} \frac{\delta V_{B}}{V_{B}}\right)^{2}} \\
& =\sqrt{(0.207)^{2}+(0.0087)^{2}+\left(\frac{1}{30}\right)^{2}+\left(\frac{2}{3} * \frac{0.003226}{0.0539}\right)^{2}}=0.214
\end{aligned}
$$

Pressure Drag:

$$
\begin{aligned}
& \delta\left(r_{i+1}-r_{i}\right)=\sqrt{(\delta r)^{2}+(\delta r)^{2}}=\sqrt{0.001588^{2}+0.001588^{2}}=0.002246 \mathrm{~m} \\
& \frac{\delta\left[2 \pi r_{i+1}\left(r_{i+1}-r_{i}\right)\right]}{2 \pi r_{i+1}\left(r_{i+1}-r_{i}\right)}=\sqrt{\left(\frac{\delta r}{r}\right)^{2}+\left(\frac{\delta\left(r_{i+1}-r_{i}\right)}{r_{i+1}-r_{i}}\right)^{2}}=\sqrt{\left(\frac{0.001588}{0.05}\right)^{2}+\left(\frac{0.002246}{0.01}\right)^{2}} \\
& =0.2268 \mathrm{~m} \\
& \delta\left(\pi\left(r_{i+1}-r_{i}\right)^{2}\right)=2 * \pi * \delta\left(r_{i+1}-r_{i}\right)=0.01411 \\
& \frac{\delta R}{R}=\sqrt{\left(\frac{\delta\left[2 \pi r_{i+1}\left(r_{i+1}-r_{i}\right)\right]}{2 \pi r_{i+1}\left(r_{i+1}-r_{i}\right)}\right)^{2}+\left(\frac{\delta\left(\pi\left(r_{i+1}-r_{i}\right)^{2}\right)}{\left(r_{i+1}-r_{i}\right)^{2}}\right)^{2}}=\sqrt{(0.2268)^{2}+(0.01411)^{2}}=0.2272 \\
& \frac{\delta D_{p}}{D_{p}}=\sqrt{\left(\frac{1}{2} \frac{\delta \Delta P}{\Delta P}\right)^{2}+\left(\frac{\delta R}{R}\right)^{2}}=\sqrt{\left(\frac{1}{2} \frac{47.79 P a}{547.86 P a}\right)^{2}+(0.2272)^{2}}=0.2313 \\
& \frac{\delta C_{d, p}}{C_{d, p}}=\sqrt{\left(\frac{\delta D_{p}}{D_{p}}\right)^{2}+\left(\frac{\delta q}{q}\right)^{2}+\left(\frac{2}{3} \frac{\delta V_{B}}{V_{B}}\right)^{2}}=\sqrt{(0.2313)^{2}+(0.0751)^{2}+\left(\frac{2}{3} * \frac{0.003226}{0.0539}\right)^{2}} \\
& =0.2464
\end{aligned}
$$

Solid Blockage: 


$$
\frac{\delta \varepsilon_{s b}}{\varepsilon_{s b}}=\sqrt{\left(\frac{3}{2} \frac{\delta C}{C}\right)^{2}+\left(\frac{\delta V_{B}}{V_{B}}\right)^{2}}=\sqrt{\left(\frac{3}{2} * \frac{0.001588 m}{1.0247 m}\right)^{2}+\left(\frac{0.003226 m^{3}}{0.05394 m^{3}}\right)^{2}}=0.0599
$$

Buoyancy:

$$
\frac{\delta D_{B}}{D_{B}}=4 \sqrt{\left(\frac{\delta S}{S}\right)^{2}+\left(\frac{\delta p}{p}\right)^{2}}=\sqrt{\left(\frac{0.001588 m}{0.04 m}\right)^{2}+\left(\frac{33.79 P a}{101110 P a}\right)^{2}}=0.159 \mathrm{et}
$$




\section{Appendix C: Raw Data}

\section{Cusp A}

\begin{tabular}{|c|c|c|c|c|c|c|c|c|}
\hline \multirow{3}{*}{0.1} & & $100 \mathrm{~W}$ & Zero Run & $200 W$ & Zero Run & $300 \mathrm{~W}$ & Zero Run & $400 \mathrm{~W}$ \\
\hline & Drag & -0.033917 & -0.032932 & -0.032722 & -0.019489 & -0.030659 & -0.019158 & -0.029176 \\
\hline & Thrust & -0.005766 & -0.006543 & -0.007116 & -0.006098 & -0.007511 & -0.006416 & -0.007833 \\
\hline \multirow{7}{*}{0.2} & Torque & 0.003643 & 0.002065 & 0.001805 & 0.003374 & 0.001572 & 0.003014 & 0.000853 \\
\hline & $\dot{m}$ & 0.103281 & 0.000000 & 0.103433 & 0.000000 & 0.102929 & 0 & 0.101930 \\
\hline & Fan Power & 105.98 & 186.00 & 189.55 & 0.83468 & 280.02 & 0.88974 & 355.95 \\
\hline & Drag & -0.032855 & & -0.030949 & -0.020781 & -0.028851 & & -0.026927 \\
\hline & Thrust & -0.006089 & & -0.006941 & -0.006099 & -0.007387 & & -0.008404 \\
\hline & Torque & 0.003187 & & 0.001654 & 0.003374 & 0.001747 & & 0.000256 \\
\hline & $\dot{m}$ & 0.099309 & & 0.097619 & 0 & 0.098127 & & 0.098020 \\
\hline \multirow{3}{*}{0.3} & Fan Power & 106.43 & & 192.22 & 0.84552 & 273.20 & & 363.51 \\
\hline & Drag & -0.032162 & & -0.030163 & & -0.028947 & -0.021233 & -0.027103 \\
\hline & Thrust & -0.006164 & & -0.007293 & & -0.007832 & -0.006479 & -0.007883 \\
\hline \multirow{7}{*}{0.4} & Torque & 0.003160 & & 0.001719 & & 0.001048 & 0.003 & 0.001022 \\
\hline & $\dot{m}$ & 0.097508 & & 0.097195 & & 0.097387 & & 0.097995 \\
\hline & Fan Power & 106.80 & & 190.33 & & 297.60 & 0.846354 & 354.64 \\
\hline & Drag & -0.032930 & & -0.031354 & & -0.028882 & & -0.027564 \\
\hline & Thrust & -0.005816 & & -0.006354 & & -0.007464 & & -0.008191 \\
\hline & Torque & 0.004053 & & 0.002922 & & 0.001536 & & 0.000735 \\
\hline & $\dot{m}$ & 0.096069 & & 0.095604 & & 0.096540 & & 0.097400 \\
\hline \multirow{3}{*}{0.5} & Fan Power & 39.11 & & 120.64 & & 229.84 & & 335.74 \\
\hline & Drag & -0.031619 & & -0.029956 & & -0.028508 & & -0.027010 \\
\hline & Thrust & -0.006109 & & -0.006426 & & -0.007603 & & -0.008404 \\
\hline \multirow{8}{*}{0.6} & Torque & 0.003697 & & 0.002568 & & 0.001424 & & 0.000692 \\
\hline & $\dot{m}$ & 0.096789 & & 0.095418 & & 0.096623 & & 0.096404 \\
\hline & Fan Power & 69.14 & & 146.21 & & 251.74 & & 339.27 \\
\hline & Drag & -0.030611 & & -0.029402 & & -0.027734 & & -0.026481 \\
\hline & Thrust & -0.005999 & & -0.006844 & & -0.007178 & \multirow{3}{*}{$\begin{array}{l}\text { *From } \\
\text { Run816 } \\
\text { only }\end{array}$} & -0.008504 \\
\hline & Torque & 0.003167 & & 0.001976 & & 0.001179 & & 0.000431 \\
\hline & $\dot{m}$ & 0.095646 & & 0.097046 & & 0.098065 & & 0.098962 \\
\hline & Fan Power & 100.98 & & 178.69 & & 284.52 & & 360.22 \\
\hline
\end{tabular}

\begin{tabular}{c|cc|} 
& Calibration & Correction \\
\hline Drag & -0.022048 & -0.001354 \\
Thrust & -0.001832 & 0.004577 \\
Torque & 0.002517 & -0.000523
\end{tabular}




\section{Cusp B}

100 W Zero Run $\quad 200$ W Zero Run 300 W Zero Run 400 W

\begin{tabular}{|c|c|c|c|c|c|c|c|c|}
\hline \multirow[t]{5}{*}{0.1} & Drag & -0.032690 & & -0.032560 & & -0.0309134 & -0.01984 & -0.0288611 \\
\hline & Thrust & 0.103700 & & 0.103946 & & 0.10415 & 0.103779 & 0.104302 \\
\hline & Torque & 0.003948 & & 0.002862 & & 0.001559 & 0.004179 & 0.001268 \\
\hline & $\dot{m}$ & 0.099872 & & 0.103204 & & 0.104042 & 0 & 0.102908 \\
\hline & $\begin{array}{c}\text { Fan } \\
\text { Power }\end{array}$ & 47.20 & & 127.24 & & 237.23 & 0.784340 & 318.18 \\
\hline \multirow[t]{5}{*}{0.2} & Drag & -0.031720 & & -0.029735 & -0.018778 & -0.027260 & -0.019058 & -0.025221 \\
\hline & Thrust & 0.103959 & & 0.104107 & 0.103825 & 0.104136 & 0.103811 & 0.104256 \\
\hline & Torque & 0.003227 & & 0.001695 & 0.00336 & 0.001316 & 0.003433 & 0.001056 \\
\hline & $\dot{m}$ & 0.097548 & & 0.097579 & 0 & 0.096969 & 0 & 0.098125 \\
\hline & $\begin{array}{c}\text { Fan } \\
\text { Power }\end{array}$ & 106.24 & & 191.21 & 0.848864 & 276.09 & 0.844929 & 346.14 \\
\hline \multirow[t]{5}{*}{0.3} & Drag & -0.032718 & & -0.030713 & & -0.027665 & -0.019259 & -0.02626 \\
\hline & Thrust & 0.103744 & & 0.103993 & & 0.104088 & 0.10383 & 0.104222 \\
\hline & Torque & 0.004152 & & 0.003034 & & 0.001752 & 0.003279 & 0.001373 \\
\hline & $\dot{m}$ & 0.096343 & & 0.095691 & & 0.098271 & 0 & 0.098234 \\
\hline & $\begin{array}{c}\text { Fan } \\
\text { Power }\end{array}$ & 38.96 & & 120.04 & & 226.68 & 0.886983 & 309.42 \\
\hline \multirow[t]{5}{*}{0.4} & Drag & -0.032451 & & -0.030085 & & -0.027633 & & -0.026259 \\
\hline & Thrust & 0.103831 & & 0.104029 & & 0.104059 & & 0.104180 \\
\hline & Torque & 0.004003 & & 0.002652 & & 0.001393 & & 0.001380 \\
\hline & $\dot{m}$ & 0.096572 & & 0.095464 & & 0.097388 & & 0.096158 \\
\hline & $\begin{array}{l}\text { Fan } \\
\text { Power }\end{array}$ & 38.91 & & 123.03 & & 222.46 & & 305.54 \\
\hline \multirow[t]{5}{*}{0.5} & Drag & -0.032099 & -0.020034 & -0.029725 & & -0.027643 & & -0.025955 \\
\hline & Thrust & 0.103858 & 0.103824 & 0.103991 & & 0.104038 & & 0.104146 \\
\hline & Torque & 0.003660 & 0.003805 & 0.002615 & & 0.001468 & & 0.001197 \\
\hline & $\dot{m}$ & 0.095052 & 0 & 0.094633 & & 0.096190 & & 0.096428 \\
\hline & $\begin{array}{l}\text { Fan } \\
\text { Power }\end{array}$ & 47.57 & 0.860053 & 129.82 & & 227.93 & & 308.42 \\
\hline \multirow[t]{5}{*}{0.6} & Drag & -0.032039 & -0.02028 & -0.029820 & & -0.027815 & & -0.026091 \\
\hline & Thrust & 0.103862 & 0.103836 & 0.103982 & & 0.104014 & & 0.104116 \\
\hline & Torque & 0.003620 & 0.003813 & 0.002550 & & 0.001503 & & 0.001199 \\
\hline & $\dot{m}$ & 0.095586 & & 0.095530 & & 0.096251 & & 0.096780 \\
\hline & $\begin{array}{l}\text { Fan } \\
\text { Power }\end{array}$ & 47.44 & 0.87224 & 129.98 & & 229.43 & & 310.41 \\
\hline
\end{tabular}

\section{Calibration Correction}

\begin{tabular}{c|cc|}
\hline Drag & -0.022048 & -0.002564 \\
Thrust & -0.001832 & -0.105645 \\
Torque & 0.002517 & -0.000993
\end{tabular}




\section{Cusp C}

Wind On

100 Zero Run

200

300

Zero Run

400

\begin{tabular}{|c|c|c|c|c|c|c|c|c|}
\hline \multirow[t]{5}{*}{0.1} & Drag & -0.031949 & -0.032795 & -0.019263 & -0.031646 & -0.029985 & & -0.028541 \\
\hline & Thrust & -0.007448 & -0.007308 & -0.007199 & -0.007862 & -0.008307 & & -0.008732 \\
\hline & Torque & 0.002158 & 0.002916 & 0.002958 & 0.001346 & 0.001509 & & 0.000516 \\
\hline & $\dot{m}$ & & 0.1023305 & & 0.103536 & 0.104089 & & 0.103068 \\
\hline & Fan Power & 0.868970 & 107.01 & 0.884889 & 187.56 & 273.63 & & 342.73 \\
\hline \multirow[t]{5}{*}{0.2} & Drag & -0.032836 & -0.033015 & -0.02248 & -0.031654 & -0.029255 & -0.019546 & -0.026984 \\
\hline & Thrust & -0.006714 & -0.006976 & -0.006624 & -0.007063 & -0.008165 & -0.00713 & -0.008515 \\
\hline & Torque & 0.003911 & 0.003820 & 0.004000 & 0.003072 & 0.001253 & 0.003366 & 0.001067 \\
\hline & $\dot{m}$ & & 0.097092 & & 0.098159 & 0.096722 & & 0.097768 \\
\hline & Fan Power & 0.820674 & 38.91 & 0.864373 & 118.19 & 222.45 & 0.872327 & 307.12 \\
\hline \multirow[t]{5}{*}{0.3} & Drag & -0.032865 & -0.03297 & -0.020404 & -0.030510 & -0.028318 & & -0.026238 \\
\hline & Thrust & -0.006742 & -0.006907 & -0.006699 & -0.007556 & -0.008208 & & -0.008516 \\
\hline & Torque & 0.004078 & 0.003809 & 0.003936 & 0.002478 & 0.001363 & & 0.001090 \\
\hline & $\dot{m}$ & & 0.095089 & & 0.095387 & 0.095867 & & 0.096714 \\
\hline & Fan Power & 0.877321 & 38.92 & 0.044564 & 122.71 & 221.13 & & 306.07 \\
\hline \multirow[t]{5}{*}{0.4} & Drag & -0.032912 & -0.03030 & -0.020063 & -0.028533 & -0.026928 & & -0.024835 \\
\hline & Thrust & -0.006662 & -0.007334 & -0.007279 & -0.008086 & -0.008637 & & -0.008852 \\
\hline & Torque & 0.003998 & 0.002569 & 0.003158 & 0.001514 & 0.000957 & & 0.000887 \\
\hline & $\dot{m}$ & & 0.094880 & & 0.095212 & 0.096169 & & 0.096569 \\
\hline & Fan Power & 1.38 & 110.01 & 0.887410 & 190.27 & 278.24 & & 340.35 \\
\hline \multirow[t]{5}{*}{0.5} & Drag & -0.032489 & -0.030072 & -0.020636 & -0.028929 & -0.026536 & & -0.024975 \\
\hline & Thrust & -0.006815 & -0.007603 & -0.007327 & -0.008031 & -0.008795 & & -0.008763 \\
\hline & Torque & 0.003969 & 0.002576 & 0.003407 & 0.001518 & 0.001120 & & 0.000937 \\
\hline & $\dot{m}$ & & 0.095336 & & 0.096299 & 0.096802 & & 0.096886 \\
\hline & Fan Power & 0.870987 & 109.80 & 0.975906 & 188.79 & 274.46 & & 336.42 \\
\hline \multirow[t]{5}{*}{0.6} & Drag & -0.032637 & -0.031519 & -0.020719 & -0.0297825 & -0.027778 & & -0.026017 \\
\hline & Thrust & -0.006869 & -0.007103 & -0.006959 & -0.008124 & -0.008660 & & -0.008839 \\
\hline & Torque & 0.003988 & 0.003344 & 0.003810 & 0.002359 & 0.001557 & & 0.001211 \\
\hline & $\dot{m}$ & & 0.094257 & & 0.095873 & 0.095715 & & 0.096915 \\
\hline & Fan Power & 0.926399 & 63.39 & 0.812138 & 141.88 & 235.21 & & 307.64 \\
\hline
\end{tabular}

Calibration Correction

(V)

\begin{tabular}{c|cc|}
\hline Drag & -0.022048 & -0.003639 \\
Thrust & -0.001832 & 0.004581 \\
Torque & 0.002517 & -0.000626
\end{tabular}

Page 89 


\section{Appendix D: Processed Data}

\section{Cusp A}

$\begin{array}{ccccccc}\text { Tunnel } & \text { Fan Power Wind } & \text { Drag Wind } & C_{D} \text { wind on } & D_{p} \text { Wind On } & C_{d, p} \text { Wind On } \\ \text { Velocity } & \text { On } & \text { On } & (\mathrm{N}) & \end{array}$

\begin{tabular}{|c|c|c|c|c|c|c|c|c|}
\hline \multirow[t]{4}{*}{0.1} & 100 & 0.043116 & 31.637235 & 0.049738 & 0.243932 & 0.013635 & -0.866167 & -0.008809 \\
\hline & 200 & 0.043100 & 31.664072 & 0.049738 & 0.243932 & & -0.866167 & -0.008797 \\
\hline & 300 & 0.043074 & 31.628379 & 0.049738 & 0.243932 & & -0.866167 & -0.008820 \\
\hline & 400 & 0.043054 & 31.679128 & 0.049738 & 0.243932 & & -0.866167 & -0.008794 \\
\hline \multirow[t]{4}{*}{0.2} & 100 & 0.043102 & 31.570093 & 0.686211 & 0.290417 & 0.016923 & -0.960592 & -0.009756 \\
\hline & 200 & 0.043077 & 31.593335 & 0.686211 & 0.290417 & & -0.960592 & -0.009745 \\
\hline & 300 & 0.043050 & 31.580367 & 0.686211 & 0.290417 & & -0.960592 & -0.009757 \\
\hline & 400 & 0.043025 & 31.597596 & 0.686211 & 0.290417 & & -0.960592 & -0.009750 \\
\hline \multirow[t]{4}{*}{0.3} & 100 & 0.043093 & 31.570496 & 0.746034 & 0.317350 & 0.019230 & -0.816395 & -0.008292 \\
\hline & 200 & 0.043067 & 31.611601 & 0.746034 & 0.317350 & & -0.816395 & -0.008274 \\
\hline & 300 & 0.043052 & 31.636645 & 0.746034 & 0.317350 & & -0.816395 & -0.008263 \\
\hline & 400 & 0.043027 & 31.660817 & 0.746034 & 0.317350 & & -0.816395 & -0.008253 \\
\hline \multirow[t]{4}{*}{0.4} & 100 & 0.043103 & 31.634999 & 0.747208 & 0.361250 & 0.020896 & -0.728921 & -0.007375 \\
\hline & 200 & 0.043082 & 31.661046 & 0.747208 & 0.361250 & & -0.728921 & -0.007365 \\
\hline & 300 & 0.043050 & 31.665055 & 0.747208 & 0.361250 & & -0.728921 & -0.007367 \\
\hline & 400 & 0.043033 & 31.684314 & 0.747208 & 0.361247 & & -0.728921 & -0.007360 \\
\hline \multirow[t]{4}{*}{0.5} & 100 & 0.043086 & 31.596616 & 0.764981 & 0.390000 & 0.024531 & -0.474868 & -0.004810 \\
\hline & 200 & 0.043064 & 31.627533 & 0.764981 & 0.390000 & & -0.474868 & -0.004802 \\
\hline & 300 & 0.043046 & 31.642680 & 0.764981 & 0.390000 & & -0.474868 & -0.004799 \\
\hline & 400 & 0.043026 & 31.650304 & 0.764981 & 0.390000 & & -0.474868 & -0.004798 \\
\hline \multirow[t]{4}{*}{0.6} & 100 & 0.043073 & 31.602902 & 0.049240 & 0.365847 & 0.0258056 & -0.730347 & -0.007401 \\
\hline & 200 & 0.043057 & 31.626611 & 0.049240 & 0.365847 & & -0.730347 & -0.007392 \\
\hline & 300 & 0.043036 & 31.641705 & 0.049240 & 0.365847 & & -0.730347 & -0.007387 \\
\hline & 400 & 0.043019 & 31.632265 & 0.049240 & 0.365847 & & -0.730347 & -0.007394 \\
\hline
\end{tabular}


Thrust Wind On Torque Wind On Fan Power Drag (lbs) $\quad C_{D} \quad$ Pressure Drag (N) $C_{d, p}$

\begin{tabular}{|c|c|c|c|c|c|c|c|c|}
\hline \multirow[t]{4}{*}{0.1} & 100 & -1.094213 & 1.702012 & 105.98 & 0.543672 & 0.030390 & -2.982861 & -0.030337 \\
\hline & 200 & -1.094213 & 1.702012 & 189.55 & 0.429137 & 0.025172 & -3.147340 & -0.031963 \\
\hline & 300 & -1.094213 & 1.702012 & 280.02 & 0.231409 & 0.016283 & -2.705944 & -0.027554 \\
\hline & 400 & -1.094213 & 1.702012 & 355.95 & 0.089271 & 0.009817 & -2.603669 & -0.026436 \\
\hline \multirow[t]{4}{*}{0.2} & 100 & -1.133450 & 1.728683 & 106.43 & 0.441820 & 0.025745 & -2.377849 & -0.024149 \\
\hline & 200 & -1.133450 & 1.728683 & 192.22 & 0.259140 & 0.017474 & -2.098868 & -0.021292 \\
\hline & 300 & -1.133450 & 1.728683 & 273.20 & 0.058057 & 0.008410 & -1.908132 & -0.019382 \\
\hline & 400 & -1.133450 & 1.728683 & 363.51 & -0.126333 & 7.89E-05 & -1.918921 & -0.019478 \\
\hline \multirow[t]{4}{*}{0.3} & 100 & -0.861753 & 1.578593 & 106.80 & 0.375400 & 0.022747 & -2.018290 & -0.020500 \\
\hline & 200 & -0.861753 & 1.578593 & 190.33 & 0.183838 & 0.014062 & -1.806183 & -0.01830 \\
\hline & 300 & -0.861753 & 1.578593 & 297.60 & 0.067322 & 0.008797 & -2.043913 & -0.020687 \\
\hline & 400 & -0.861753 & 1.578593 & 354.64 & -0.109464 & 0.000837 & -2.089284 & -0.021121 \\
\hline \multirow[t]{4}{*}{0.4} & 100 & -0.773285 & 1.552707 & 39.11 & 0.449025 & 0.025974 & -1.941021 & -0.019639 \\
\hline & 200 & -0.773285 & 1.552707 & 120.64 & 0.297973 & 0.019150 & -1.862112 & -0.018816 \\
\hline & 300 & -0.773285 & 1.552707 & 229.84 & 0.061076 & 0.008504 & -1.832744 & -0.018524 \\
\hline & 400 & -0.773285 & 1.552707 & 335.74 & -0.065232 & 0.002823 & -2.135813 & -0.021566 \\
\hline \multirow[t]{4}{*}{0.5} & 100 & -0.935785 & 1.711948 & 69.14 & 0.323404 & 0.020342 & -1.776066 & -0.017990 \\
\hline & 200 & -0.935785 & 1.711948 & 146.21 & 0.164014 & 0.013139 & -1.612567 & -0.016307 \\
\hline & 300 & -0.935785 & 1.711948 & 251.74 & 0.025214 & 0.006891 & -1.961524 & -0.019823 \\
\hline & 400 & -0.935785 & 1.711948 & 339.27 & -0.118394 & 0.000435 & -2.157442 & -0.021799 \\
\hline \multirow[t]{4}{*}{0.6} & 100 & -0.982795 & 1.716916 & 100.98 & 0.2267762 & 0.015996 & -1.387132 & -0.014057 \\
\hline & 200 & -0.982795 & 1.716916 & 178.69 & 0.110868 & 0.010758 & -1.684943 & -0.017053 \\
\hline & 300 & -0.982795 & 1.716916 & 284.52 & -0.049018 & 0.003557 & -2.061618 & -0.020853 \\
\hline & 400 & -0.982795 & 1.716916 & 360.22 & -0.16908 & -0.001846 & -2.143419 & -0.0216988 \\
\hline
\end{tabular}


Thrust (lbs) Torque (lbs) Mass Flow Delta P Fan $\quad C_{q} \quad \Delta C_{p, s l o t}$

\begin{tabular}{|c|c|c|c|c|c|c|c|}
\hline \multirow[t]{4}{*}{0.1} & 100 & -0.2343317 & 1.167939 & 0.072052 & 924.5963 & 0.013126 & 0.437492 \\
\hline & 200 & 0.265508 & 0.687426 & 0.072102 & 1393.6673 & 0.013145 & 0.685331 \\
\hline & 300 & 0.411536 & 0.626632 & 0.071703 & 1855.4945 & 0.013104 & 0.964142 \\
\hline & 400 & 0.530912 & 0.438584 & 0.070975 & 2168.9513 & 0.012962 & 1.124667 \\
\hline \multirow[t]{4}{*}{0.2} & 100 & -0.114893 & 1.048879 & 0.069303 & 901.3470 & 0.012570 & 0.367713 \\
\hline & 200 & 0.200668 & 0.648030 & 0.068087 & 1340.8508 & 0.012353 & 0.594108 \\
\hline & 300 & 0.365530 & 0.672217 & 0.068414 & 1722.2137 & 0.012428 & 0.759567 \\
\hline & 400 & 0.742089 & 0.282437 & 0.068318 & 2042.5223 & 0.012412 & 0.861454 \\
\hline \multirow[t]{4}{*}{0.3} & 100 & -0.087070 & 1.04168 & 0.068057 & 869.5015 & 0.012340 & 0.381281 \\
\hline & 200 & 0.330964 & 0.664895 & 0.067810 & 1263.4506 & 0.012289 & 0.532669 \\
\hline & 300 & 0.530542 & 0.489616 & 0.067919 & 1707.9385 & 0.012308 & 0.627808 \\
\hline & 400 & 0.549420 & 0.482644 & 0.068331 & 1937.8151 & 0.012378 & 0.674746 \\
\hline \multirow[t]{4}{*}{0.4} & 100 & -0.215824 & 1.275320 & 0.067084 & 450.2134 & 0.012132 & 0.197834 \\
\hline & 200 & -0.016554 & 0.979456 & 0.066728 & 919.7699 & 0.012069 & 0.376223 \\
\hline & 300 & 0.394262 & 0.617044 & 0.067352 & 1382.5381 & 0.012191 & 0.513834 \\
\hline & 400 & 0.663121 & 0.407686 & 0.067929 & 1804.8322 & 0.012296 & 0.595569 \\
\hline \multirow[t]{4}{*}{0.5} & 100 & -0.107429 & 1.182277 & 0.067577 & 637.2555 & 0.012220 & 0.278438 \\
\hline & 200 & 0.009912 & 0.886892 & 0.066599 & 1005.7168 & 0.012039 & 0.375987 \\
\hline & 300 & 0.445776 & 0.587889 & 0.067410 & 1475.8390 & 0.012190 & 0.490907 \\
\hline & 400 & 0.742212 & 0.396355 & 0.067236 & 1808.7036 & 0.012163 & 0.575617 \\
\hline \multirow[t]{5}{*}{0.6} & 100 & -0.147961 & 1.043692 & 0.066777 & 777.7117 & 0.012082 & 0.296881 \\
\hline & 200 & 0.164577 & 0.732096 & 0.067730 & 1149.4926 & 0.012254 & 0.385146 \\
\hline & 300 & -33.513813 & 0.523740 & 0.068405 & 1600.9615 & 0.012383 & 0.532851 \\
\hline & 400 & -41.001225 & 0.328196 & 0.069012 & 1886.5889 & 0.012503 & 0.614189 \\
\hline & & Throttle & & 1436 & 1631 & 1785 & 1890 \\
\hline \multirow[t]{2}{*}{0.1} & & Speed (RPM) & 0 & 20750.09 & 25974.17 & 30361.14 & 33065.57 \\
\hline & & ev & & 123.97 & 101.11 & 120.77 & 54.41 \\
\hline \multirow[t]{2}{*}{0.2} & & Speed (RPM) & 0 & 20802.34 & 26128.33 & 30224.90 & 33264.71 \\
\hline & & ev & & 108.48 & 77.80 & 146.36 & 51.15 \\
\hline \multirow[t]{2}{*}{0.3} & & Speed (RPM) & 0 & 20724.84 & 26063.53 & 30851.46 & 33105.61 \\
\hline & & ev & & 86.56 & 93.62 & 74.268 & 59.28 \\
\hline \multirow[t]{2}{*}{0.4} & & Speed (RPM) & 0 & 13565.19 & 21711.21 & 27977.35 & 32230.81 \\
\hline & & ev & & 71.43 & 78.68 & 78.39 & 108.43 \\
\hline \multirow[t]{2}{*}{0.5} & & Speed (RPM) & 0 & 17313.03 & 23490.04 & 28977.54 & 32332.69 \\
\hline & & ev & & 62.29 & 103.28 & 89.21 & 142.02 \\
\hline \multirow[t]{2}{*}{0.6} & & Speed (RPM) & 0 & 20306.40 & 25499.84 & 30299.83 & 32969.24 \\
\hline & & ev & & 76.37 & 99.97 & 101.74 & 138.76 \\
\hline
\end{tabular}




\section{Cusp B}

\begin{tabular}{|c|c|c|c|c|c|c|c|c|}
\hline & & $\varepsilon$ & $\begin{array}{l}\text { Tunnel } \\
\text { Velocity }\end{array}$ & $\begin{array}{c}\text { Fan Power Wind } \\
\text { On }\end{array}$ & $\begin{array}{l}\text { Drag Wind } \\
\text { On }\end{array}$ & $C_{D}$ Wind On & $D_{p}$ Wind On & $C_{d, p}$ Wind On \\
\hline \multirow[t]{4}{*}{0.1} & 100 & 0.043120 & 31.5247 & 0.900421 & 0.520551 & 0.029562 & -2.089289 & -0.021576 \\
\hline & 200 & 0.043119 & 31.5401 & 0.900421 & 0.520551 & & -2.089289 & -0.021555 \\
\hline & 300 & 0.043096 & 31.5456 & 0.900421 & 0.520551 & & -2.089289 & -0.021555 \\
\hline & 400 & 0.043068 & 31.5549 & 0.900421 & 0.520551 & & -2.089289 & -0.021551 \\
\hline \multirow[t]{4}{*}{0.2} & 100 & 0.043107 & 31.5064 & 0.900421 & 0.520551 & 0.030775 & -2.089289 & -0.021605 \\
\hline & 200 & 0.043080 & 31.5076 & 0.900421 & 0.520551 & & -2.089289 & -0.021612 \\
\hline & 300 & 0.043047 & 31.5365 & 0.900421 & 0.520551 & & -2.089289 & -0.021584 \\
\hline & 400 & 0.043019 & 31.5332 & 0.900421 & 0.520551 & & -2.089289 & -0.021597 \\
\hline \multirow[t]{4}{*}{0.3} & 100 & 0.043121 & 31.5502 & 0.816589 & 0.501190 & 0.028465 & -2.208874 & -0.022833 \\
\hline & 200 & 0.043094 & 31.5510 & 0.816589 & 0.501190 & & -2.208874 & -0.022842 \\
\hline & 300 & 0.043052 & 31.5622 & 0.816589 & 0.501190 & & -2.208874 & -0.022840 \\
\hline & 400 & 0.043033 & 31.5576 & 0.816589 & 0.501190 & & -2.208874 & -0.022853 \\
\hline \multirow[t]{4}{*}{0.4} & 100 & 0.043117 & 31.5223 & 0.803752 & 0.533394 & 0.030632 & -2.029321 & -0.021015 \\
\hline & 200 & 0.043085 & 31.5411 & 0.803752 & 0.533394 & & -2.029321 & -0.021000 \\
\hline & 300 & 0.043052 & 31.5609 & 0.803752 & 0.533394 & & -2.029321 & -0.020984 \\
\hline & 400 & 0.043033 & 31.5805 & 0.803752 & 0.533394 & & -2.029321 & -0.020964 \\
\hline \multirow[t]{4}{*}{0.5} & 100 & 0.043113 & 31.7068 & 0.839392 & 0.556684 & 0.032446 & -2.006788 & -0.020805 \\
\hline & 200 & 0.043080 & 31.7126 & 0.839392 & 0.556684 & & -2.006788 & -0.020808 \\
\hline & 300 & 0.043052 & 31.7357 & 0.839392 & 0.556684 & & -2.006788 & -0.020787 \\
\hline & 400 & 0.043029 & 31.7557 & 0.839392 & 0.556684 & & -2.006788 & -0.020768 \\
\hline \multirow[t]{4}{*}{0.6} & 100 & 0.043112 & 31.5237 & 0.815411 & 0.540103 & 0.031605 & -2.048469 & -0.021268 \\
\hline & 200 & 0.043082 & 31.5477 & 0.815411 & 0.540103 & & -2.048469 & -0.021246 \\
\hline & 300 & 0.043054 & 31.5411 & 0.815411 & 0.540103 & & -2.048469 & -0.021264 \\
\hline & 400 & 0.043030 & 31.5634 & 0.815411 & 0.540103 & & & \\
\hline
\end{tabular}


Thrust Wind On Torque Wind On Fan Power (W) Drag (lbs) $\quad C_{D} \quad D_{D}(\mathrm{~N}) \quad C_{d, p}$

\begin{tabular}{|c|c|c|c|c|c|c|c|c|}
\hline \multirow[t]{4}{*}{0.1} & 100 & -0.004536 & 1.255483 & 47.20 & 0.542004 & 0.030781 & -2.408147 & -0.024868 \\
\hline & 200 & -0.004536 & 1.255483 & 127.24 & 0.529544 & 0.030180 & -3.027146 & -0.031231 \\
\hline & 300 & -0.004536 & 1.255483 & 237.23 & 0.371751 & 0.022938 & -3.105385 & -0.032038 \\
\hline & 400 & -0.004536 & 1.255483 & 318.18 & 0.175045 & 0.013909 & -2.916333 & -0.030083 \\
\hline \multirow[t]{4}{*}{0.2} & 100 & -0.004536 & 1.255483 & 106.24 & 0.449018 & 0.026546 & -2.328274 & -0.024076 \\
\hline & 200 & -0.004536 & 1.255483 & 191.21 & 0.258798 & 0.017802 & -2.082560 & -0.021543 \\
\hline & 300 & -0.004536 & 1.255483 & 276.09 & 0.021598 & 0.006878 & -1.794835 & -0.018542 \\
\hline & 400 & -0.004536 & 1.255483 & 346.14 & -0.173830 & -0.002104 & -1.759041 & -0.018183 \\
\hline \multirow[t]{4}{*}{0.3} & 100 & 0.027297 & 1.244239 & 38.96 & 0.544672 & 0.030934 & -2.122711 & -0.021943 \\
\hline & 200 & 0.027297 & 1.244239 & 120.04 & 0.3525504 & 0.022108 & -1.889342 & -0.019537 \\
\hline & 300 & 0.027297 & 1.244239 & 226.68 & 0.060367 & 0.008668 & -1.706689 & -0.017647 \\
\hline & 400 & 0.027297 & 1.244239 & 309.42 & -0.074263 & 0.002477 & -1.944159 & -0.020114 \\
\hline \multirow[t]{4}{*}{0.4} & 100 & 0.025076 & 1.253914 & 38.91 & 0.519113 & 0.029812 & -1.909044 & -0.019769 \\
\hline & 200 & 0.025076 & 1.253914 & 123.03 & 0.292296 & 0.019350 & -1.621991 & -0.016785 \\
\hline & 300 & 0.025076 & 1.253914 & 222.46 & 0.057316 & 0.008528 & -1.847911 & -0.019108 \\
\hline & 400 & 0.025076 & 1.253914 & 305.54 & -0.074343 & 0.002469 & -1.984772 & -0.020504 \\
\hline \multirow[t]{4}{*}{0.5} & 100 & 0.016193 & 1.262020 & 47.57 & 0.485392 & 0.028291 & -1.726549 & -0.017900 \\
\hline & 200 & 0.016193 & 1.262020 & 129.82 & 0.25780761 & 0.017798 & -1.542966 & -0.015999 \\
\hline & 300 & 0.016193 & 1.262020 & 227.93 & 0.058306 & 0.008588 & -1.867372 & -0.019342 \\
\hline & 400 & 0.016193 & 1.262020 & 308.42 & -0.103496 & 0.001132 & -1.8563339 & -0.019211 \\
\hline \multirow[t]{4}{*}{0.6} & 100 & 0.018784 & 1.237964 & 47.44 & 0.479641 & 0.028067 & -1.610523 & -0.016721 \\
\hline & 200 & 0.018784 & 1.237964 & 129.98 & 0.266913 & 0.018223 & -1.461136 & -0.015154 \\
\hline & 300 & 0.018784 & 1.237964 & 229.43 & 0.074744 & 0.009365 & -1.907679 & -0.019802 \\
\hline & 400 & 0.018784 & 1.237964 & 310.41 & -0.090429 & 0.001737 & -1.919994 & -0.019909 \\
\hline
\end{tabular}


Thrust (lbs) Torque (lbs) Mass Flow (kg/s) Delta P Fan (Pa) $\quad C_{q} \quad \Delta C_{D, \text { slot }}$

\begin{tabular}{|c|c|c|c|c|c|c|c|}
\hline \multirow{4}{*}{0.1} & 100 & 0.045312 & 1.124873 & 0.069720 & 527.6375 & 0.012834 & 0.258237 \\
\hline & 200 & -0.045748 & 0.841037 & 0.071979 & 1058.7437 & 0.013268 & 0.541666 \\
\hline & 300 & -0.121137 & 0.500372 & 0.072493 & 1651.3002 & 0.013387 & 0.876999 \\
\hline & 400 & -0.177278 & 0.424325 & 0.071660 & 2051.8315 & 0.013245 & 1.106762 \\
\hline \multirow[t]{4}{*}{0.2} & 100 & -0.050251 & 0.936346 & 0.068075 & 901.8333 & 0.012547 & 0.386631 \\
\hline & 200 & -0.105220 & 0.535803 & 0.068060 & 1341.1537 & 0.012557 & 0.610376 \\
\hline & 300 & -0.115893 & 0.436745 & 0.067604 & 1742.6386 & 0.012473 & 0.808910 \\
\hline & 400 & -0.160189 & 0.368804 & 0.068390 & 2016.8986 & 0.012627 & 0.905849 \\
\hline \multirow[t]{4}{*}{0.3} & 100 & 0.029148 & 1.178390 & 0.0672770 & 451.9689 & 0.0123992 & 0.185367 \\
\hline & 200 & -0.062898 & 0.885924 & 0.066785 & 937.6403 & 0.012322 & 0.431088 \\
\hline & 300 & -0.098310 & 0.550707 & 0.068550 & 1432.7686 & 0.012656 & 0.625177 \\
\hline & 400 & -0.147603 & 0.451606 & 0.068508 & 1792.7853 & 0.012656 & 0.673268 \\
\hline \multirow[t]{4}{*}{0.4} & 100 & -0.002994 & 1.139298 & 0.067441 & 439.8420 & 0.012439 & 0.204325 \\
\hline & 200 & -0.076162 & 0.786213 & 0.066636 & 907.4817 & 0.012294 & 0.401506 \\
\hline & 300 & -0.087329 & 0.456879 & 0.067951 & 1368.1629 & 0.012539 & 0.516787 \\
\hline & 400 & -0.132056 & 0.453480 & 0.067081 & 1731.9102 & 0.012376 & 0.559256 \\
\hline \multirow[t]{4}{*}{0.5} & 100 & -0.012927 & 1.049654 & 0.066375 & 493.6106 & 0.012329 & 0.239563 \\
\hline & 200 & -0.062343 & 0.776408 & 0.066058 & 916.6757 & 0.012276 & 0.373308 \\
\hline & 300 & -0.079494 & 0.476534 & 0.067117 & 1370.5298 & 0.012475 & 0.478768 \\
\hline & 400 & -0.119656 & 0.405673 & 0.067270 & 1726.6994 & 0.012500 & 0.523681 \\
\hline \multirow[t]{4}{*}{0.6} & 100 & -0.014469 & 1.039108 & 0.066753 & 487.7525 & 0.012343 & 0.229935 \\
\hline & 200 & -0.0588265 & 0.759542 & 0.066692 & 908.9761 & 0.012331 & 0.337016 \\
\hline & 300 & -0.070918 & 0.485555 & 0.067164 & 1369.6361 & 0.012432 & 0.466467 \\
\hline & 400 & -0.108366 & 0.406283 & 0.067515 & 1721.5459 & 0.012495 & 0.545335 \\
\hline
\end{tabular}

$\begin{array}{lllll}\text { Throttle } & 1436 & 1631 & 1785 & 1890\end{array}$

\begin{tabular}{|c|c|c|c|c|c|c|}
\hline \multirow[t]{2}{*}{0.1} & Fan Speed (RPM) & 0 & 14943.62 & 22397.24 & 28468.71 & 31972.37 \\
\hline & Std Dev & & 68.22 & 108.11 & 67.31 & 89.28 \\
\hline \multirow[t]{2}{*}{0.2} & Fan Speed (RPM) & 0 & 20915.53 & 26244.62 & 30442.38 & 33100.36 \\
\hline & Std Dev & & 107.70 & 100.77 & 104.24 & 93.60 \\
\hline \multirow[t]{2}{*}{0.3} & Fan Speed (RPM) & 0 & 13705.02 & 21858.22 & 28090.93 & 31855.17 \\
\hline & Std Dev & & 66.16 & 87.39 & 39.46 & 103.16 \\
\hline \multirow[t]{2}{*}{0.4} & Fan Speed (RPM) & 0 & 13637.98 & 21990.98 & 27920.69 & 31804.31 \\
\hline & Std Dev & & 69.74 & 77.75 & 155.09 & 119.67 \\
\hline \multirow[t]{2}{*}{0.5} & Fan Speed (RPM) & 0 & 14968.93 & 22555.37 & 28253.42 & 31981.87 \\
\hline & Std Dev & & 184.36 & 66.33 & 151.29 & 115.03 \\
\hline \multirow[t]{2}{*}{0.6} & Fan Speed (RPM) & 0 & 14899.32 & 22597.52 & 28352.49 & 32005.12 \\
\hline & Std Dev & & 54.83 & 69.50 & 137.88 & 147.05 \\
\hline
\end{tabular}




\section{Cusp C}

$\varepsilon \quad$ Tunnel Velocity $(\mathrm{m} / \mathrm{s}) \quad$ Fan Power Wind On Drag Wind On $C_{D}$ Wind On $D_{p}$ Wind On $C_{d, p}$ Wind On

\begin{tabular}{|c|c|c|c|c|c|c|c|c|}
\hline \multirow[t]{4}{*}{0.1} & 100 & 0.043137 & 31.5597 & 0.868970 & 0.573984 & 0.031659 & -2.064113 & -0.021408 \\
\hline & 200 & 0.043121 & 31.5560 & 0.868970 & 0.573984 & & -2.064113 & -0.021419 \\
\hline & 300 & 0.043099 & 31.5638 & 0.868970 & 0.573984 & & -2.064113 & -0.021415 \\
\hline & 400 & 0.043079 & 31.5544 & 0.868970 & 0.573984 & & -2.064113 & -0.021435 \\
\hline \multirow[t]{4}{*}{0.2} & 100 & 0.043140 & 31.4957 & 0.820674 & 0.658999 & 0.036261 & -2.004730 & -0.020849 \\
\hline & 200 & 0.043122 & 31.4753 & 0.820674 & 0.658999 & & -2.004730 & -0.020882 \\
\hline & 300 & 0.043089 & 31.5619 & 0.820674 & 0.658999 & & -2.004730 & -0.020778 \\
\hline & 400 & 0.043058 & 31.5520 & 0.820674 & 0.658999 & & -2.004730 & -0.020801 \\
\hline \multirow[t]{4}{*}{0.3} & 100 & 0.043140 & 31.5084 & 0.877321 & 0.661778 & 0.036447 & -2.023323 & -0.021040 \\
\hline & 200 & 0.043106 & 31.5065 & 0.877321 & 0.661778 & & -2.023323 & -0.021053 \\
\hline & 300 & 0.043076 & 31.5443 & 0.877321 & 0.661778 & & -2.023323 & -0.02101 \\
\hline & 400 & 0.043047 & 31.5525 & 0.877321 & 0.661778 & & -2.023323 & -0.021011 \\
\hline \multirow[t]{4}{*}{0.4} & 100 & 0.043103 & 31.5127 & 1.381477 & 0.666283 & 0.040372 & -2.153676 & -0.022431 \\
\hline & 200 & 0.043079 & 31.5258 & 1.381477 & 0.666283 & & -2.153676 & -0.022420 \\
\hline & 300 & 0.043057 & 31.5634 & 1.381477 & 0.666283 & & -2.153676 & -0.022374 \\
\hline & 400 & 0.043028 & 31.5632 & 1.381477 & 0.666283 & & -2.153676 & -0.022384 \\
\hline \multirow[t]{4}{*}{0.5} & 100 & 0.043100 & 31.5240 & 0.870987 & 0.625741 & 0.038398 & -2.101637 & -0.021881 \\
\hline & 200 & 0.043084 & 31.5364 & 0.870987 & 0.625741 & & -2.101637 & -0.021869 \\
\hline & 300 & 0.043052 & 31.5427 & 0.870987 & 0.625741 & & -2.101637 & -0.021871 \\
\hline & 400 & 0.043030 & 31.5609 & 0.870987 & 0.625741 & & -2.101637 & -0.021853 \\
\hline \multirow[t]{4}{*}{0.6} & 100 & 0.043120 & 31.5219 & 0.926399 & 0.639926 & 0.036731 & -2.000396 & -0.020810 \\
\hline & 200 & 0.043096 & 31.5187 & 0.926399 & 0.639926 & & -2.000396 & -0.020822 \\
\hline & 300 & 0.043069 & 31.5409 & 0.926399 & 0.639926 & & -2.000396 & -0.0208010 \\
\hline & 400 & 0.043044 & 31.5342 & 0.926399 & 0.639926 & & -2.000396 & -0.0208173 \\
\hline
\end{tabular}


Thrust Wind On Torque Wind On Fan Power (W) Drag (lbs) $\quad C_{D} \quad D_{P}(\mathrm{~N}) \quad C_{d, p}$

\begin{tabular}{|c|c|c|c|c|c|c|c|c|}
\hline \multirow[t]{4}{*}{0.1} & 100 & 0.386686 & 0.752683 & 107.01 & 0.655021 & 0.036129 & -2.987641 & -0.030987 \\
\hline & 200 & 0.386686 & 0.752683 & 187.56 & 0.544895 & 0.031063 & -3.378145 & -0.035054 \\
\hline & 300 & 0.386686 & 0.752683 & 273.63 & 0.385729 & 0.023713 & -3.353532 & -0.034793 \\
\hline & 400 & 0.386686 & 0.752683 & 342.73 & 0.247313 & 0.017340 & -3.248433 & -0.033733 \\
\hline \multirow[t]{4}{*}{0.2} & 100 & 0.114988 & 1.211057 & 38.91 & 0.676171 & 0.037206 & -2.379240 & -0.024744 \\
\hline & 200 & 0.114988 & 1.211057 & 118.19 & 0.545678 & 0.031218 & -2.440316 & -0.025419 \\
\hline & 300 & 0.114988 & 1.211057 & 222.45 & 0.315762 & 0.020463 & -2.125453 & -0.022030 \\
\hline & 400 & 0.114988 & 1.211057 & 307.11 & 0.098130 & 0.010441 & -1.968819 & -0.020428 \\
\hline \multirow[t]{4}{*}{0.3} & 100 & 0.125353 & 1.254724 & 38.92 & 0.671842 & 0.037001 & -2.165164 & -0.022515 \\
\hline & 200 & 0.125353 & 1.254724 & 122.71 & 0.436079 & 0.026112 & -1.756027 & -0.018272 \\
\hline & 300 & 0.125353 & 1.254724 & 221.13 & 0.225971 & 0.016356 & -1.723614 & -0.017900 \\
\hline & 400 & 0.125353 & 1.254724 & 306.07 & 0.026598 & 0.007145 & -1.775776 & -0.018440 \\
\hline \multirow[t]{4}{*}{0.4} & 100 & 0.095740 & 1.233806 & 110.01 & 0.415984 & 0.025206 & -1.524657 & -0.015879 \\
\hline & 200 & 0.095740 & 1.233806 & 190.27 & 0.246530 & 0.017347 & -1.692562 & -0.017620 \\
\hline & 300 & 0.095740 & 1.233806 & 278.24 & 0.0927150 & 0.010203 & -1.760908 & -0.018294 \\
\hline & 400 & 0.095740 & 1.233806 & 340.35 & -0.107889 & 0.000934 & -1.531385 & -0.015916 \\
\hline \multirow[t]{4}{*}{0.5} & 100 & 0.152374 & 1.226223 & 109.80 & 0.394099 & 0.024184 & -1.436486 & -0.014956 \\
\hline & 200 & 0.152374 & 1.226223 & 188.79 & 0.284485 & 0.019097 & -1.672245 & -0.017401 \\
\hline & 300 & 0.152374 & 1.226223 & 274.46 & 0.055175 & 0.008483 & -1.788776 & -0.018616 \\
\hline & 400 & 0.152374 & 1.226223 & 336.42 & -0.094439 & 0.001556 & -1.673298 & -0.017399 \\
\hline \multirow[t]{4}{*}{0.6} & 100 & 0.172363 & 1.231191 & 63.39 & 0.532755 & 0.030580 & -1.349578 & -0.014039 \\
\hline & 200 & 0.172363 & 1.231191 & 141.88 & 0.366336 & 0.022892 & -1.677417 & -0.017460 \\
\hline & 300 & 0.172363 & 1.231191 & 235.21 & 0.174247 & 0.013984 & -1.764680 & -0.018350 \\
\hline & 400 & 0.172363 & 1.231191 & 307.64 & 0.005464 & $6.18 \mathrm{E}-03$ & -1.818377 & -0.018923 \\
\hline
\end{tabular}


Thrust (lbs) Torque (lbs) Mass Flow (kg/s) Delta P Fan (Pa) $\quad C_{q} \quad \Delta C_{p, \text { slot }}$

\begin{tabular}{|c|c|c|c|c|c|c|c|}
\hline \multirow[t]{5}{*}{0.1} & 100 & 0.334740 & 0.950754 & 0.071384 & 935.3427 & 0.013235 & 0.474869 \\
\hline & 200 & 0.539747 & 0.540274 & 0.072166 & 1412.9370 & 0.013403 & 0.725126 \\
\hline & 300 & 0.704715 & 0.582852 & 0.072500 & 1865.3058 & 0.013481 & 0.977881 \\
\hline & 400 & 0.862156 & 0.323333 & 0.071752 & 2186.1938 & 0.013360 & 1.167345 \\
\hline & 500 & & & & 2555.6908 & & 1.289576 \\
\hline \multirow[t]{5}{*}{0.2} & 100 & 0.211847 & 1.187175 & 0.067797 & 451.2487 & 0.012554 & 0.193890 \\
\hline & 200 & 0.244236 & 0.991632 & 0.068494 & 979.0916 & 0.012709 & 0.427073 \\
\hline & 300 & 0.652029 & 0.515956 & 0.067448 & 1510.8846 & 0.012497 & 0.691684 \\
\hline & 400 & 0.781770 & 0.467452 & 0.068149 & 1894.8510 & 0.012641 & 0.867823 \\
\hline & 500 & & & & 2032.2577 & & 0.771128 \\
\hline \multirow[t]{5}{*}{0.3} & 100 & 0.186306 & 1.184343 & 0.066402 & 446.1017 & 0.012298 & 0.198069 \\
\hline & 200 & 0.426478 & 0.836444 & 0.066572 & 946.5826 & 0.012344 & 0.454084 \\
\hline & 300 & 0.667822 & 0.544675 & 0.066878 & 1432.3783 & 0.012397 & 0.609979 \\
\hline & 400 & 0.78214 & 0.473291 & 0.067447 & 1804.8011 & 0.012507 & 0.700854 \\
\hline & 500 & & & & 2214.5480 & & 0.759267 \\
\hline \multirow[t]{4}{*}{0.4} & 100 & 0.344549 & 0.860107 & 0.066234 & 833.4747 & 0.012289 & 0.400979 \\
\hline & 200 & 0.622848 & 0.584202 & 0.066442 & 1227.1973 & 0.012331 & 0.493850 \\
\hline & 300 & 0.826683 & 0.438558 & 0.067094 & 1622.1583 & 0.012443 & 0.547857 \\
\hline & 400 & 0.906267 & 0.420211 & 0.067360 & 1872.6873 & 0.012498 & 0.613231 \\
\hline \multirow[t]{4}{*}{0.5} & 100 & 0.443999 & 0.861894 & 0.066558 & 815.3973 & 0.012347 & 0.358568 \\
\hline & 200 & 0.602612 & 0.585205 & 0.067212 & 1203.5511 & 0.012470 & 0.420784 \\
\hline & 300 & 0.885106 & 0.481354 & 0.067541 & 1596.3996 & 0.012537 & 0.514073 \\
\hline & 400 & 0.873323 & 0.433329 & 0.067588 & 1835.6983 & 0.012542 & 0.573353 \\
\hline \multirow[t]{4}{*}{0.6} & 100 & 0.258857 & 1.062667 & 0.065821 & 568.18348 & 0.012197 & 0.273881 \\
\hline & 200 & 0.637037 & 0.805197 & 0.066927 & 973.9238 & 0.012411 & 0.356291 \\
\hline & 300 & 0.835196 & 0.595446 & 0.066795 & 1414.4157 & 0.012386 & 0.448485 \\
\hline & 400 & 0.901393 & 0.505061 & 0.067615 & 1721.5510 & 0.012547 & 0.536028 \\
\hline
\end{tabular}

\section{Throttle}

1436

1631

1785

1890

1986

\begin{tabular}{|c|c|c|c|c|c|c|c|}
\hline \multirow[t]{2}{*}{0.1} & Fan Speed (RPM) & 0 & 20757.46 & 26071.29 & 30267.74 & 32886.16 & 34501.09 \\
\hline & Std Dev & & 339.04 & 149.71 & 129.98 & 119.12 & 74.52 \\
\hline \multirow[t]{2}{*}{0.2} & Fan Speed (RPM) & 0 & 13733.13 & 21898.03 & 27958.27 & 31789.89 & 34958.33 \\
\hline & Std Dev & & 61.99 & 111.12 & 141.96 & 117.58 & 111.85 \\
\hline \multirow[t]{2}{*}{0.3} & Fan Speed (RPM) & 0 & 13672.49 & 21987.22 & 27902.87 & 31784.09 & 34570.36 \\
\hline & Std Dev & & 61.04 & 81.14 & 164.64 & 89.77 & 79.38 \\
\hline \multirow[t]{2}{*}{0.4} & Fan Speed (RPM) & 0 & 21034.38 & 26234.07 & 30604.31 & 33113.43 & 34996.15 \\
\hline & Std Dev & & 58.63 & 134.79 & 127.74 & 97.14 & 58.36 \\
\hline \multirow[t]{2}{*}{0.5} & Fan Speed (RPM) & 0 & 21046.72 & 26217.63 & 30536.22 & 33025.92 & 34998.64 \\
\hline & Std Dev & & 52.57 & 130.24 & 157.42 & 100.59 & 86.98 \\
\hline 0.6 & Fan Speed (RPM) & 0 & 16754.75 & 23423.50 & 28681.10 & 31968.06 & 35172.75 \\
\hline
\end{tabular}

Page 98 
Page 99 